\author{
Universidade de São Paulo \\ Instituto de Física
}

\title{
Investigação da influência das velocidades de deriva no funcionamento de um transistor de spin
}

\author{
Nícolas Massarico Kawahala
}

Orientador: Prof. Dr. Felix G. G. Hernandez

Dissertação de mestrado apresentada ao Instituto de Física da Universidade de São Paulo, como requisito parcial para a obtenção do título de Mestre em Ciências.

Banca Examinadora:

Prof. Dr. Felix Guillermo Gonzalez Hernandez - Orientador (IF - USP)

Prof. Dr. Marcio Peron Franco de Godoy (DF - UFSCar)

Prof. Dr. Marcio Daldin Teodoro (DF - UFSCar) 


\section{FICHA CATALOGRÁFICA}

\section{Preparada pelo Serviço de Biblioteca e Informação}

do Instituto de Física da Universidade de São Paulo

Kawahala, Nícolas Massarico

Investigação da influência das velocidades de deriva no funcionamento de um transistor de spin. São Paulo, 2019.

Dissertação (Mestrado) - Universidade de São Paulo. Instituto de Física. Depto. de Física dos Materiais e Mecânica

Orientador: Prof. Dr. Felix Guillermo Gonzalez Hernandez Área de Concentração: Spintrônica e Semicondutores

Unitermos: 1. Spintrônica; 2. Transistor de spin; 3. Interações de Rashba e Dresselhaus; 4. Deriva de spin. 
University of São Paulo

Physics Institute

\title{
Investigation of drift velocities influence on the operation of a spin transistor
}

\author{
Nícolas Massarico Kawahala
}

Supervisor: Prof. Dr. Felix G. G. Hernandez

Dissertation submitted to the Physics Institute of the University of São Paulo in partial fulfillment of the requirements for the degree of Master of Science.

Examining Committee:

Prof. Dr. Felix Guillermo Gonzalez Hernandez - Supervisor (IF - USP)

Prof. Dr. Marcio Peron Franco de Godoy (DF - UFSCar)

Prof. Dr. Marcio Daldin Teodoro (DF - UFSCar) 




\section{Agradecimentos}

Agradeço ao meu orientador, Felix G. G. Hernandez, pelas orientações que recebi desde as iniciações científicas até essa dissertação de mestrado, estando sempre acessível a discussões e nos auxílios com o laboratório. Agradeço também a meus colegas de grupo Saeed, Amina e Flávio, por tudo que com eles pude aprender.

Agradeço a todos os professores que tive, pelo importante ofício de transmissão de conhecimento, e a todos os meus colegas de graduação e pós, que de alguma forma contribuíram em meu caminho pelo estudo de física. Quero também agradecer a todos os funcionários do DFMT e do IFUSP, pois fornecem a estrutura necessária para que ensino e pesquisa possam ser, de fato, realizados.

Agradeço em especial à minha companheira Tárcila, por tudo que sempre compartilhamos e por todo o seu carinho e apoio. Agradeço também a nosso cãozinho Yuppi que esteve por perto enquanto eu escrevia essa dissertação, a meus pais Rita e André pelo incentivo que sempre me deram, e a meus avós por todo seu amor.

Por fim, agradeço ao CNPq, pelo auxílio financeiro, sob o processo 131114/2017-4, sem o qual essa dissertação não poderia ter sido realizada. 



\section{Resumo}

A spintrônica oferece um paradigma de uma eletrônica baseada no spin do elétron, ao invés de sua carga, para manipular e transportar informação. Para que o conceito de um transistor de spin possa se traduzir em um dispositivo prático, é necessário que se conheça a influência causada pelo movimento dos elétrons polarizados na dinâmica de magnetização de spins em um canal de transporte. Neste sentido, foi estudado um gás de elétrons bidimensional confinado em um poço quântico de GaAs, dopado simetricamente com $\mathrm{Si}$, em um sistema composto de duas sub-bandas. A injeção e detecção de polarização de spin na amostra foi realizada opticamente em uma configuração de bombeio-prova, através da técnica de microscopia de rotação de Kerr com resolução espacial e temporal. Induzindo deriva de spins pela aplicação de voltagens no plano da amostra, foram encontradas mobilidades de spin com valores próximos à mobilidade de carga e que podiam ser modificadas por voltagens aplicadas em um eletrodo de porta. Através de medidas dos campos spin-órbita gerados na amostra, foi possível a avaliação de sua relação com as velocidades de deriva, em comparação com o previsto por um modelo teórico. Dessas medidas puderam ser obtidos os coeficientes spin-órbita das interações de Rashba e Dresselhaus, em que ambos mostraram um comportamento de dependência com as velocidades de deriva não descrito pelo modelo utilizado, o que sugere que a magnitude das interações spin-órbita seja influenciada por essas velocidades.

Palavras-chave: spintrônica; transistor de spin; interações de Rashba e Dresselhaus; deriva de spin. 



\section{Abstract}

Spintronics offers a paradigm of an electronics based on the electron spin, rather than its charge, for the manipulation and transport of information. In order that the concept of a spin transistor can be translated into a practical device, it is necessary to know the influence caused by the movement of spin-polarized electrons in the spin magnetization dynamics in a transport channel. In this sense, it was studied two-dimensional electron gases confined in a GaAs quantum well, symmetrically doped with $\mathrm{Si}$, in a system composed of two subbands. Injection and detection of spin polarization in the sample was performed optically in a pump-probe configuration, using space and time resolved Kerr rotation microscopy technique. By the application of in-plane voltages inducing spin drift in the sample, spin mobilities were found with values close to the charge mobility and that could be modified by gate voltages. Through measures of the spin-orbit fields generated in the sample, it was possible to evaluate their relation with the drift velocities, in comparison with that predicted by a theoretical model. From these measures the spin-orbit coefficients of Rashba and Dresselhaus interactions could be obtained, in which both showed a dependence behavior with the drift velocities not described by the model used, suggesting that the magnitude of the spin-orbit interactions is influenced by these velocities.

Keywords: spintronics; spin transistor; Rashba and Dresselhaus interactions; spin drift. 



\section{Lista de Figuras}

2.1 Representação esquemática de um átomo de Hidrogênio clássico em dois referenciais: (a) elétron orbitando um próton estático que gera um campo elétrico

$\vec{E} ;$ (b) próton orbitando um elétron estático e respectivo campo magnético efe-

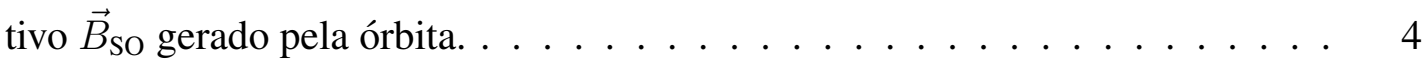

2.2 Representação das estruturas cristalinas: (a) do diamante, na qual cristalizam semicondutores elementares IV, como Si; e (b) blenda de zinco, presente em semicondutores binários III-V, como o GaAs. . . . . . . . . . . . . . . . 6

2.3 Representação dos campos spin-órbita efetivos de: $a$ ) Rashba; $b$ ) Dresselhaus linear; c) Rashba + Dresselhaus linear $\operatorname{com} \alpha=\beta_{1}$; e $d$ ) Dresselhaus cúbico. . . 9

2.4 Estrutura de banda do GaAs bulk. . . . . . . . . . . . . . . . . . . . 11

2.5 Diagrama da estrutura de banda simplificada do GaAs, próximo ao ponto $\Gamma$, para: (a) o cristal bulk; (b) um poço quântico. . . . . . . . . . . . . . . . . . . 11

2.6 Transições eletrônicas permitidas pelas regras de seleção ópticas para um poço quântico de GaAs no ponto $\Gamma$. . . . . . . . . . . . . . . . . . . 12

2.7 Representação da diferença na população de spins na CB (à esquerda), e consequentes comportamentos de absorção, índices de refração e rotação de Kerr (à direita). . . . . . . . . . . . . . . . . 13

2.8 Ilustração para o funcionamento de um spin-FET: em (a) sem aplicar uma voltagem $V_{g}$ no eletrodo de porta; e em (b) com uma $V_{\mathrm{g}}$ não-nula. Se a polarização de spin do elétron que chega ao dreno for oposta à magnetização nesse contato, a passagem desse elétron será bloqueada. . . . . . . . . . . . . . . . 14

3.1 Perfil da banda de condução de um poço quântico simples como função de sua largura $W$, para as três primeiras sub-bandas. . . . . . . . . . . . . . . . 17 
3.2 Esquema de camadas da amostra ao longo da direção de crescimento (z). $\quad$. . . 18

3.3 Foto da amostra capturada com o auxílio de um microscópio. . . . . . . . . . . 19

3.4 Esquema simplificado do setup óptico utilizado para o experimento. . . . . . . 20

3.5 Esquema da técnica de microscopia de rotação de Kerr adotada para medir polarização de spin na amostra em uma configuração de bombeio-prova. . . . . 21

3.6 Comportamento da evolução temporal de uma polarização de spin descrito pela

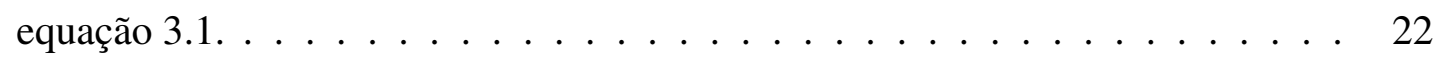

3.7 Exemplos de interferência construtiva (acima) e destrutiva (abaixo) entre os dois primeiros termos da soma na equação 3.3 . . . . . . . . . . . . . . . . . 24

3.8 Curvas típicas de RSA (equação 3.6 ) para: (a) $B_{\mathrm{SO}, \|}=B_{\mathrm{SO}, \perp}=0 ;$ (b) $B_{\mathrm{SO}, \|} \neq$ $0, B_{\mathrm{SO}, \perp}=0 ; \mathrm{e}$ (c) $B_{\mathrm{SO}, \|}=0, B_{\mathrm{SO}, \perp} \neq 0 . \ldots \ldots \ldots . \ldots \ldots 24$

$4.1 \quad$ Esquema simplificada do setup óptico utilizado para o mapeamento da amostra pela reflexão do bombeio. . . . . . . . . . . . . . . . . 25

4.2 Mapa das reflexões do feixe de bombeio na amostra, variando-se os parâmetros $H$ e $V$ do espelho motorizado. . . . . . . . . . . . . . . . . . 26

4.3 Gráfico de intensidades da reflexão do bombeio em função de $H$ com $V=4,75$ fixado. As regiões destacadas em vermelho são identificadas como funções erro. 28

4.4 Gráfico de intensidades da reflexão do bombeio em função de $V$ com $H=4,46$ fixado. As regiões destacadas em vermelho são identificadas como funções erro. 28

\begin{tabular}{|ll|l|l|}
\hline 4.5 & Gaussianas obtidas ao derivar as funções erro apontadas na figura & 4.3 & Através \\
\hline
\end{tabular} do ajuste, as posições encontradas para os contatos do canal horizontal foram $H_{\mathrm{c} \text {, esquerda }}=4,34$ e $H_{\mathrm{c} \text {, direita }}=4,57 . \ldots \ldots \ldots \ldots \ldots$. . . . . . . . 29

\begin{tabular}{|lll|l|l|}
\hline 4.6 & Gaussianas obtidas ao derivar as funções erro apontadas na figura & 4.4 & Através \\
\hline
\end{tabular} do ajuste, as posições encontradas para os contatos do canal vertical foram $V_{\mathrm{c} \text {, esquerda }}=4,34 \mathrm{e} V_{\mathrm{c} \text { direita }}=4,57 . \ldots \ldots \ldots \ldots \ldots \ldots$

4.7 Largura $w$ do feixe de bombeio em função da posição $z$ da lente em frente à janela do criostato $\ldots \ldots \ldots \ldots \ldots$ 
4.8 Comportamento esperado para o sinal da rotação de Kerr do feixe de prova, em função da posição de injeção de polarização de spin pelo bombeio na amostra. . 31

4.9 Mapa de RSA na direção horizontal com o campo magnético externo $B_{\text {ext }}$ variando de -40 a $40 \mathrm{mT}$, para a situação em que não há deriva de spin. . . . . . . 33

4.10 Curva de RSA obtida para a posição de overlap, extraída do mapa da figura 4.9, para a situação em que não há deriva de spin. . . . . . . . . . . . . . . . . . . 33

4.11 Amplitude de RSA em função das posições no canal $y$ da amostra, mostrando o comportamento da distribuição de polarização de spin em torno da posição de overlap, para a situação em que não há deriva. . . . . . . . . . . . . . . . . . . 34

4.12 Campo spin-órbita perpendicular, obtido do ajuste das curvas de RSA, em função das posições no canal $y$ da amostra em torno do overlap, para a situação em que não há deriva. . . . . . . . . . . . . . . . . . . . . . . . . . . 35

4.13 Amplitude do fator-g do elétron, obtido do ajuste das curvas de RSA, em função das posições no canal $y$ da amostra em torno do overlap, para a situação em que não há deriva . . . . . . . . . . . . . . . . . . . . . . . 35

4.14 Mapa de RSA na direção vertical com o campo magnético externo $B_{\text {ext }}$ variando de -40 a $40 \mathrm{mT}$, para a situação em que não há deriva de spin. . . . . . . . . . 37

4.15 Amplitude de RSA em função das posições no canal $x$ da amostra, mostrando o comportamento da distribuição de polarização de spin em torno da posição de overlap, para a situação em que não há deriva. . . . . . . . . . . . . . . . . . . 37

4.16 Curva de RSA obtida para a posição de overlap, extraída do mapa da figura 4.14 para a situação em que não há deriva de spin. . . . . . . . . . . . . . . . 38

5.1 Comportamento esperado para o sinal da rotação de Kerr do feixe de prova, em função da posição de injeção de polarização de spin pelo bombeio na amostra, para a situação em que há deriva. . . . . . . . . . . . . . . . . . . . . . . . . 39

5.2 Amplitudes de RSA em função das posições no canal $y$ da amostra para derivas de polarização de spin induzidas por alguns valores positivos de voltagens $V_{\mathrm{ip}}$. 
5.3 Gráfico da velocidade de deriva na direção $y$ em função do campo elétrico $E_{\text {ip }}$ gerado pela voltagem $V_{\text {ip }}$ aplicada entre os contatos do canal horizontal da amostra. 42

5.4 Gráfico do campo spin órbita no overlap em função da velocidade de deriva no canal $y$ da amostra. . . . . . . . . . . . . . . . . . . 44

5.5 Gráfico dos coeficientes $b^{y}$, calculados ponto-a-ponto a partir da inserção dos dados da figura 5.4 diretamente na equação 5.4 | em função das velocidades de deriva no canal $y$ da amostra. . . . . . . . . . . . . . . . . 44

5.6 Gráfico da amplitude do fator-g do elétron em função da velocidade de deriva na direção $x . \ldots \ldots \ldots \ldots \ldots$. . . . . . . . . . . . . . . . . . . . . .

5.7 Amplitudes de RSA em função das posições no canal $x$ da amostra para derivas de polarização de spin induzidas por alguns valores positivos de voltagens $V_{\text {ip. }}$. 46

5.8 Gráfico da velocidade de deriva na direção $x$ em função do campo elétrico $E_{\text {ip }}$ gerado pela voltagem $V_{\text {ip }}$ aplicada entre os contatos do canal vertical da amostra. 46

5.9 Gráfico do campo spin órbita no overlap em função da velocidade de deriva na direção $x . \ldots \ldots \ldots \ldots \ldots \ldots$. . . . . . . . . . . . . . . . . . .

5.10 Gráfico dos coeficientes $b^{x}$ calculados ponto-a-ponto a partir dos dados da figura 5.9| em função da velocidade de deriva na direção $x$. . . . . . . . . . . . 47

5.11 Gráfico da amplitude do fator-g do elétron em função da velocidade de deriva na direção $y . \ldots \ldots \ldots \ldots$. . . . . . . . . . . . . . . . . . 48

5.12 Velocidades de deriva do pacote de polarização de spin em função do campo elétrico aplicado nos canais $y$ (em vermelho) e $x$ (em azul) do dispositivo. . . .

5.13 Campos spin órbita, obtidos para a posição de overlap, em função das velocidades de deriva nos canais $y$ (em vermelho) e $x$ (em azul) do dispositivo. . . . . . 50

5.14 Coeficientes $b$ calculados ponto-a-ponto a partir dos dados da figura 5.13 , em função das velocidades de deriva. . . . . . . . . . . . . . . . . . . 52

5.15 Dependência dos coeficientes spin órbita de Rashba $\left(\sum \alpha_{\nu}\right)$ e de Dresselhaus $\left(\sum \beta_{\nu}^{*}\right)$ com a velocidade, como obtido através da inserção das retas ajustadas na figura $5.14 \mid$ nas equações $|5.9| \ldots \ldots$. . . . . . . . . . . . . 52 
5.16 Variação das mobilidades de spin, medidas em ambos os canais $y$ (em verme-

lho) e $x$ (em azul), como função da voltagem $V_{\mathrm{g}}$ aplicada no eletrodo de porta \begin{tabular}{|l}
\hline do dispositivo, com a temperatura na amostra estabilizada em $T=10 \mathrm{~K}$. \\
\hline
\end{tabular} . . . 54

5.17 Comportamento dos campos spin-órbita, gerados por deriva nos canais $y$ (em vermelho) e $x$ (em azul), como função da voltagem $V_{\mathrm{g}}$ aplicada no eletrodo de porta do dispositivo, com a temperatura na amostra estabilizada em $T=10 \mathrm{~K} . \quad 54$

5.18 Coeficientes $b^{y}$ (em vermelho) e $b^{x}$ (em azul), calculados a partir da divisão direta entre os $B_{\mathrm{SO}}$ e as velocidades de deriva para cada voltagem $V_{\mathrm{g}}$ no eletrodo de porta, com a temperatura na amostra estabilizada em $T=10 \mathrm{~K}$. . . . . . . . 55

5.19 Variação das mobilidades de spin, medidas em ambos os canais y (em verme-

lho) e $x$ (em azul), como função da voltagem $V_{\mathrm{g}}$ aplicada no eletrodo de porta do dispositivo, com a temperatura na amostra estabilizada em $T=20 \mathrm{~K}$. . . . . 56

5.20 Comportamento dos campos spin-órbita, gerados por deriva nos canais $y$ (em vermelho) e $x$ (em azul), como função da voltagem $V-\mathrm{g}$ aplicada no eletrodo de porta do dispositivo, com a temperatura na amostra estabilizada em $T=20 \mathrm{~K}$. 56

5.21 Coeficientes $b^{y}$ (em vermelho) e $b^{x}$ (em azul), calculados a partir da divisão direta entre os $B_{\mathrm{SO}}$ e as velocidades de deriva para cada voltagem $V_{\mathrm{g}}$ no eletrodo de porta, com a temperatura na amostra estabilizada em $T=20 \mathrm{~K}$. . . . . . . 57

5.22 Medidas de mobilidade de spin como função da temperatura na câmara da

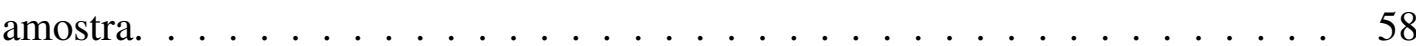

5.23 Campos spin-órbita $B_{\mathrm{SO}}^{x}$ como função da temperatura na câmara da amostra. . . 59

5.24 Coeficientes $b^{y}$ como função da temperatura na câmara da amostra. . . . . . . . 59 



\section{Lista de Tabelas}

4.1 Parâmetros utilizados ao longo do experimento para que o sinal medido fosse optimizado. Nessa tabela, $\lambda$ é o comprimento de onda do laser, $P_{\text {bombeio }}$ e $P_{\text {prova }}$ são as potências dos feixes de bombeio e prova medidas antes da janela do criostato, e $T_{\text {amostra }}$ é a temperatura na câmara da amostra. . . . . . . . . . . . 32

4.2 Parâmetros optimizados obtidos através do ajuste da função de RSA (equação 4.5p nos dados do gráfico da figura 4 .10 para a posição de overlap, na situação em que não há deriva de spin. . . . . . . . . . . . . . . . . . . . . . 36

4.3 Parâmetros optimizados obtidos através do ajuste da função de RSA (equação 4.5) nos dados do gráfico da figura 4 .16, para a posição de overlap, na situação em que não há deriva de spin. . . . . . . . . . . . . . . . . . . . . . 38

5.1 Mobilidades de spin obtidas para os canais $y$ e $x$ da amostra, através do ajuste da equação $|5.7|$ nos dados da figura| $5.12 \mid$. . . . . . . . . . . . . . . . . . . . . 49 



\section{Sumário}

\begin{tabular}{lll}
\hline & Motivação & 1
\end{tabular}

\begin{tabular}{|lll}
\hline 2 & Introdução & 3 \\
\hline
\end{tabular}

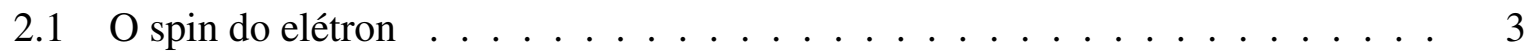

2.2 Interação spin-órbita $\ldots \ldots \ldots \ldots \ldots \ldots \ldots$

$2.2 .1 \quad$ Interação de Dresselhaus $\ldots \ldots \ldots \ldots$. . . . . . . . . . . 5

2.2 .2 Interação de Rashba $\ldots \ldots \ldots \ldots$. . . . . . . . . . . 7

2.2 .3 Campo magnético spin-órbita efetivo . . . . . . . . . . . 8

2.3 Estrutura de banda do $\mathrm{GaAs} \ldots \ldots \ldots \ldots$

2.3 .1 Polarização de spin por orientação óptica . . . . . . . . . . . . . . 12

2.3 .2 Efeito Kerr magneto-óptico $\ldots \ldots \ldots \ldots$

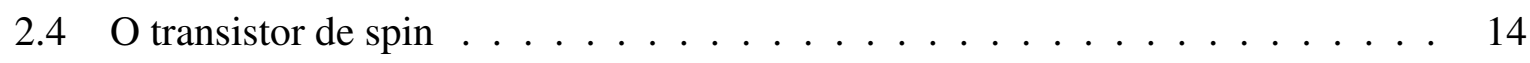

\begin{tabular}{|ll}
\hline Materiais e Métodos & 17
\end{tabular}

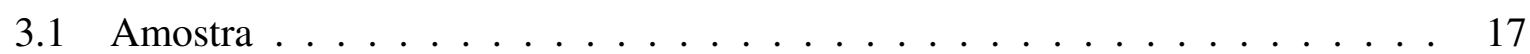

3.1 .1 Dispositivo . . . . . . . . . . . . . . . . . 19

$3.2 \quad$ Aparato experimental $\ldots \ldots \ldots \ldots$. . . . . . . . . . . . . . . . . . . . . . . . 19

3.2 .1 Resolução temporal . . . . . . . . . . . . . . . . . . 21

3.3 Amplificação de spin ressonante (RSA) $\ldots \ldots \ldots \ldots$

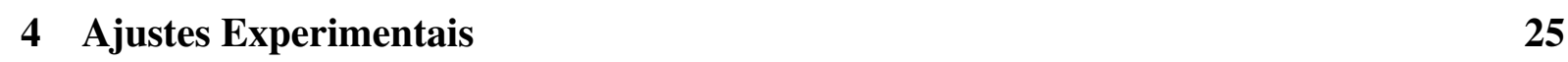

4.1 Mapeamento da amostra pela reflexão do bombeio $\ldots$. . . . . . . . . . . 25 
4.2 Ajuste do foco dos feixes na amostra . . . . . . . . . . . . . 30

4.3 Posição de overlap entre bombeio e prova $\ldots \ldots \ldots$. . . . . . . . . . . 31

$4.3 .1 \quad$ Varredura horizontal $\ldots \ldots \ldots \ldots$

4.3 .2 varredura vertical . . . . . . . . . . . . . . . 36

5 Deriva de polarização de spin 39

5.1 Deriva de spin na direção $y . \ldots \ldots \ldots$. . . . . . . . . . . . . 41

5.2 Deriva de spin na direção $\mathrm{x} \ldots \ldots \ldots \ldots \ldots \ldots$

5.3 Resultados combinados $\ldots \ldots \ldots \ldots \ldots$. . . . . . . . . . . . . 49

5.4 Medidas como função da voltagem no eletrodo de porta $\ldots$. . . . . . . . . . . 53

5.5 Medidas como função da temperatura $\ldots \ldots \ldots$. . . . . . . . . 57

6 Considerações Finais $\quad 61$

\begin{tabular}{|l|l}
\hline Referências Bibliográficas & 63
\end{tabular} 


\section{Capítulo 1}

\section{Motivação}

Desde as últimas décadas, a importância da eletrônica em nosso cotidiano vem aumentando rapidamente, estando presente tanto em atividades básicas como cozinhar e se locomover, quanto em complexos processos industriais. Isso é hoje possível graças à invenção do transistor em 1947 por John Bardeen, Walter Brattain e William Shockley, considerada por muitos a mais importante invenção do século passado [1], substituindo nos anos $195^{\circ}$ as grandes e frágeis válvulas utilizadas na eletrônica até então, as quais além de ocuparem muito espaço, superaqueciam e consumiam muita energia. Alguns anos depois, surgiam os primeiros circuitos integrados e microchips, que culminaram na revolução dos microcomputadores.

A eletrônica moderna é fundamentada portanto no emprego de dispositivos semicondutores em circuitos projetados para manipular correntes elétricas, possibilitando o processamento, o armazenamento e a transmissão de informação. Em 1965, Gordon E. Moore publicou um artigo [2] onde apontava a tendência de o número de transistores em um circuito integrado dobrar a cada ano, recalibrando posteriormente essa estimativa para um período de dois anos, em 1975 [3]. A Lei de Moore, como ficou conhecida, é usada desde então pela indústria de semicondutores para guiar a pesquisa e o desenvolvimento de novos componentes.

Entretanto, esse crescente processo de miniaturização dos componentes eletrônicos faz com que nos aproximemos de um limite de dimensões em que os efeitos quânticos passam a ser importantes, impossibilitando o controle do fluxo de elétrons. Diante desse cenário, faz-se necessário o desenvolvimento de alternativas viáveis à eletrônica convencional.

A Spintrônica, como o próprio nome sugere, oferece o paradigma de uma eletrônica baseada no spin do elétron, uma propriedade quântica associada a seu momento magnético intrínseco, com dois valores distintos permitidos, de acordo com sua orientação: up e down. Esses valores podem ser associados aos 0 e 1 da linguagem binária dos computadores e su- 
perpostos de maneira coerente, de forma que o acoplamento de vários desses estados pode ser utilizado para o desenvolvimento de novos algoritmos extremamente poderosos, conhecidos como computação quântica [4,5]. A implementação de dispositivos spintrônicos na tecnologia atual apresenta potenciais vantagens como não-volatilidade, aumento na velocidade de processamento de dados, diminuição no consumo de potência elétrica, e aumento na densidade de integração, em comparação com dispositivos semicondutores convencionais baseados em propriedades da carga do elétron [6]. Não obstante, existem ainda grandes desafios para a implantação tecnológica da spintrônica, como injeção, transporte, manipulação e detecção eficientes de polarização de spin [7].

O primeiro conceito de um transistor de spin foi proposto em um artigo de 1990 e ficou conhecido como transistor Datta-Das, por causa do nome de seus idealizadores [8]. Tratase da ideia de um transistor de efeito de campo (FET) em que elétrons com spins polarizados seriam injetados por contatos ferromagnéticos em um canal semicondutor unidimensional. Uma região de filtragem por um eletrodo de porta selecionaria quais elétrons poderiam passar para um contato de detecção de acordo com a orientação de seus spins. Esse modelo requer, entretanto, que o transporte através do canal ocorra de forma balística para que o dispositivo funcione corretamente, sendo esse um empecilho para a construção de um transistor Datta-Das.

Uma proposta mais interessante de um spin-FET não-balístico foi apresentada em um artigo de 2003 [9], tendo seu funcionamento baseado em ambas as interações spin-órbita (SOI) de Rashba [10] e Dresselhaus [11], diferentemente do modelo de Datta-Das que se fundamentava apenas na primeira. No regime em que ambas as interações de Rashba e Dresselhaus têm a mesma magnitude, forma-se a hélice de spin persistente (PSH) [12-14], permitindo que haja conservação da polarização de spin e protegendo contra os mecanismos de relaxação que geram decoerência de spin. Dessa forma, um dispositivo operando nesse regime não estará mais restrito a um transporte balístico.

Faz-se importante, portanto, o estudo da dinâmica de deriva de polarização de spin em semicondutores e de como a magnitude das interações spin-órbita, dada pelas constantes $\alpha$ de Rashba e $\beta$ de Dresselhaus, se relaciona com esse transporte. Nesse trabalho, são utilizadas técnicas ópticas de injeção e detecção de polarização de spin em um sistema bidimensional não ferromagnético composto por duas sub-bandas, propondo-se investigar como diferentes velocidades de deriva podem influenciar na dinâmica de magnetização dos spins. 


\section{Capítulo 2}

\section{Introdução}

\subsection{O spin do elétron}

Em mecânica quântica, o termo spin se refere a um tipo intrínseco de momento angular carregado por partículas, cujo nome é uma alegoria ao movimento clássico de rotação de objetos macroscópicos em torno do próprio eixo - ainda que para partículas pontuais, como o elétron, não seja possível definir uma rotação desse tipo.

As partículas na natureza podem ser divididas em duas categorias de acordo com o seu spin. Os elétrons pertencem ao grupo dos férmions, partículas com spin semi-inteiro, e que, diferentemente dos bósons que possuem spin inteiro (como os fótons), obedecem ao princípio de exclusão de Pauli, isto é não podem ocupar um mesmo estado quântico com um mesmo spin.

Devido ao princípio de incerteza de Heisenberg, não é possível saber com exatidão os valores das projeções do spin nas direções $x, y$ e $z$ simultaneamente. Para o elétron, ao se realizar medidas de alguma dessas componentes - por exemplo, $S_{z}$-, verifica-se que os únicos resultados possíveis são: $S_{z}=+\frac{1}{2} \hbar$ ou $S_{z}=-\frac{1}{2} \hbar$, onde $\hbar$ é a constante de Planck reduzida. Ou seja, a magnitude será sempre a mesma com duas orientações opostas, as quais podem ser chamadas de spin up $(\uparrow)$ e spin down $(\downarrow)$. Como consequência de seu spin e de sua carga elétrica $q_{e}=-e$, os elétrons possuem um momento magnético intrínseco - dado por

$$
\vec{\mu}_{S}=-\frac{g \mu_{\mathrm{B}}}{\hbar} \vec{S}
$$

onde $g$ é o fator-g de Landé do elétron e $\mu_{\mathrm{B}}$ é o magnéton de Bohr - que pode interagir com um campo magnético externo, por exemplo. Essa propriedade permitiu que os spins fossem descobertos através do famoso experimento de Stern-Gerlach, em 1922 [16]. 


\subsection{Interação spin-órbita}

Átomos podem ser descritos classicamente como elétrons se movendo em órbitas circulares específicas - chamadas níveis de energia atômicos - em torno de um núcleo positivamente carregado. O exemplo mais simples de um átomo é o hidrogênio, composto de um elétron orbitando um próton essencialmente estático - por ter massa maior -, ligados através da força Coulombiana. Nesse referencial o elétron está sujeito a uma força central devido à interação entre sua carga e o campo elétrico $\vec{E}$ gerado pelo próton.

Por outro lado, é possível fazer uma descrição distinta do átomo de Hidrogênio, adotando o ponto de vista do elétron, isto é, no referencial em que ele se encontra fixo sendo orbitado pelo próton. Como uma consequência relativística, nesse referencial o elétron enxerga não mais um campo elétrico, mas um campo magnético efetivo $\vec{B}_{\mathrm{SO}}$, que pode ser escrito em termos de uma transformação de Lorentz

$$
\vec{B}_{\mathrm{SO}}=-\frac{1}{c^{2}} \frac{\vec{v} \times \vec{E}}{\sqrt{1-v^{2} / c^{2}}}
$$

onde $c$ é a velocidade da luz, $v$ é a velocidade do elétron e $E$ é o campo elétrico.

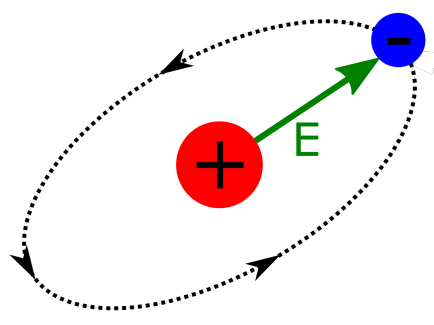

(a)

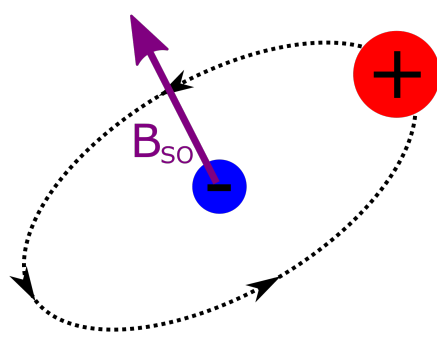

(b)

Figura 2.1: Representação esquemática de um átomo de Hidrogênio clássico em dois referenciais: (a) elétron orbitando um próton estático que gera um campo elétrico $\vec{E}$; (b) próton orbitando um elétron estático e respectivo campo magnético efetivo $\vec{B}_{\text {SO }}$ gerado pela órbita.

Como o momento magnético intrínseco do elétron $\mu_{\mathrm{S}}$, dado pela equação 2.1, pode interagir com o campo magnético efetivo $B_{\text {So }}$ proveniente de sua órbita, através de uma energia de Zeeman

$$
\epsilon_{\mathrm{Z}}=-\vec{\mu}_{\mathrm{S}} \cdot \vec{B}_{\mathrm{SO}}
$$




\subsection{INTERAÇÃO SPIN-ÓRBITA}

essa interação é chamada de interação spin-órbita (SOI), a qual é responsável pela separação de Zeeman na estrutura fina dos níveis de energia atômicos, por exemplo [17, 18]. Essa interação pode também ser descrita através do seguinte Hamiltoniano:

$$
\mathcal{H}_{\mathrm{SO}}=\frac{g \mu_{\mathrm{B}}}{\hbar} \vec{B}_{\mathrm{SO}} \cdot \vec{S}
$$

onde $\vec{S}=(\hbar / 2)\left(\sigma_{x} \hat{x}+\sigma_{y} \hat{y}+\sigma_{z} \hat{z}\right)$, em que $\sigma_{i}$ são as matrizes de Pauli:

$$
\sigma_{x}=\left(\begin{array}{cc}
0 & 1 \\
1 & 0
\end{array}\right) \quad \sigma_{y}=\left(\begin{array}{cc}
0 & -i \\
i & 0
\end{array}\right) \quad \sigma_{z}=\left(\begin{array}{cc}
1 & 0 \\
0 & -1
\end{array}\right)
$$

Em contrapartida, uma descrição similar da SOI pode ser feita para elétrons se movimentando através de sólidos. Nesse caso, uma transformação de Lorentz, para o referencial do elétron, do campo elétrico que surge do potencial do cristal também resulta em um campo magnético efetivo $B_{\mathrm{SO}}$. Entretanto, esse campo spin-órbita só será não-nulo se houverem algumas assimetrias no cristal. A seguir, serão introduzidos dois tipos de assimetria de inversão que são de interesse para esse trabalho, por serem responsáveis por campos spin-órbita importantes para o funcionamento de um transistor de spin não-balístico [9].

\subsubsection{Interação de Dresselhaus}

Semicondutores elementares do grupo IV como o silício ( $\mathrm{Si}$ ) são amplamente utilizados na fabricação de dispositivos para a eletrônica convencional. Esses materiais são formados por átomos de apenas um elemento em ligações tetraédricas e cristalizam na estrutura do diamante, representada na figura 2.2a, a qual pode ser considerada como duas sub-redes cúbica de face centrada (fcc) deslocadas entre si de um quarto da diagonal do cubo [19,20]. Esses semicondutores, no entanto, possuem simetria de inversão, o que impossibilita a criação de campos spin-órbita não-nulos no cristal bulk.

Por outro lado, alguns dos semicondutores do grupo III-V - isto é, semicondutores binários formados a partir da combinação de elementos dos grupos III e V da tabela periódica -, assim como o arsenieto de gálio (GaAs), cristalizam em uma estrutura denominada blenda de zinco. Essa estrutura é similar a do diamante, com a diferença de que uma das sub redes é formada por átomos de um tipo (gálio, por exemplo, para o GaAs), enquanto a segunda é 


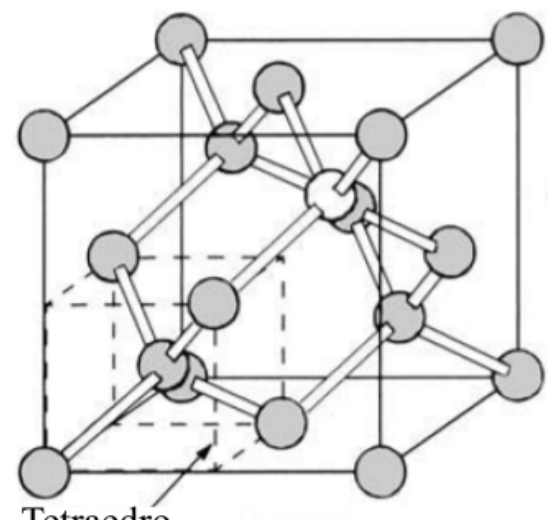

Tetraedro

(a) Diamante

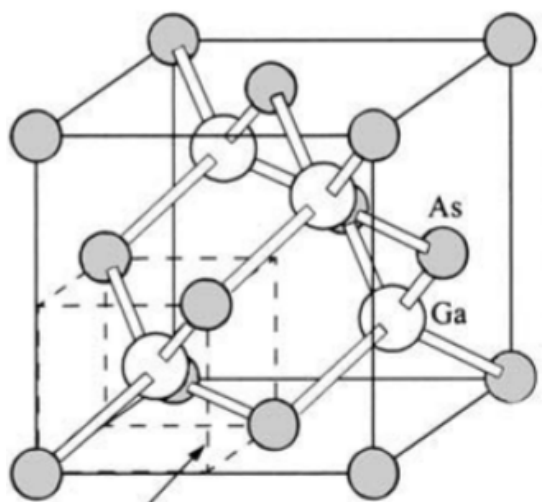

Tetraedro

(b) Blenda de zinco

Figura 2.2: Representação das estruturas cristalinas: (a) do diamante, na qual cristalizam semicondutores elementares IV, como Si; e (b) blenda de zinco, presente em semicondutores binários III-V, como o GaAs. Extraída de [20].

formada por átomos do outro tipo (arsênio, para o mesmo exemplo), como mostra a figura $2.2 \mathrm{~b}$.

Diferentemente do que ocorre na estrutura do diamante, a natureza iônica dos cristais bulk com estrutura blenda de zinco faz com que esses semicondutores possuam uma chamada assimetria de inversão de bulk (BIA). De fato, uma troca entre o ânion e o cátion inverte o campo elétrico microscópico, o que possibilita o surgimento de campos spin-órbita $B_{\mathrm{SO}}$. Essa assimetria foi prevista por Dresselhaus em um artigo de 1955 [11], e por isso a SOI gerada pela BIA é chamada interação de Dresselhaus.

Uma descrição dessa SOI pode ser feita no sistema de coordenadas $(x, y, z)$ definido pelas direções cristalográficas cúbicas [100], [010] e [001]. Essas direções estão especificadas em uma célula primitiva de GaAs, com o cátion (Ga) em $(0,0,0)$ e o ânion (As) em $\left(\frac{1}{4}, \frac{1}{4}, \frac{1}{4}\right)$. Nesse sistema, o Hamiltoniano de Dresselhaus para o cristal bulk é dado por [14,15]:

$$
\mathcal{H}_{\mathrm{D}}^{\text {bulk }}=\gamma\left[\sigma_{x} k_{x}\left(k_{y}^{2}-k_{z}^{2}\right)+\sigma_{y} k_{y}\left(k_{z}^{2}-k_{x}^{2}\right)+\sigma_{z} k_{z}\left(k_{x}^{2}-k_{y}^{2}\right)\right]
$$

onde $\gamma$, dado em unidades de energia vezes distância ao quadrado $\left(\mathrm{eV} \mathrm{m}^{2}\right)$, é o parâmetro de Dresselhaus dependente do material, $\sigma_{i}(i=x, y, z)$ são as matrizes de Pauli e $k_{i}$ são as componentes do vetor de onda $\vec{k}$.

De outra forma, se forem considerados elétrons restritos a um plano bidimensional, como em um poço quântico $(\mathrm{QW})$ crescido na direção $z$, por exemplo, o confinamento desses elétrons na direção de crescimento resultará em estados ligados com o valor esperado $\left\langle k_{z}\right\rangle=0$ 
e um valor quantizado para $\left\langle k_{z}^{2}\right\rangle$. Dessa forma, o Hamiltoniano (equação 2.6) pode ser reescrito como:

$$
\mathcal{H}_{\mathrm{D}}^{\mathrm{QW}}=\gamma\left\langle k_{z}^{2}\right\rangle\left(\sigma_{y} k_{y}-\sigma_{x} k_{x}\right)+\gamma\left(k_{x} k_{y}^{2} \sigma_{x}-k_{x}^{2} k_{y} \sigma_{y}\right)
$$

ou, definindo os seguintes coeficientes $\beta_{1}=-\gamma\left\langle k_{z}^{2}\right\rangle$ e $\beta_{3}=-\gamma k_{\mathrm{F}}^{2} / 4$, onde $k_{\mathrm{F}}$ é o vetor de onda de Fermi:

$$
\mathcal{H}_{\mathrm{D}}=\beta_{1}\left(\sigma_{x} k_{x}-\sigma_{y} k_{y}\right)-\beta_{3}\left[\sigma_{x} k_{x}\left(\frac{k_{y}}{k_{\mathrm{F}}}\right)^{2}-\sigma_{y} k_{y}\left(\frac{k_{x}}{k_{\mathrm{F}}}\right)^{2}\right]
$$

O parâmetro $\beta_{1}$ é chamado coeficiente linear de Dresselhaus e depende da largura $w$ do poço quântico, já que usando a aproximação para poços quânticos infinitos $\left\langle k_{z}^{2}\right\rangle \approx(\pi / w)^{2}[21]$, tem-se

$$
\beta_{1} \approx-\gamma\left(\frac{\pi}{w}\right)^{2}
$$

Em contrapartida, $\beta_{3}$ é chamado coeficiente cúbico de Dresselhaus e depende da densidade de portadores de carga $n_{\mathrm{s}}$, já que o número de onda de Fermi para um gás de elétrons bidimensional é dado por $k_{\mathrm{F}}=\sqrt{2 \pi n_{\mathrm{s}}}$, resultando em

$$
\beta_{3}=-\frac{1}{2} \gamma \pi n_{\mathrm{s}}
$$

\subsubsection{Interação de Rashba}

Como visto acima, a introdução de nano estruturas como poços quânticos pode fornecer formas de se manipular a magnitude da SOI que não seriam possíveis em um cristal bulk, onde a estrutura de banda e a interação spin-órbita são puramente determinadas pelo cristal. Com o coeficiente linear de Dresselhaus $\beta_{1}$, por exemplo, é introduzida uma dependência da SOI com a largura $w$ do poço, que pode ser escolhida no processo de crescimento.

Entretanto, sistemas como esse podem também conter uma segunda origem para a interação spin-órbita, diferente da BIA. Haverá uma assimetria de inversão de estrutura (SIA) no material, se houver no próprio poço quântico uma assimetria de potencial, por exemplo, que pode ser causada tanto como consequência de dopagens diferentes em ambos os lados do poço, ou com a fabricação de eletrodos de porta (gate); essa última sendo interessante pela possibilidade de se controlar a SOI eletricamente através de voltagens $V_{\mathrm{g}}$. 
À SOI que surge da SIA dá-se o nome de interação de Rashba, sendo ela descrita pelo seguinte Hamiltoniano (para uma direção de crescimento z) [10]:

$$
\mathcal{H}_{\mathrm{R}}=\alpha[\vec{\sigma} \cdot(\vec{k} \times \hat{\vec{z}})]=\alpha\left(\sigma_{x} k_{y}-\sigma_{y} k_{x}\right)
$$

onde $\alpha$, dado em unidades de energia vezes distância ao quadrado $\left(\mathrm{eV} \mathrm{m}^{2}\right)$, é o coeficiente spin-órbita de Rashba, o qual depende portanto da assimetria do poço.

\subsubsection{Campo magnético spin-órbita efetivo}

Juntando os termos de Dresselhaus e Rashba (eqs. 2.8 e 2.11), o Hamiltoniano para a interação spin-órbita total pode ser resumido como

$$
\mathcal{H}_{\mathrm{SO}}=\alpha\left(\sigma_{x} k_{y}-\sigma_{y} k_{x}\right)+\beta_{1}\left(\sigma_{x} k_{x}-\sigma_{y} k_{y}\right)-\beta_{3}\left[\sigma_{x} k_{x}\left(\frac{k_{y}}{k_{\mathrm{F}}}\right)^{2}-\sigma_{y} k_{y}\left(\frac{k_{x}}{k_{\mathrm{F}}}\right)^{2}\right]
$$

e deve ser igual ao Hamiltoniano da energia de Zeeman, dado pela equação 2.4 .

$$
\mathcal{H}_{\mathrm{SO}}=\frac{g \mu_{B}}{\hbar} \vec{B}_{\mathrm{SO}}(\vec{k}) \cdot \vec{S}
$$

Dessa forma, o campo magnético spin-órbita efetivo deve conter contribuições de ambas as SOI de Rashba e Dresselhaus

$$
\vec{B}_{\mathrm{SO}}(\vec{k})=\vec{B}_{\mathrm{R}}(\vec{k})+\vec{B}_{\mathrm{D}, 1}(\vec{k})+\vec{B}_{\mathrm{D}, 3}(\vec{k})
$$

onde $\vec{B}_{\mathrm{R}}$ é o campo spin-órbita de Rashba e $\vec{B}_{\mathrm{D}}=\vec{B}_{\mathrm{D}, 1}+\vec{B}_{\mathrm{D}, 3}$ é o campo spin-órbita de Dresselhaus, composto pela soma dos termos linear e cúbico. Os valores desses campos podem ser obtidos ao se igualar as equações $2.4 \mathrm{e} 2.12$

$$
\vec{B}_{\mathrm{R}}=\frac{2 \alpha}{g \mu_{B}}\left(\begin{array}{c}
k_{y} \\
-k_{x}
\end{array}\right) \quad \vec{B}_{\mathrm{D}, 1}=\frac{2 \beta_{1}}{g \mu_{B}}\left(\begin{array}{c}
k_{x} \\
-k_{y}
\end{array}\right) \quad \vec{B}_{\mathrm{D}, 3}=\frac{2 \beta_{3}}{g \mu_{B}}\left(\begin{array}{c}
-k_{x} k_{y}^{2} / k_{\mathrm{F}}^{2} \\
k_{x}^{2} k_{y} / k_{\mathrm{F}}^{2}
\end{array}\right)
$$

Os campos acima estão definidos em um sistema de coordenadas cúbico $x \|$ [100], $y \|$ [010], z $\|$ [001]. É interessante, porém, defini-los também em termos das direções crista- 
lográficas $x^{\prime} \|$ [1]0], $y^{\prime} \|$ [110], $z^{\prime} \|$ [001], que serão úteis para a amostra (Capítulo 3). Através da rotação do sistema de coordenadas $x^{\prime}=x-y$ e $y^{\prime}=x+y$, os campos SO são reescritos como

$$
\vec{B}_{\mathrm{R}}=\frac{2 \alpha}{g \mu_{B}}\left(\begin{array}{c}
k_{y}^{\prime} \\
-k_{x}^{\prime}
\end{array}\right) \quad \vec{B}_{\mathrm{D}, 1}=\frac{2 \beta_{1}}{g \mu_{B}}\left(\begin{array}{c}
k_{y}^{\prime} \\
k_{x}^{\prime}
\end{array}\right) \quad \vec{B}_{\mathrm{D}, 3}=\frac{\beta_{3}}{g \mu_{B}}\left(\begin{array}{c}
\left(k_{x}^{\prime 2}-k_{y}^{\prime 2}\right) k_{y}^{\prime} / k_{\mathrm{F}}^{2} \\
-\left(k_{x}^{\prime 2}-k_{y}^{\prime 2}\right) k_{x}^{\prime} / k_{\mathrm{F}}^{2}
\end{array}\right)
$$

Os campos spin-órbita definidos acima estão ilustrados na figura 2.3 , onde se pode ver que, para as componentes de Rashba $\vec{B}_{\mathrm{R}}$ e Dresselhaus $\vec{B}_{\mathrm{D}, 1}, \vec{B}_{\mathrm{D}, 3}$, isoladamente, as direções dos campos SO dependem da direção do momento dos elétrons. Por outro lado, ao se considerar a soma dos campos de Rashba e Dresselhaus para a situação em que $\alpha=\beta_{1}$ e $\beta_{3}=0$, como representada na figura 2.3 c), observa-se um campo SO efetivo uniaxial, como pode ser confirmado pelas equações 2.16. É nesse cenário que surge o fenômeno da hélice de spin persistente (PSH) [12-14] na qual se fundamenta o funcionamento de um transistor de spin não-balístico, pois em um campo uniaxial, independentemente de $\vec{k}$ todos os spins precessam em torno do mesmo eixo, o que torna a precessão robusta contra processos de espalhamento independentes do spin [9].

a) $B_{R}$

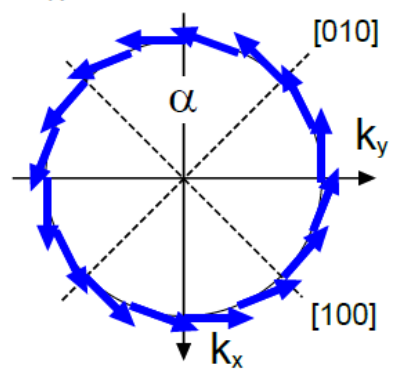

c) $\mathrm{B}_{\mathrm{R}}+\mathrm{B}_{\mathrm{D}, 1}$

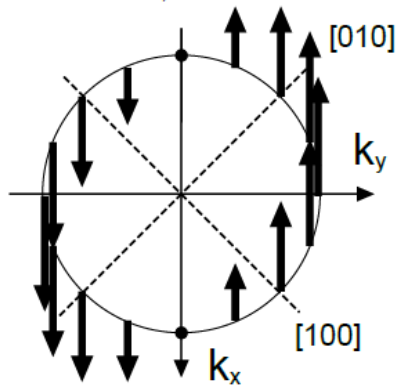

b) $B_{D, 1}$

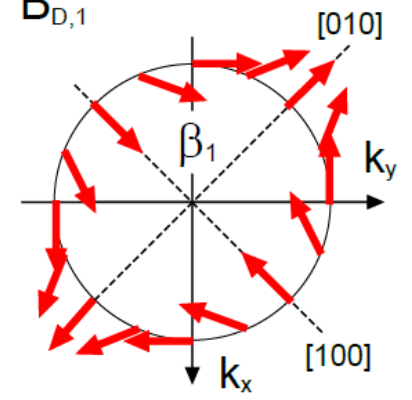

d) $B_{D, 3}$

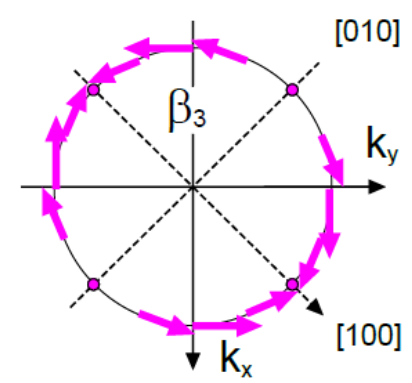

Figura 2.3: Representação dos campos spin-órbita efetivos de: $a$ ) Rashba; $b$ ) Dresselhaus linear; c) Rashba + Dresselhaus linear com $\alpha=\beta_{1}$; e d) Dresselhaus cúbico. Extraída de [14]. 


\subsection{Estrutura de banda do GaAs}

Semicondutores são materiais fundamentais para a eletrônica moderna, sendo utilizados para a fabricação de inúmeros dispositivos presentes em outros incontáveis aparelhos eletrônicos. O próprio transistor, símbolo dessa revolução tecnológica, é um dispositivo semicondutor, assim como diodos, células fotovoltaicas, sensores magnéticos, termistores, entre outros [19].

As propriedades únicas dos semicondutores surgem da estrutura de banda desses materiais. Diferentemente dos condutores, que permitem um fluxo livre de elétrons por não possuírem um gap de energia entre as bandas de valência e condução, os semicondutores contam com um pequeno gap separando essas bandas (tipicamente de até $3 \mathrm{eV}$ ), mas que por ser menor do que o de materiais isolantes, pode permitir o controle do fluxo de elétrons e buracos sob certas condições; como ao se adicionar impurezas, em um processo denominado dopagem [20].

O GaAs é um semicondutor com um gap de banda direto, o que quer dizer que o mínimo da banda de condução está alinhado ao máximo da banda de valência, como pode ser visto na linha de maior simetria $\Gamma$ do gráfico de energia versus vetor de onda exposto na figura 2.4. Essa propriedade faz com que o GaAs seja adequado para estudos ópticos, pois permite excitação e recombinação diretas de elétrons e buracos, havendo conservação de momento.

A banda de condução do GaAs (CB na figura 2.5, e $\Gamma_{6}$ na figura 2.4) tem uma simetria tipo $s$, o que significa que o número quântico do momento angular orbital vale $l=0$, e portanto $j=1 / 2$ e $m_{j}= \pm 1 / 2$ descrevem o momento angular total $(\vec{J}=\vec{L}+\vec{S})$. Já a banda de valência (VB), separada da CB pelo gap de banda direto $E_{\mathrm{g}}$, tem uma simetria tipo $p(l=1)$, e é dividida pela interação spin-órbita em bandas com $j=3 / 2\left(\Gamma_{8}\right)$ e $j=1 / 2\left(\Gamma_{7}\right)$, essa última chamada de banda split-off (so). Para o cristal bulk, a banda dos buracos leves (lh, $m_{j}= \pm 1 / 2$ ) e pesados (hh, $m_{j}= \pm 3 / 2$ ) é degenerada no ponto $\Gamma$, enquanto que para um poço quântico (figura $2.5 \mathrm{~b}$ ) essa degenerescência é quebrada. 


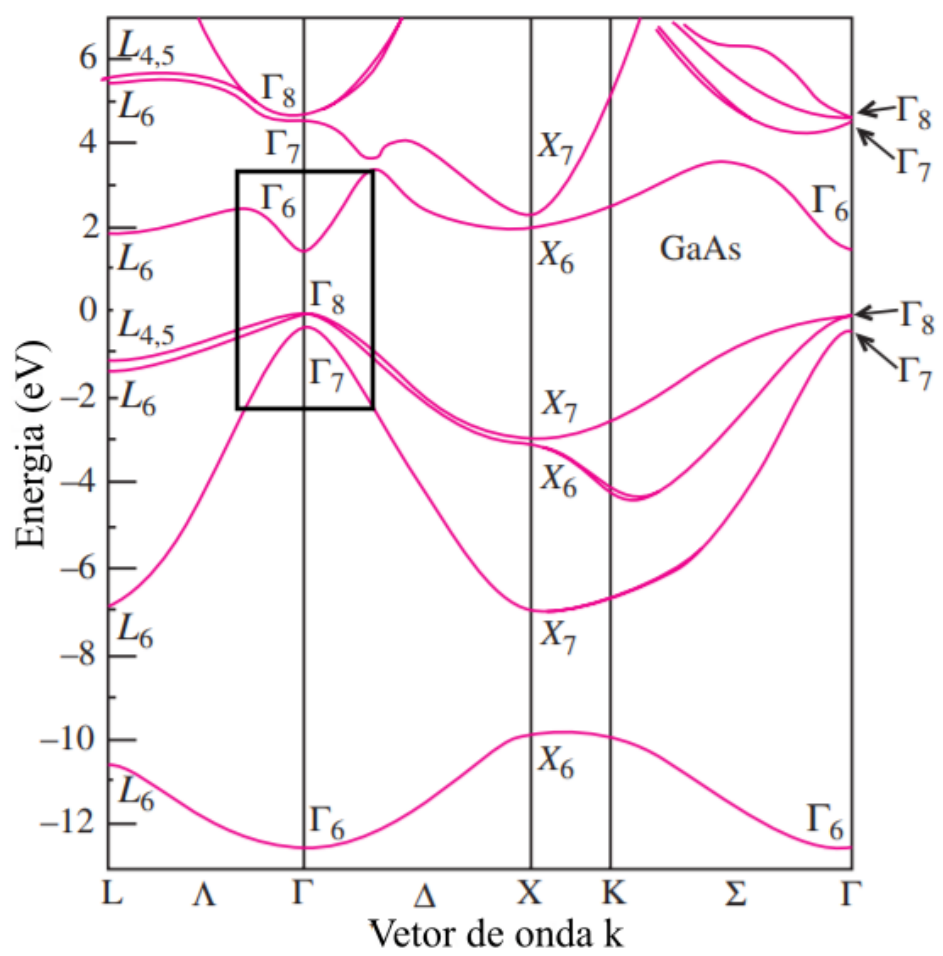

Figura 2.4: Estrutura de banda do GaAs bulk. Extraída de [22].

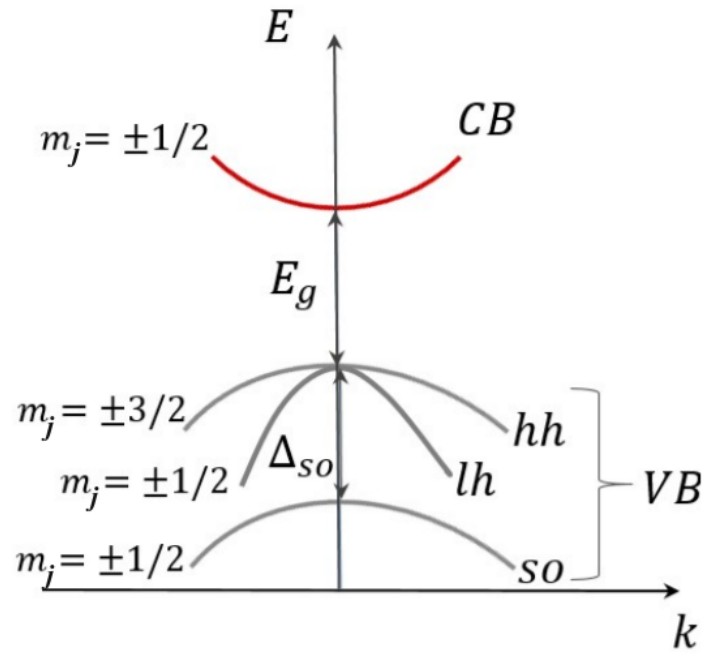

(a)

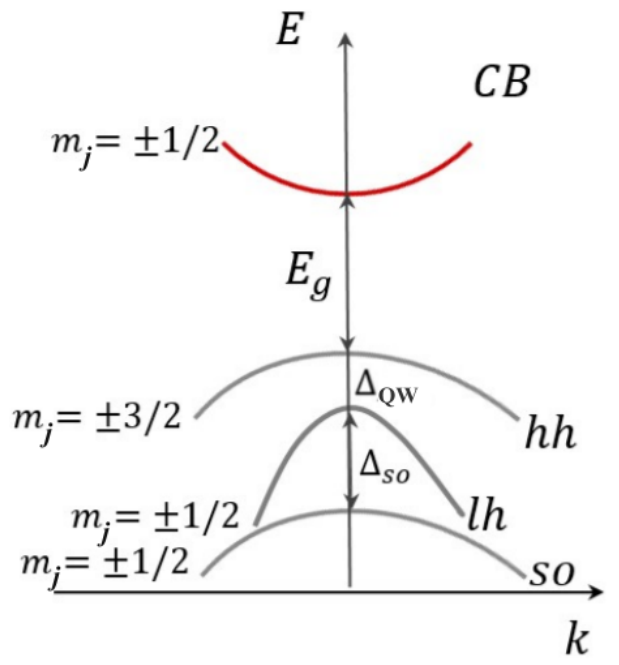

(b)

Figura 2.5: Diagrama da estrutura de banda simplificada do GaAs, próximo ao ponto $\Gamma$, para: (a) o cristal bulk; (b) um poço quântico. Nas figuras, CB representa a banda de condução separada da banda de valência VB pelo gap de banda direto $E_{g}$. Para o cristal bulk, a banda dos buracos leves e pesados (lh e hh) é degenerada no ponto $\Gamma$ e separada da banda split-off (so) por $\Delta_{\text {so. }}$. Para o poço quântico há uma quebra de degenerescência entre lh e hh com uma separação $\Delta_{\mathrm{QW}}$. 


\subsubsection{Polarização de spin por orientação óptica}

Nessa dissertação, a indução de polarização de spin na amostra é feita através da absorção de luz circularmente polarizada. Devido às regras de seleção ópticas, as transições eletrônicas devem satisfazer às seguintes condições:

$$
\begin{aligned}
\Delta j & = \pm 1 \\
\Delta m_{j} & = \pm 1,
\end{aligned}
$$

Na figura 2.6 estão representadas as transições eletrônicas permitidas pelas regras de seleção ópticas (equação 2.17) em um poço quântico de GaAs no ponto $\Gamma$. As duas direções de polarização circular estão representadas como $\sigma^{+}$e $\sigma^{-}$, as quais causam transições de $\Delta m_{j}=1$ e $\Delta m_{j}=-1$, respectivamente. Para $\sigma^{-}$, por exemplo, as possíveis transições são: $(i)$ da banda hh, com $m_{j}=3 / 2$, para a banda de condução, com $m_{j}=1 / 2$ (spin up, $\uparrow$ ); ou (ii) da banda lh, $\operatorname{com} m_{j}=1 / 2$, para a CB, com $m_{j}=-1 / 2(\operatorname{spin}$ down, $\downarrow)$.

Nota-se que para um cristal bulk, a banda dos buracos leves e pesados é degenerada $\left(\Delta_{\mathrm{QW}}=0\right)$, e portanto uma luz circularmente polarizada induziria tanto spin up quanto spin down na $\mathrm{CB}$, diminuindo a eficiência da polarização. Por outro lado, como em um poço quântico há uma separação $\Delta_{\mathrm{QW}}$ não-nula entre as bandas hh e lh, é possível selecionar energeticamente apenas uma das transições, resultando em uma polarização na CB com spins de apenas um tipo, e uma eficiência teórica de $100 \%$.

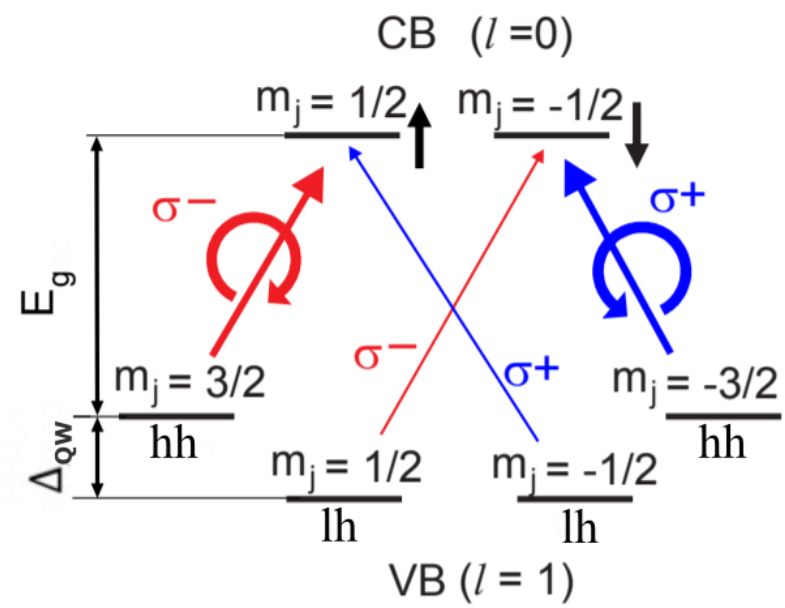

Figura 2.6: Transições eletrônicas permitidas pelas regras de seleção ópticas para um poço quântico de GaAs no ponto Г. Extraída de [14]. 


\subsubsection{Efeito Kerr magneto-óptico}

O efeito Kerr magneto-óptico (MOKE) é um fenômeno em que uma luz linearmente polarizada tem a sua direção de polarização rotacionada ao ser refletida por um material magnetizado. No caso dessa dissertação, o efeito Kerr é utilizado para medir a magnetização na amostra de GaAs devido à polarização de spins em sua banda de condução, induzida por luz circularmente polarizada, como descrito na seção 2.3.1 acima.

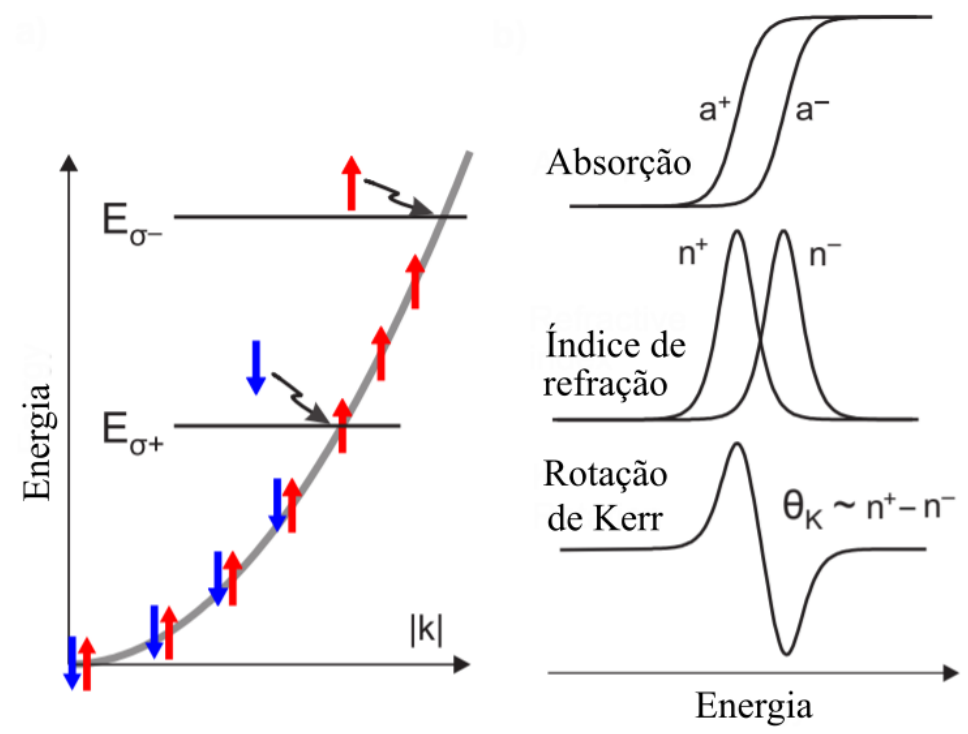

Figura 2.7: Representação da diferença na população de spins na CB (à esquerda), e consequentes comportamentos de absorção, índices de refração e rotação de Kerr (à direita). Extraída de $[14]$.

Devido às regras de seleção ópticas, os estados com spin up são preenchidos até energias mais altas do que os estados com spin down, causando um desvio nas curvas de absorção para luzes com polarização circular para a esquerda $\left(\sigma^{-}\right)$e para a direita $\left(\sigma^{+}\right)$, como mostrado na figura 2.7. De acordo com as relações de Kramers-Kronig, essa diferença na absorção faz com que os índices de refração $n^{+}$e $n^{-}$para as polarizações $\sigma^{+}$e $\sigma^{-}$sejam diferentes (o que é conhecido como birrefringência circular). Desse modo, como uma luz linearmente polarizada pode ser decomposta em uma base das polarizações circulares $\sigma^{+}$e $\sigma^{-}$, a defasagem causada pela diferença entre os índices de refração causará uma rotação na polarização dessa luz ao ser refletida pelo material. A rotação de Kerr é portanto proporcional a essa diferença: $\theta_{\mathrm{K}} \propto$ $n^{+}-n^{-}$(figura 2.7). 


\subsection{O transistor de spin}

Como antecipado no capítulo 1, em 1990, Supriyo Datta e Biswajit Das propuseram o primeiro conceito de um transistor de efeito de campo (FET) fundamentado no transporte de spins eletrônicos, ao contrário dos transistores convencionais baseados em correntes de carga. Essa proposta ficou conhecida como Transistor Datta-Das [8], e consiste de dois contatos ferromagnéticos, com uma magnetização definida, chamados de fonte e dreno, separados por um canal de transporte não ferromagnético, usualmente de um material semicondutor como o GaAs. Nesse dispositivo, o eletrodo de fonte injetaria elétrons com spins polarizados a serem transportados balisticamente ao longo do canal até o contato de dreno, onde seriam bloqueados ou deixados passar, a depender da orientação dos spins e da magnetização no dreno.

Para um dispositivo ativo, é necessário que haja maneiras de se manipular os spins desses elétrons. Por exemplo, pode-se fazer com que esses spins precessem em torno de um campo magnético externo, e dependendo da intensidade do campo e do comprimento do canal, pode-se controlar com quais polarizações esses spins chegarão ao dreno. Por outro lado, se o canal for composto de uma estrutura que confine os elétrons em uma região bidimensional, é possível a introdução de campos spin-órbita de Rashba que podem ser controlados por um eletrodo de porta, como visto na seção 2.2.2. A figura 2.8 abaixo ajuda a ilustrar o funcionamento de um spin-FET com um eletrodo de porta instalado.

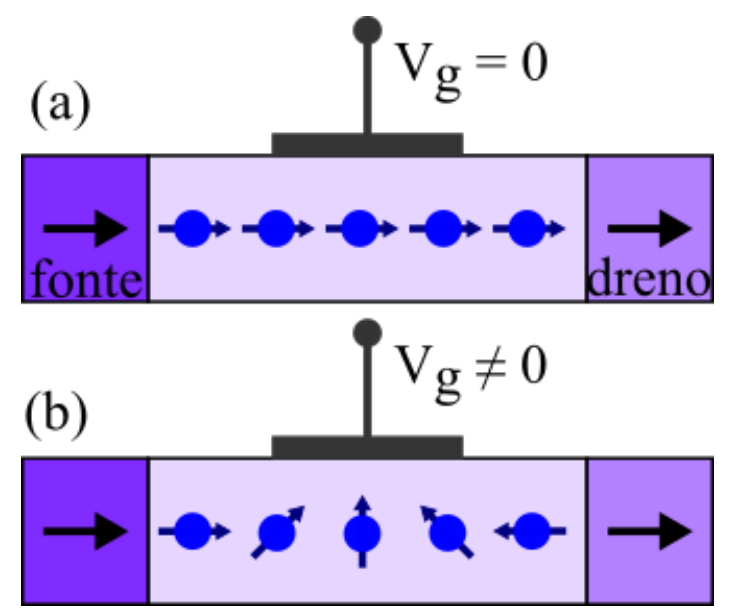

Figura 2.8: Ilustração para o funcionamento de um spin-FET: em (a) sem aplicar uma voltagem $V_{g}$ no eletrodo de porta; e em (b) com uma $V_{\mathrm{g}}$ não-nula. Se a polarização de spin do elétron que chega ao dreno for oposta à magnetização nesse contato, a passagem desse elétron será bloqueada. 
Um empecilho para o funcionamento de um dispositivo como o Datta-Das é o requerimento de que o transporte ao longo do canal ocorra de forma balística, o que é impossibilitado devido a mecanismos de relaxação de spin decorrentes da interação spin-órbita.

Em 2003, entretanto, foi apresentada uma proposta de um spin-FET não-balístico [9], que se fundamenta na formação da hélice de spin persistente (PSH) em um canal semicondutor em que haja ambas as contribuições das interações spin-órbita de Rashba e Dresselhaus. Como discutido na seção 2.2.3, a hélice de spin é formada quando as interações de Rashba e Dresselhaus têm a mesma magnitude, de forma que o campo SO efetivo é uniaxial, permitindo, portanto, a conservação de polarização de spin ao proteger o canal contra esses mecanismos de relaxação que geram decoerência de spin. Dessa forma, faz-se importante o estudo de como os coeficientes spin-órbita $\alpha$ de Rashba e $\beta$ de Dresselhaus podem ser ativamente manipulados, e de como eles podem ser influenciados pelo transporte dos spins ao longo do canal semicondutor. Entender esses mecanismos é dar passos importantes em direção à construção de um transistor de spin funcional. 



\section{Capítulo 3}

\section{Materiais e Métodos}

\subsection{Amostra}

A amostra utilizada nesse trabalho consiste em um poço quântico simples de GaAs com $45 \mathrm{~nm}$ de largura, crescido na direção cristalográfica [001] (z) e dopado simetricamente com Si. Devido à repulsão Coulombiana entre os elétrons, a distribuição de carga está sujeita a uma barreira dentro do poço que gera duas sub-bandas representadas pelas funções de onda simétrica e antissimétrica (as duas primeiras sub-bandas na figura 3.1), com uma separação de $\Delta_{\text {SAS }}=2 \mathrm{meV}$ entre si. As densidades das sub-bandas, obtidas em [24] através das oscilações Shubnikov-de Hass, são dadas por $n_{1}=3,7 \times 10^{11} \mathrm{~cm}^{-1}$ e $n_{2}=3,3 \times 10^{11} \mathrm{~cm}^{-1}$, e sua mobilidade de carga a baixas temperaturas é de $2,2 \times 10^{6} \mathrm{~cm}^{2} / \mathrm{Vs}$.

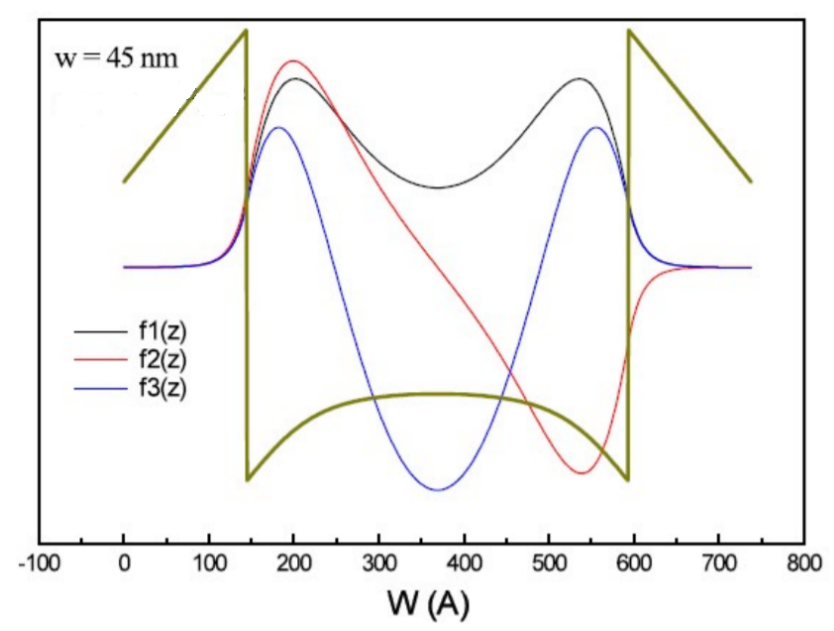

Figura 3.1: Perfil da banda de condução de um poço quântico simples como função de sua largura $W$, para as três primeiras sub-bandas. Extraída de [32].

A amostra foi crescida por A. K. Bakarov, da Universidade de Novosibirsk na Rússia, através da epitaxia de feixe molecular (MBE), uma técnica de crescimento epitaxial de filmes 
semicondutores - isto é, deposição de uma película monocristalina sobre um substrato - de forma altamente controlada e em condições de vácuo ultra-alto [23]. Essa mesma amostra foi ensaiada também em outros trabalhos recentes, como em [24] com o mesmo dispositivo utilizado aqui, e em [25] com pedaços distintos do mesmo wafer e dispositivos diferentes.

Na figura 3.2 encontra-se um esquema do crescimento da amostra camada a camada, descrito da esquerda para a direita, desde o substrato de GaAs onde foi crescida a nanoestrutura do poço quântico. Logo acima do substrato encontram-se as camadas do Buffer que servem para uniformizar a superfície das camadas, seguidas de uma super rede de GaAs/AlAs com o intuito de bloquear a migração de impurezas na nanoestrutura de interesse, e outra camada de buffer promovendo maior isolamento ao poço quântico. Na sequência, uma chamada graded layer com $\mathrm{Al}_{x} \mathrm{Ga}_{1-x} \mathrm{As}$ variando a concentração de 0 a 0,3 é utilizada para inibir a migração de elétrons da primeira camada dopante $\delta$ - Si para a camada anterior. A camada seguinte de $\mathrm{Al}_{0.33} \mathrm{Ga}_{0.67} \mathrm{As}$ protege a migração de portadores para a graded layer. Uma super rede anterior à camada de dopagem a isola do substrato abaixo, enquanto outra super rede posterior - chamada spacer - a separa do poço quântico.

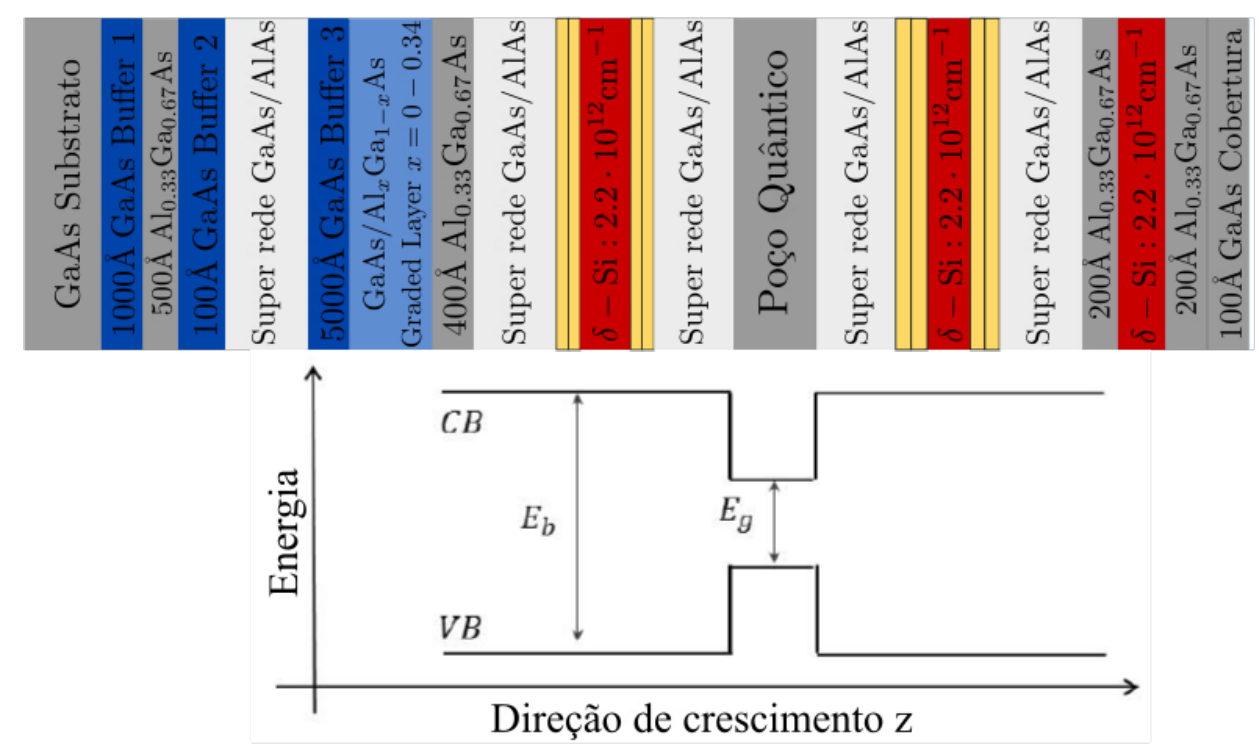

Figura 3.2: Esquema de camadas da amostra ao longo da direção de crescimento (z).

Acima do poço, novamente uma sequência de camadas super rede - dopante - super rede é utilizada para isola-lo da superfície da amostra. Na sequência, uma camada de $\mathrm{Al}_{0.33} \mathrm{Ga}_{0.67} \mathrm{As}$ permite a deposição de uma terceira camada de dopagem para saturar as ligações pendentes na superfície, seguida de uma outra camada de $\mathrm{Al}_{0.33} \mathrm{Ga}_{0.67}$ As para isolar a superfície e a camada 
dopante. Por último, a camada de cobertura protege contra a migração de As para a superfície, evitando portanto a oxidação do material.

\subsubsection{Dispositivo}

A amostra contém um dispositivo fabricado em uma configuração em forma de cruz com uma largura de $270 \mu \mathrm{m}$ e canais ao longo das direções cristalográficas [110] (x) e [110] (y). Em ambos os canais, pares de contatos ôhmicos estão dispostos a uma distância de $l=500 \mu \mathrm{m}$ entre si, podendo ser utilizados para aplicar voltagens no plano $V_{\text {ip }}$, induzindo transporte por deriva. Ademais, a amostra conta também com um contato semitransparente acima do dispositivo, chamado eletrodo de porta, o qual pode ser utilizado para modificar a simetria do poço e a ocupação das subbandas através da aplicação de uma voltagem $V_{\mathrm{g}}$.

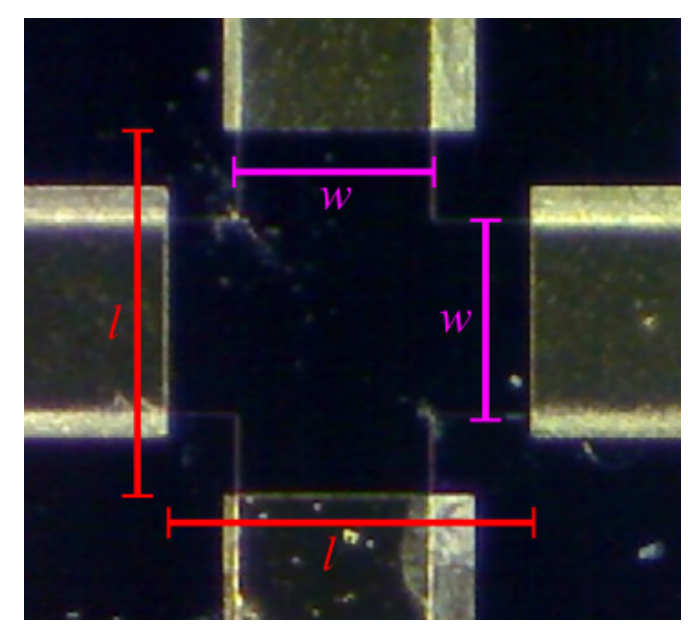

Figura 3.3: Foto da amostra capturada com o auxílio de um microscópio. As dimensões apontadas na figura são $w=270 \mu \mathrm{m}$ para a largura dos canais e $l=500 \mu \mathrm{m}$ para a distância entre os contatos.

\subsection{Aparato experimental}

A amostra foi colocada no interior de um criostato equipado com bobinas supercondutoras capazes de gerar um campo magnético (o qual será denominado campo magnético externo, para diferenciá-lo dos campos spin-órbita) de até $B_{\text {ext }}=6 T$. Para isso, as bobinas devem ser resfriadas com Hélio líquido, o qual também é utilizado para resfriar a amostra a temperaturas de até $T=4,2 \mathrm{~K}$ (ou até $T=1,2 \mathrm{~K}$ com o auxílio de uma bomba de vácuo). A amostra foi instalada com sua direção cristalográfica $y$ posicionada na horizontal do criostato, paralela ao 
campo $B_{\text {ext }}$, enquanto que sua direção cristalográfica $x$ foi posicionada na vertical.

Um laser pulsado de titânio-safira com uma taxa de repetição de $f=76 \mathrm{MHz}$ e comprimento de onda ajustável foi utilizado para as medidas e manipulações ópticas de polarização de spin na amostra. O feixe do laser é separado em dois caminhos ópticos, através do uso de um beam splitter. Em um desses caminhos, um modulador fotoelástico (MFE) é utilizado para que o feixe seja polarizado circularmente, permitindo que sua incidência na amostra induza uma polarização de spin, através das regras de seleção ópticas introduzidas na seção 2.3.1. Esse feixe é então denominado bombeio.

No outro caminho óptico, propaga um chamado feixe de prova, o qual possui polarização linear e é responsável por medir a polarização de spin na amostra através da técnica de microscopia de rotação de Kerr, descrita na seção 2.3.2.

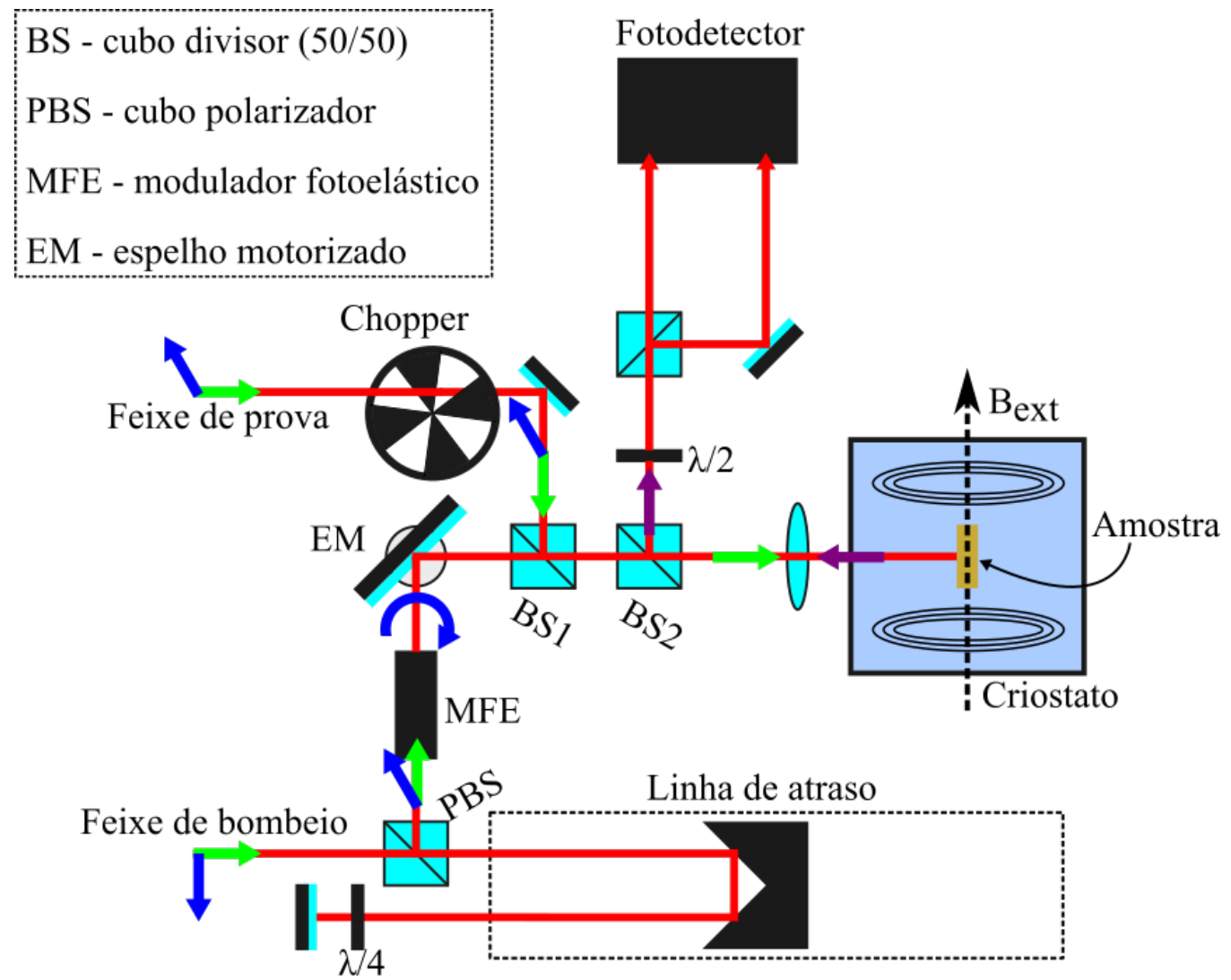

Figura 3.4: Esquema simplificado do setup óptico utilizado para o experimento. As setas verdes correspondem à direção de propagação dos feixes de incidência, e as azuis a suas respectivas polarizações. As setas roxas mostram o sentido do feixe refletido, no caminho para a fotodetecção.

Da forma como o setup é construído, a incidência do feixe de prova na amostra é mantida fixa em uma posição, sem que haja a possibilidade de alterá-la ao longo das medidas. Pela 
simetria da amostra, é desejável que se escolha fixar o feixe de prova incidindo em seu centro, porque assim as medidas serão realizadas no centro de ambos os canais. Em contrapartida, o feixe de bombeio pode ter sua posição de incidência controlada por um espelho motorizado (EM), cujos ângulos vertical e horizontal podem ser ajustados remotamente via computador.

Ambos os feixes são refletidos pela amostra, mas apenas a reflexão do feixe de prova deve chegar ao detector para que não ocorra interferência na medida. Por isso, o sistema é alinhado de forma que, mesmo que bombeio e prova incidam na mesma posição, seja possível separá-los antes da detecção. Isso é garantido se os feixes incidirem com um pequeno ângulo entre si, permitindo que a reflexão do bombeio seja bloqueada por um pin-hole alinhado para deixar passar apenas a reflexão de prova.

Por fim, os sinais obtidos pelo fotodetector são recuperados através do uso de dois lockin's. Esses equipamentos são utilizados para minimizar os ruídos na medida, isolando um sinal de entrada modulado por uma frequência conhecida. O sinal do detector é recebido pelo primeiro lock-in sincronizado na frequência do modulador fotoelástico e depois enviado ao segundo lock-in, sincronizado com a frequência de um chopper instalado no caminho óptico do feixe de prova.

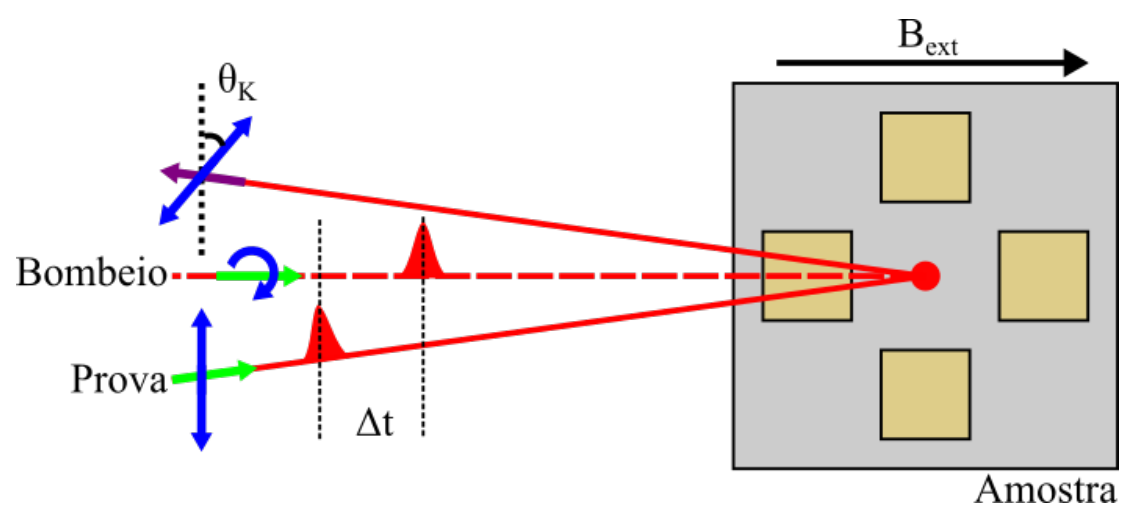

Figura 3.5: Esquema da técnica de microscopia de rotação de Kerr adotada para medir polarização de spin na amostra em uma configuração de bombeio-prova.

\subsubsection{Resolução temporal}

Para que possam ser realizadas medidas de deriva de spin, além da resolução espacial garantida pelo espelho motorizado, também é necessário que o sistema tenha uma resolução temporal. Como bombeio e prova são separados de um mesmo feixe pulsado, se seus caminhos ópticos tiverem o mesmo tamanho, ambos incidirão em fase na amostra, isto é, seus pulsos 
chegarão ao mesmo tempo. Dessa forma, uma chamada linha de atraso permite que o comprimento do caminho de bombeio seja ajustado (ver figura 3.4), fornecendo um controle para o atraso $\Delta t$ entre os feixes. Nesse sentido, se forem feitas medidas do sinal de Kerr $\theta_{\mathrm{K}}$ em função da posição da linha de atraso, é possível observar a evolução temporal da polarização de spin na amostra.

Devido a mecanismos de relaxação que causam decoerência de spin, como o mecanismo de Dyakonov-Perel [27], a polarização de spin decai com o tempo exponencialmente [28]. Por outro lado, ao se aplicar um campo magnético externo $B_{\text {ext }}$ perpendicular aos feixes de bombeio e prova (ver figura 3.5), os spins são forçados a precessar em torno desse campo, antes de perderem a coerência. Assim, a seguinte equação descreve um modelo para a evolução temporal da polarização de spin, como medido por rotação de Kerr:

$$
\theta_{\mathrm{K}}=A \exp \left[-\frac{\Delta t}{T_{2}^{*}}\right] \cos \left(w_{\mathrm{L}} \Delta t+\varphi\right)
$$

onde $A$ e $\varphi$ são, respectivamente, a amplitude e a fase iniciais, $T_{2}^{*}$ é o tempo de decoerência de spin, e $w_{\mathrm{L}}=g \mu_{\mathrm{B}} B_{\text {ext }} / \hbar$ é a frequência de Larmor da precessão dos spins em torno do campo externo. A figura 3.6 a seguir ilustra o comportamento da equação 3.1 acima.

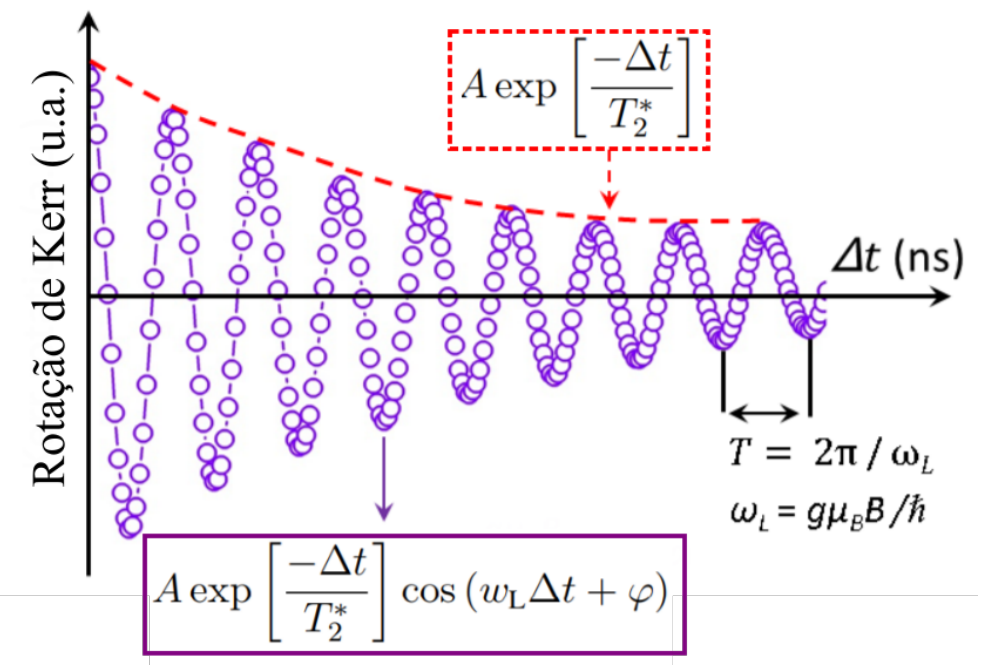

Figura 3.6: Comportamento da evolução temporal de uma polarização de spin descrito pela equação 3.1. Extraída de [28]. 


\subsection{Amplificação de spin ressonante (RSA)}

Se o tempo de vida $\left(T_{2}^{*}\right)$ da polarização de spin for suficientemente longo, antes que o sistema perca coerência, a amostra será iluminada por um ou mais outros pulsos de bombeio. De fato, a taxa de repetição do laser de titânio-safira utilizado é de $f_{\text {rep }}=76 \mathrm{MHz}$, como mencionado anteriormente, na seção 3.2 , e portanto o intervalo de tempo entre pulsos subsequentes é dado por

$$
t_{\text {rep }}=\frac{1}{f_{\text {rep }}} \approx 13 \mathrm{~ns} .
$$

Assim, para $T_{2}^{*}>t_{\text {rep }}$, a equação 3.1 deve ser reescrita para considerar a soma das rotações de Kerr devidas a diferentes pulsos:

$$
\begin{aligned}
& \Theta_{\mathrm{K}}=\sum_{n=0}^{\infty} \theta_{\mathrm{K}, n}=\sum_{n=0}^{\infty} A_{n} \exp \left[-\frac{\left(\Delta t+n t_{\text {rep }}\right)}{T_{2}^{*}}\right] \cos \left[w_{\mathrm{L}}\left(\Delta t+n t_{\text {rep }}\right)\right] \\
& \Rightarrow \Theta_{\mathrm{K}}(B, \Delta t)=\sum_{n=0}^{\infty} A_{n} \exp \left[-\frac{\left(\Delta t+n t_{\text {rep }}\right)}{T_{2}^{*}}\right] \cos \left[\frac{g \mu_{\mathrm{B}}\left(\Delta t+n t_{\text {rep }}\right)}{\hbar} B_{\text {ext }}\right] .
\end{aligned}
$$

Como o sinal de Kerr $\Theta_{\mathrm{K}}$ é agora dado por uma soma de cossenos, as oscilações devidas a diferentes pulsos causarão interferência entre si. Em particular, se a frequência de Larmor for um múltiplo da taxa de repetição do laser (em radianos) $w_{\mathrm{L}}=g \mu_{\mathrm{B}} B_{\mathrm{ext}} / \hbar=2 \pi n^{\prime} f_{\text {rep }}$, o argumento dos cossenos será dado por

$$
w_{\mathrm{L}}\left(\Delta t+n t_{\text {rep }}\right)=2 \pi n^{\prime} f_{\text {rep }}\left(\Delta t+n t_{\text {rep }}\right)=\frac{2 \pi n^{\prime}}{t_{\text {rep }}}\left(\Delta t+n t_{\text {rep }}\right)=\left(\frac{2 \pi n^{\prime}}{t_{\text {rep }}}\right) \Delta t+2 \pi n^{\prime} n,
$$

fazendo com que as oscilações estejam em fase, resultando em uma interferência construtiva. Essa situação está ilustrada na figura 3.7 .

A técnica de amplificação ressonante de spin (RSA) se baseia nessa interferência entre as polarizações de spin advindas de pulsos subsequentes de bombeio, quando o tempo de decaimento $T_{2}^{*}$ é longo. Se for escolhido fixar a defasagem entre os feixes $\Delta t$ em um valor específico, como a taxa de repetição do laser é mantida fixa, o comportamento do sinal de RSA (equação 3.3 poderá ser reescrito de forma mais simples como

$$
\Theta_{\mathrm{K}}(B)=\sum_{n=0}^{\infty} A_{n} \cos \left[\frac{g \mu_{\mathrm{B}}\left(\Delta t+n t_{\mathrm{rep}}\right)}{\hbar} B_{\mathrm{ext}}\right]
$$


tendo a amplitude $A_{n}$ absorvido o termo exponencial de decaimento (agora constante) presente anteriormente. Quando há deriva de spin, surgem também campos spin-órbita que contribuem para o comportamento do RSA, se esses termos forem introduzidos, a equação 3.5 pode ser reescrita por fim como

$$
\Theta_{\mathrm{K}}(B)=\sum_{n=0}^{\infty} A_{n} \cos \left[\frac{g \mu_{\mathrm{B}}\left(\Delta t+n t_{\mathrm{rep}}\right)}{\hbar} \sqrt{\left(B_{\mathrm{ext}}+B_{\mathrm{SO}, \|}\right)^{2}+B_{\mathrm{SO}, \perp}^{2}}\right]
$$

onde $B_{\mathrm{SO}, \|}$ e $B_{\mathrm{SO}, \perp}$ são as componentes do campo spin-órbita paralela e perpendicular ao campo magnético externo $B_{\text {ext }}$, respectivamente. Curvas típicas de RSA para diferentes configurações de $B_{\mathrm{SO}}$ estão representadas na figura 3.8 .

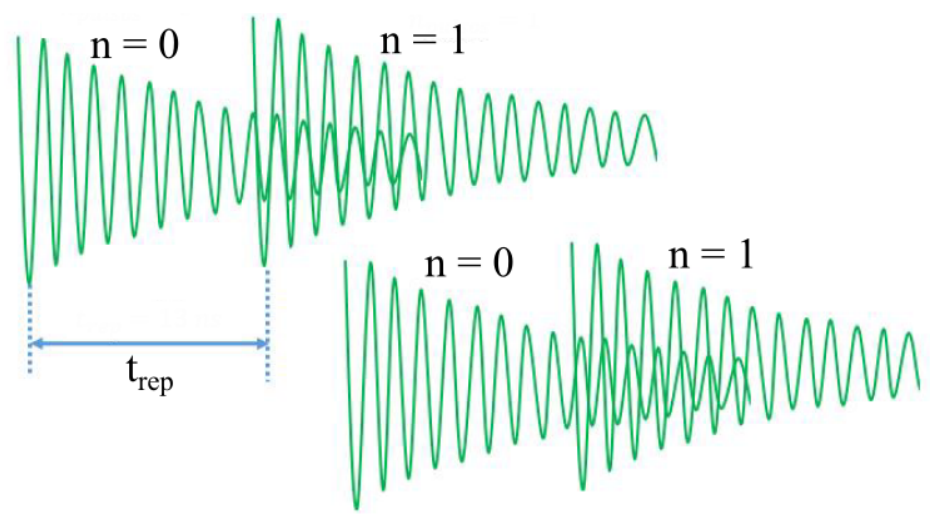

Figura 3.7: Exemplos de interferência construtiva (acima) e destrutiva (abaixo) entre os dois primeiros termos da soma na equação 3.3 .

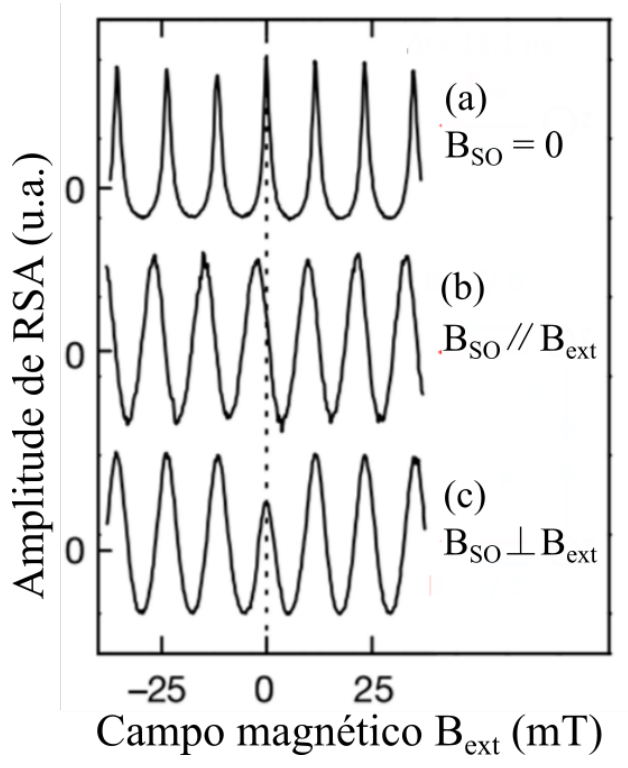

Figura 3.8: Curvas típicas de RSA (equação 3.6) para: (a) $B_{\mathrm{SO}, \|}=B_{\mathrm{SO}, \perp}=0$; (b) $B_{\mathrm{SO}, \|} \neq 0$, $B_{\mathrm{SO}, \perp}=0$, onde observa-se um deslocamento dos picos em comparação com o caso $B_{\mathrm{SO}}=0$; e (c) $B_{\mathrm{SO}, \|}=0, B_{\mathrm{SO}, \perp} \neq 0$, onde observa-se uma atenuação no pico central. Adaptada de [31]. 


\section{Capítulo 4}

\section{Ajustes Experimentais}

\subsection{Mapeamento da amostra pela reflexão do bombeio}

Para que as medidas com resolução espacial tenham significado físico, é necessário que se conheça a conversão das unidades do espelho motorizado para comprimentos reais na amostra. $\mathrm{O}$ estado do espelho pode ser lido e alterado remotamente através de dois valores, $\mathrm{He}$ $V$, que estão relacionados aos seus ângulos de inclinação horizontal e vertical, respectivamente, em unidades que serão consideradas arbitrárias (u.a.) para propósitos dessa dissertação. Cada estado $(H, V)$ deve corresponder portanto a uma única posição $(X, Y)$ na amostra, da mesma forma que cada posição $(X, Y)$ está relacionada a apenas um estado $(H, V)$.

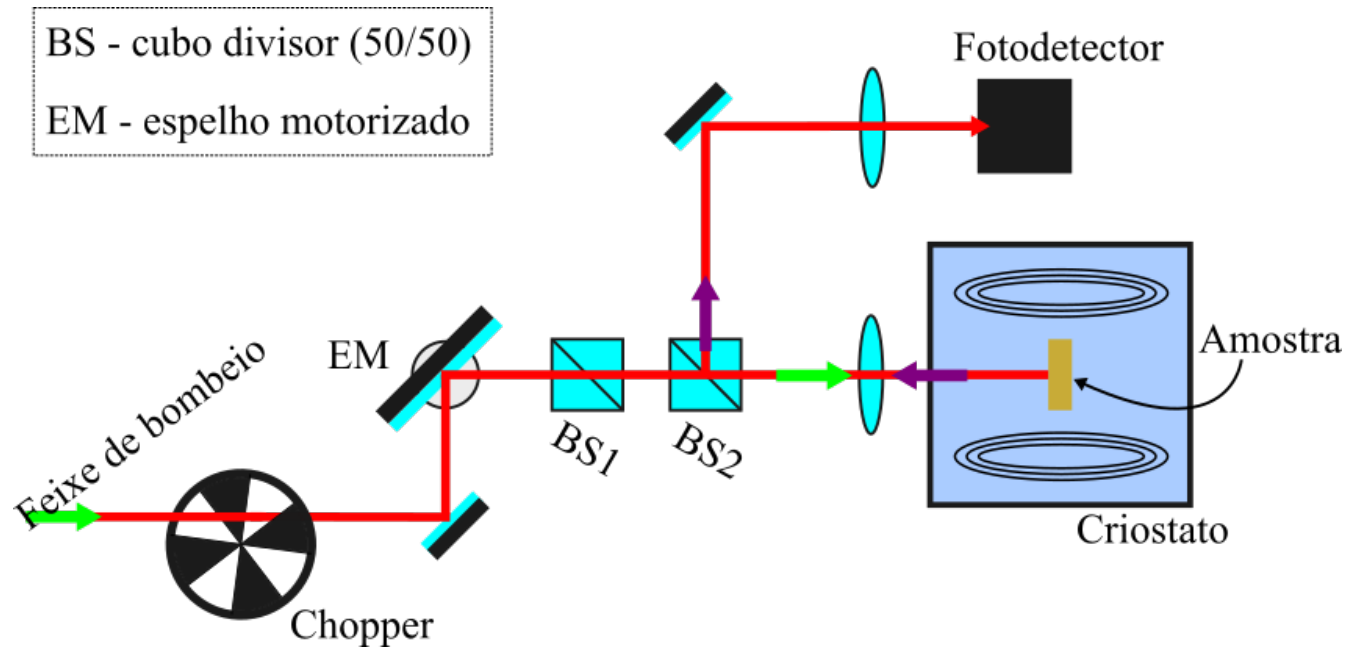

Figura 4.1: Esquema simplificada do setup óptico utilizado para o mapeamento da amostra pela reflexão do bombeio. Diferentemente do esquema apresentado na figura 3.2, o feixe de prova deve ser bloqueado e a reflexão do bombeio deve ser desviada para um outro fotodetector de intensidades. Um chopper também deve ser instalado para que o sinal modulado seja recuperado por um lock-in. 
Como a amostra é composta de algumas estruturas - a exemplo de seus contatos que podem ser identificados facilmente na foto da figura 3.3 - é de se esperar que, ao incidir um feixe em diferentes regiões da amostra, sua reflexão tenha intensidades distintas, a depender do tipo de estrutura incidida. Utilizando portanto um fotodetector para medir as intensidades de reflexão do bombeio enquanto se faz uma varredura dos valores $H$ e $V$ do espelho motorizado, é possível construir um mapa de reflexões da amostra. O setup óptico utilizado para essas medidas é um pouco diferente do apresentado na figura 3.4 e é mostrado na figura 4.1 .

Então, para realizar essas medidas, deve-se bloquear o feixe de prova de modo que ele não interfira no sinal que se deseja obter; o chopper deve ser instalado no caminho do bombeio para que o sinal possa ser modulado e recuperado por um lock-in; e por fim o feixe refletido deve ser desviado para um fotodetector de intensidades. Deve-se ter cuidado também no ajuste da potência do laser, para que este não sature o detector. O mapa obtido através desse método está exposto na figura 4.2 abaixo.

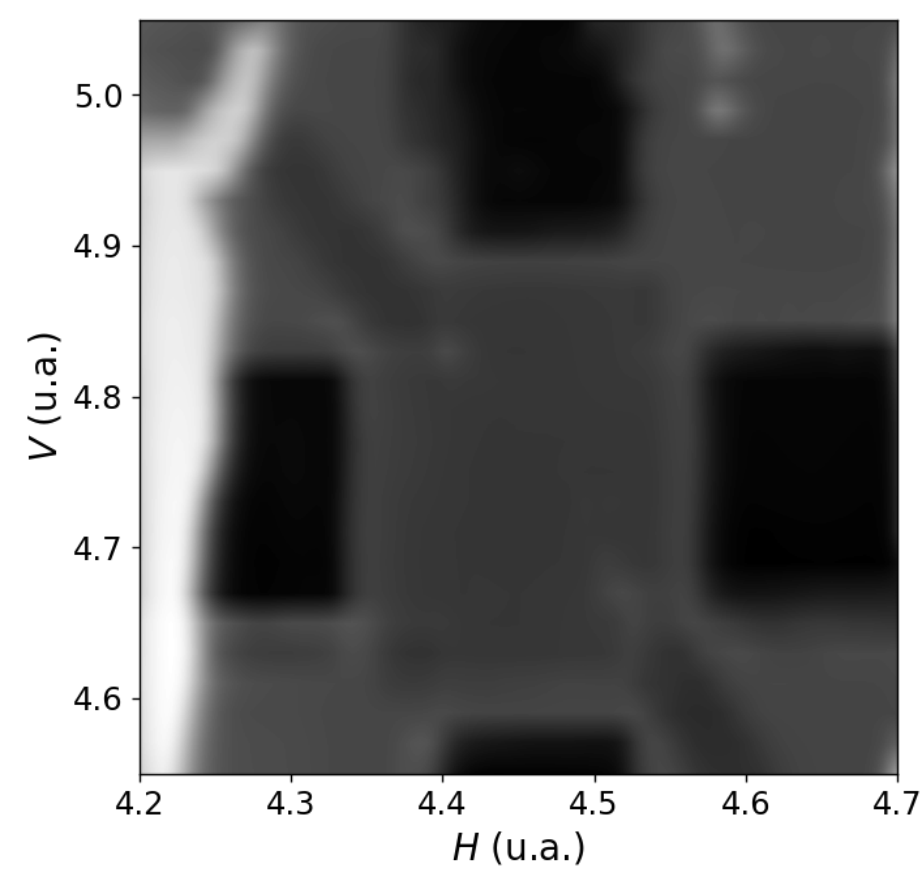

Figura 4.2: Mapa das reflexões do feixe de bombeio na amostra, variando-se os parâmetros $H$ e $V$ do espelho motorizado. Em comparação com a foto da figura 3.3, identificam-se quatro retângulos pretos nesse mapa como os contatos da amostra.

Ao comparar esse mapa com a foto apresentada anteriormente, na figura 3.3, é possível identificar quatro retângulos pretos como os contatos da amostra. Sabe-se também que, em dimensões reais, as distâncias entre os contatos em ambos os canais têm um comprimento de 
$l=500 \mu \mathrm{m}$. Dessa forma, se puderem ser extraídas as respectivas distâncias $\Delta H$ e $\Delta V$ (em unidades do espelho) entre os contatos nos canais horizontal e vertical, a conversão das unidades poderá ser calculada facilmente através de

$$
X=\frac{l}{\Delta V} V, \quad Y=\frac{l}{\Delta H} H
$$

onde utilizou-se o fato de a amostra ter sido disposta no interior do criostato com sua direção cristalográfica $y$ na horizontal, perpendicular ao eixo óptico do sistema.

Para que essas distâncias $\Delta H$ e $\Delta V$ sejam obtidas através do mapa, deve-se conhecer as posições das bordas dos contatos. Entretanto, como pode ser verificado visualmente, essas bordas não são bem definidas, como consequência da largura do feixe na amostra. De fato, ao se olhar para um recorte unidimensional do mapa no centro de ambos os canais, observam se os comportamentos ilustrados pelos gráficos das figuras $4.3 \mathrm{e} 4.4$.

No primeiro gráfico (figura 4.3), vê-se o comportamento da intensidade de reflexão do bombeio em função de $H \operatorname{com} V=4,75$ fixo, isto é, em uma posição vertical próxima ao centro da amostra (como pode ser verificado na figura 4.1), enquanto que no segundo (figura 4.4), encontra-se um mapa unidimensional em função de $V$ para $H=4,46$ fixado (uma posição horizontal também próxima ao centro da amostra). Constata-se através desses gráficos que os contatos refletem mais luz para o detector do que a região central da amostra. Assim, como o laser utilizado é composto por feixes gaussianos, a intensidade medida conforme ele percorre a transição entre uma região mais reflexiva para outra que reflete menos (regiões coloridas de vermelho no gráfico) deve ser descrita por uma função erro que depende da largura do feixe.

De fato, ao derivar o sinal da intensidade, foi possível obter as gaussianas mostradas nos gráficos das figuras 4.5 e 4.6. Ao ajustá-las de acordo com a função

$$
f(x)=A \exp \left(-\frac{\left(x-x_{c}\right)^{2}}{2 w^{2}}\right)
$$

onde $A$ é a amplitude, $x_{c}$ é a posição do centro (com $x$ representado as posições $H$ ou $V$ ) e $w$ é a largura da gaussiana, pôde-se encontrar as distâncias $\Delta H=H_{\mathrm{c} \text {, direita }}-H_{\mathrm{c} \text {, esquerda }}=0,23$ e $\Delta V=V_{\mathrm{c} \text {, direita }}-V_{\mathrm{c} \text {, esquerda }}=0,34$, de forma que as conversões 4.1 são reescritas portanto como:

$$
X=0,15 \times V \quad(\mathrm{~cm}), \quad Y=0,22 \times H \quad(\mathrm{~cm})
$$




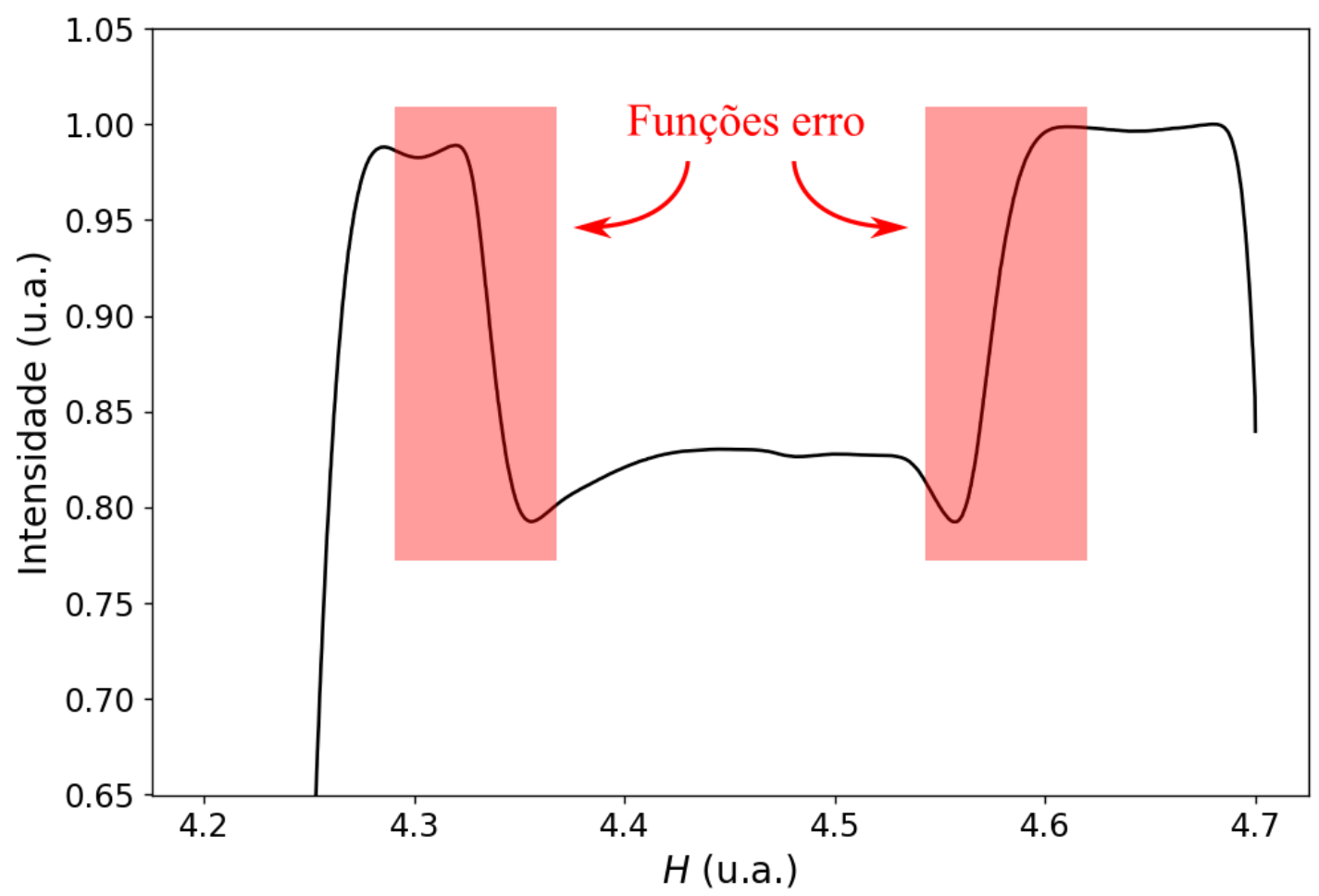

Figura 4.3: Gráfico de intensidades da reflexão do bombeio em função de $H$ com $V=4,75$ fixado. As regiões destacadas em vermelho são identificadas como funções erro.

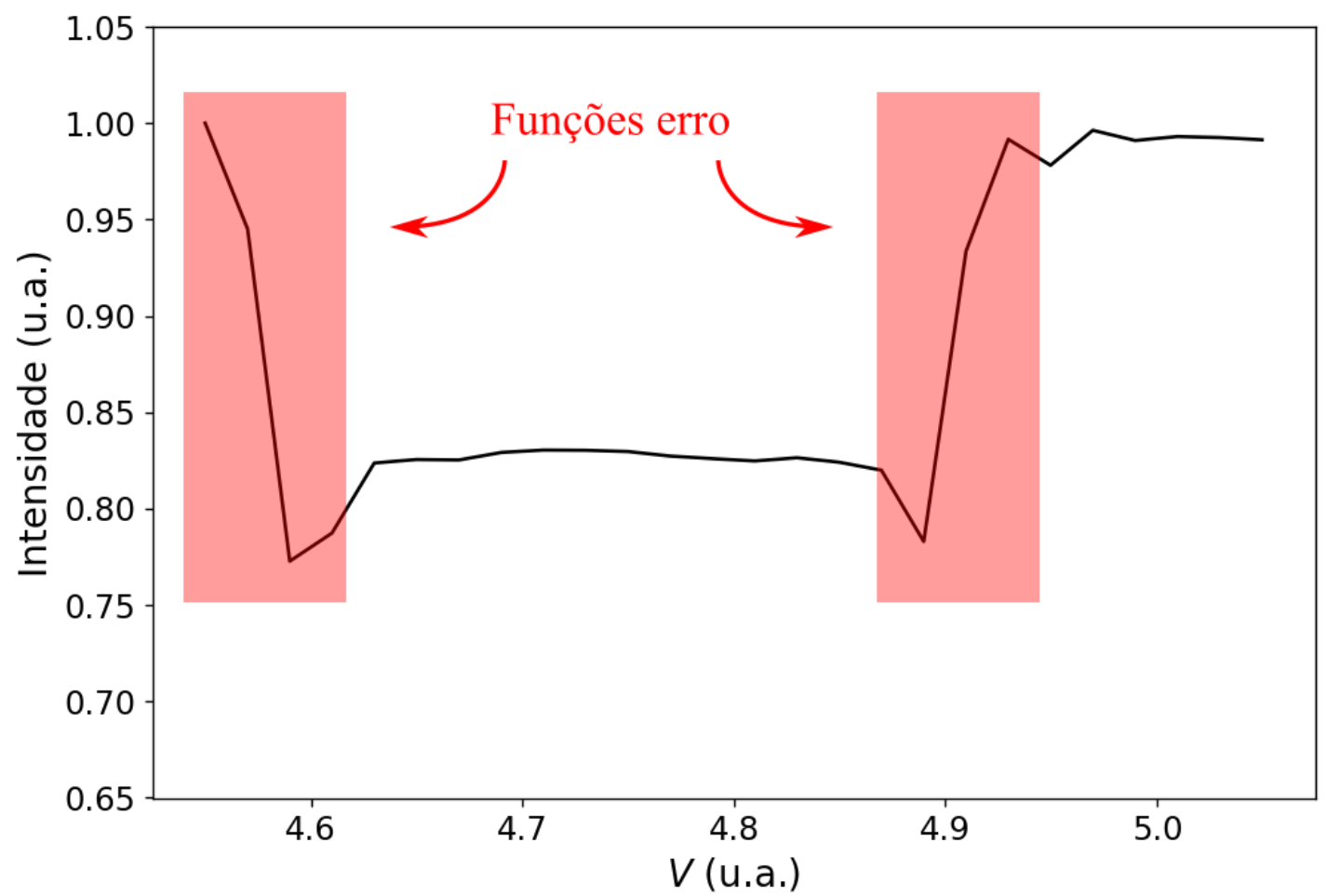

Figura 4.4: Gráfico de intensidades da reflexão do bombeio em função de $V$ com $H=4,46$ fixado. As regiões destacadas em vermelho são identificadas como funções erro. 

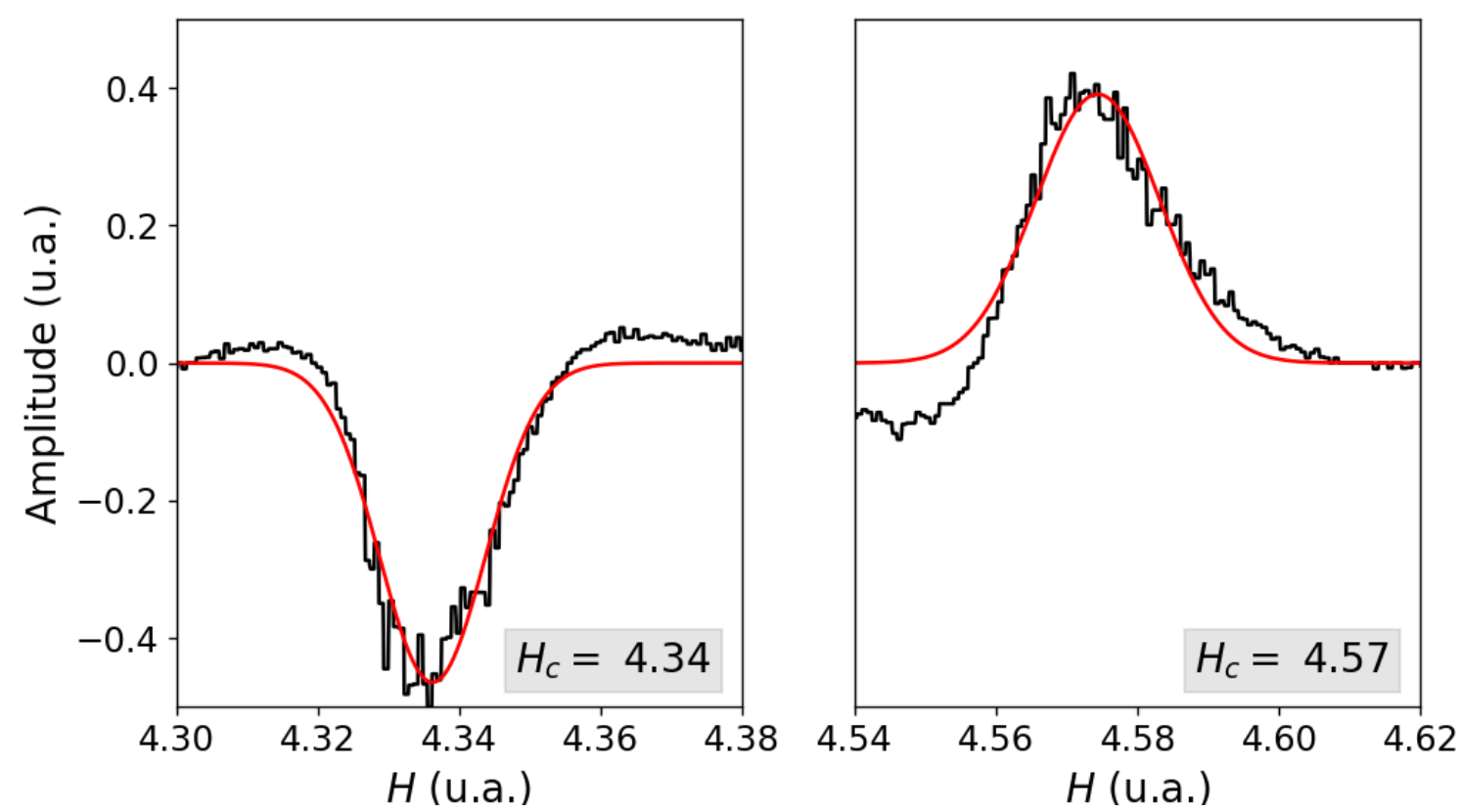

Figura 4.5: Gaussianas obtidas ao derivar as funções erro apontadas na figura 4.3. Através do ajuste, as posições encontradas para os contatos do canal horizontal foram $H_{\mathrm{c} \text {, esquerda }}=4,34 \mathrm{e}$ $H_{\mathrm{c}, \text { direita }}=4,57$.
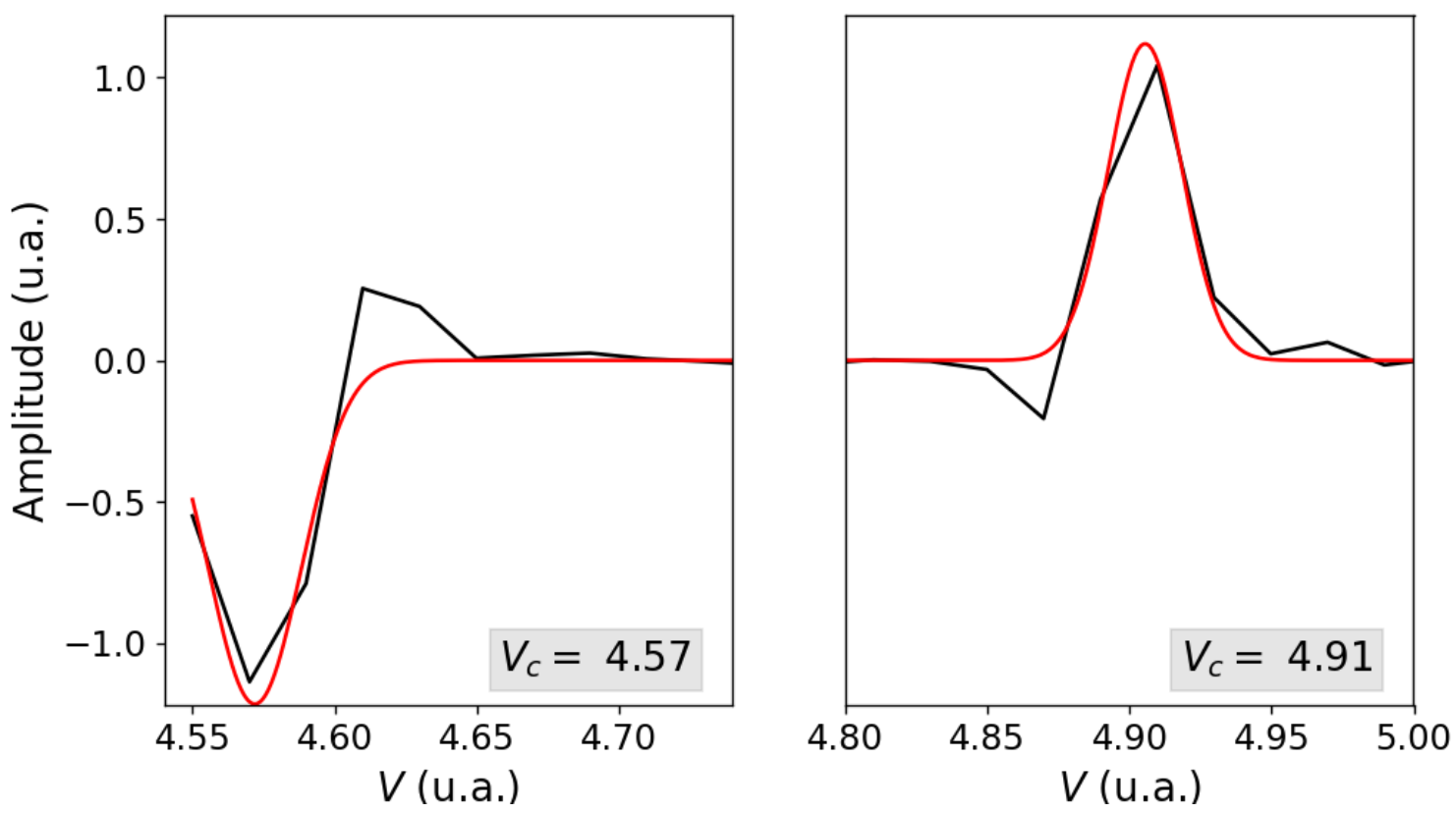

Figura 4.6: Gaussianas obtidas ao derivar as funções erro apontadas na figura 4.4. Através do ajuste, as posições encontradas para os contatos do canal vertical foram $V_{\mathrm{c} \text {, esquerda }}=4,34 \mathrm{e}$ $V_{\mathrm{c}, \text { direita }}=4,57$. 


\subsection{Ajuste do foco dos feixes na amostra}

Antes que o mapa da seção anterior pudesse ser feito, mas também para que as medidas experimentais sejam realizadas com a melhor resolução possível, foi necessário o ajuste do foco dos feixes na amostra através da manipulação da lente posicionada logo na frente do criostato.

Para realizar esse ajuste, foi utilizado um procedimento semelhante ao usado para encontrar as posições das bordas dos contatos na seção anterior. Variando a posição $z$ da lente, isto é, a posição ao longo do eixo óptico do sistema, e tomando mapas unidimensionais da reflexão do bombeio na direção $H$, como os da figura 4.3 , foi possível novamente derivar as funções erro das bordas dos contatos e extrair dessa vez os valores das larguras $w$ das gaussianas resultantes.

Os dados obtidos para $w$ em função da posição $z$ da lente (em unidades arbitrárias) estão dispostos no gráfico da figura 4.7. Os pontos foram ajustados por uma parábola, cuja posição do mínimo foi utilizada como a posição ideal da lente para que o tamanho dos feixes na amostra seja o menor possível. A largura do feixe de bombeio encontrada no foco foi de $2 w=34,2 \mu \mathrm{m}$.

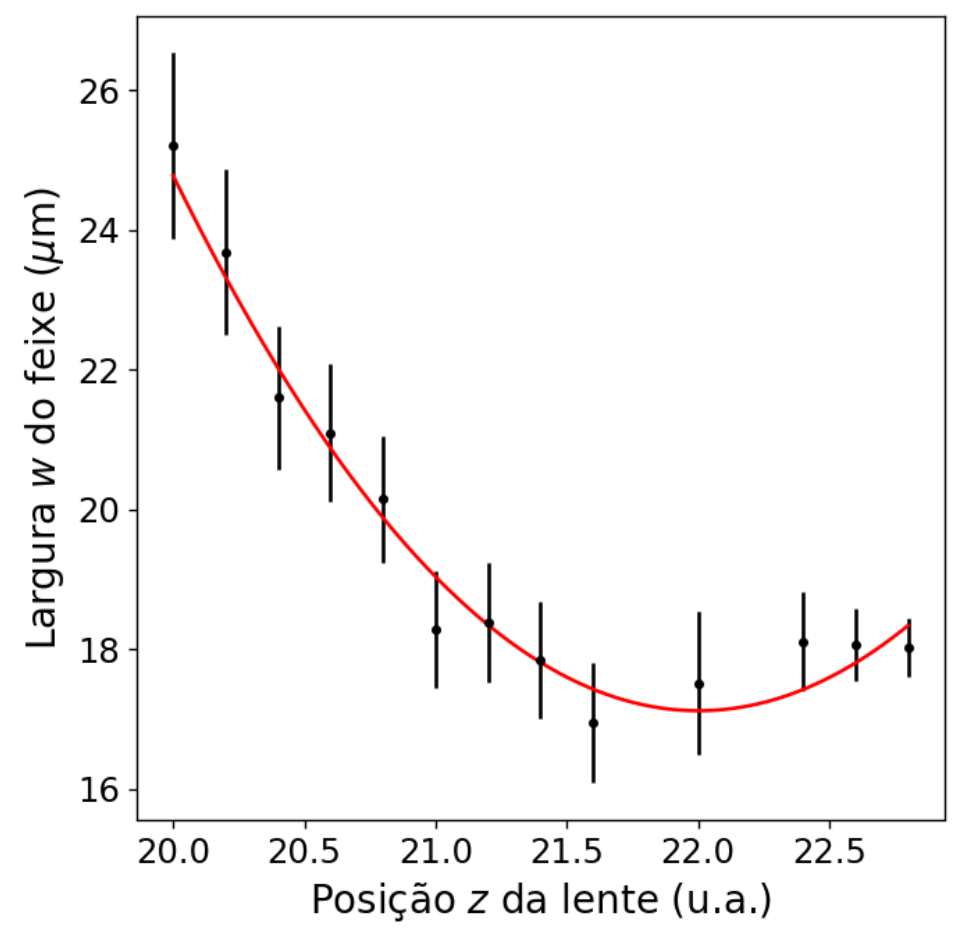

Figura 4.7: Largura $w$ do feixe de bombeio em função da posição $z$ da lente em frente à janela do criostato. 


\subsection{Posição de overlap entre bombeio e prova}

Quando o sistema foi alinhado, o feixe de prova foi fixado em uma região próxima do centro da amostra, como descrito na seção 3.2. A resolução espacial do sistema fica por conta do bombeio, cuja incidência pode ser controlada pelo espelho motorizado. Isso significa que a injeção de polarização de spin pode ser feita em diferentes posições na amostra, enquanto mede-se, através da rotação de Kerr do feixe de prova, o quanto dessa polarização chega no centro do dispositivo.

Na situação em que não há deriva de spin, o sinal de Kerr é máximo quando o feixe de bombeio incide na mesma posição em que o feixe de prova, ou seja, quando esses feixes estão sobrepostos na amostra, sendo por isso chamada posição de overlap (ou simplesmente, overlap). Como visto anteriormente, o laser utilizado é composto por feixes gaussianos, o que significa que seus perfis transversais de intensidade são descritos por uma função gaussiana. Portanto espera-se que também a polarização de spin injetada pelo bombeio seja distribuída espacialmente como uma gaussiana. Assim, conforme percorre-se o feixe de bombeio pela amostra, o sinal que se espera obter da rotação de Kerr do feixe de prova, ponto-a-ponto, deve ser parecido com o mostrado pela figura 4.8

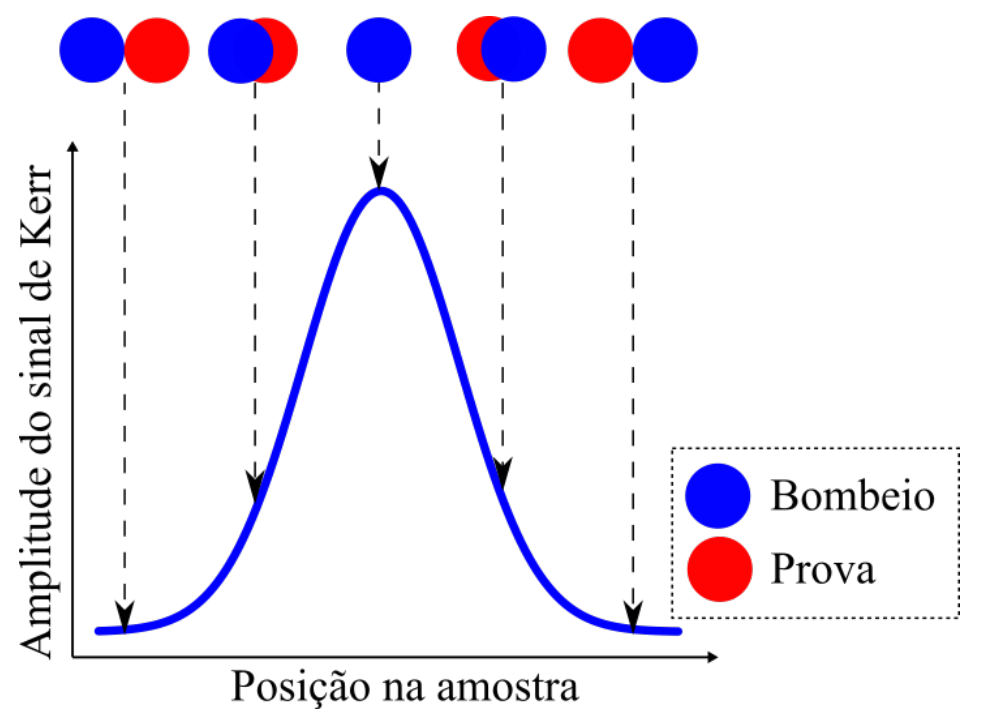

Figura 4.8: Comportamento esperado para o sinal da rotação de Kerr do feixe de prova, em função da posição de injeção de polarização de spin pelo bombeio na amostra. Acima, o feixe de bombeio é representado como um círculo azul e o de prova como um círculo vermelho. Antes que eles entrem em contato, o respectivo sinal de Kerr, abaixo, apresenta uma amplitude nula. Conforme esses feixes se sobrepõem, a amplitude aumenta como uma gaussiana até a posição de overlap total, onde a amplitude é máxima. 
Antes que os feixes entrem em contato, portanto, o sinal de Kerr medido deve ser nulo, e a amplitude deve aumentar como uma gaussiana até que eles se sobreponham totalmente. A posição de overlap será considerada o centro da gaussiana, que poderá ser obtido através de um ajuste dos dados.

Antes que se prossiga às medidas com deriva, é necessário que se conheça a posição de overlap em ambas as direções vertical e horizontal. Para tanto, utiliza-se a técnica de RSA fazendo-se varreduras em uma direção enquanto se mantém a outra posição fixa. Os seguintes parâmetros (tabela 4.1) foram escolhidos de modo que optimizassem o sinal medido:

\begin{tabular}{|c|c|c|c|}
\hline$\lambda$ & $P_{\text {bombeio }}$ & $P_{\text {prova }}$ & $T_{\text {amostra }}$ \\
\hline $819 \mathrm{~nm}$ & $1 \mathrm{~mW}$ & $0,2 \mathrm{~mW}$ & $10 \mathrm{~K}$ \\
\hline
\end{tabular}

Tabela 4.1: Parâmetros utilizados ao longo do experimento para que o sinal medido fosse optimizado. Nessa tabela, $\lambda$ é o comprimento de onda do laser, $P_{\text {bombeio }}$ e $P_{\text {prova }}$ são as potências dos feixes de bombeio e prova medidas antes da janela do criostato, e $T_{\text {amostra }}$ é a temperatura na câmara da amostra.

Para a técnica de RSA utilizada, deve-se manter a defasagem entre os feixes $\Delta t$ fixa, enquanto se varia a intensidade do campo magnético externo aplicado. Por conveniência, foi escolhida uma defasagem muito próxima da taxa de repetição do laser, $\Delta t=12,9 \mathrm{~ns} \approx t_{\text {rep }}=$ $13 \mathrm{~ns}$, primeiro porque posteriormente será interessante observar a maior deriva de spin possível, e esse é o maior intervalo de tempo permitido pelo setup; e segundo porque essa aproximação simplifica o ajuste do RSA dado pela equação 3.6 .

$$
\Theta_{\mathrm{K}}(B) \approx \sum_{n=0}^{\infty} A_{n} \cos \left[(n+1) \frac{g \mu_{\mathrm{B}} \Delta t}{\hbar} \sqrt{\left(B_{\mathrm{ext}}+B_{\mathrm{SO}, \|}\right)^{2}+B_{\mathrm{SO}, \perp}^{2}}\right]
$$

já que $\Delta t \approx t_{\text {rep. }}$ Logo será visto também que não serão necessários considerar muitos termos dessa soma para o ajuste, sendo suficiente somar apenas os três primeiros pulsos:

$$
\begin{aligned}
\Theta_{\mathrm{K}}(B) & \approx A_{0} \cos \left[\omega \sqrt{\left(B_{\mathrm{ext}}+B_{\mathrm{SO}, \|}\right)^{2}+B_{\mathrm{SO}, \perp}^{2}}\right]+A_{1} \cos \left[2 \omega \sqrt{\left(B_{\mathrm{ext}}+B_{\mathrm{SO}, \|}\right)^{2}+B_{\mathrm{SO}, \perp}^{2}}\right]+ \\
& +A_{2} \cos \left[3 \omega \sqrt{\left(B_{\mathrm{ext}}+B_{\mathrm{SO}, \|}\right)^{2}+B_{\mathrm{SO}, \perp}^{2}}\right]
\end{aligned}
$$

usando $\omega=g \mu_{\mathrm{B}} \Delta t / \hbar$. Um ajuste do RSA deve retornar portanto a optimização dos parâmetros $A_{0}, A_{1}, A_{2}, \omega, B_{\mathrm{SO}, \|}$ e $B_{\mathrm{SO}, \perp}$. 


\subsubsection{Varredura horizontal}

Fixando a posição $V$ do espelho no overlap, foram coletados os sinais de RSA, com $B_{\text {ext }}$ variando de -40 a $40 \mathrm{mT}$, para algumas posições $H$ do espelho em torno do overlap. $\mathrm{O}$ mapa de RSA obtido através desse método está disposto na figura 4.9 .

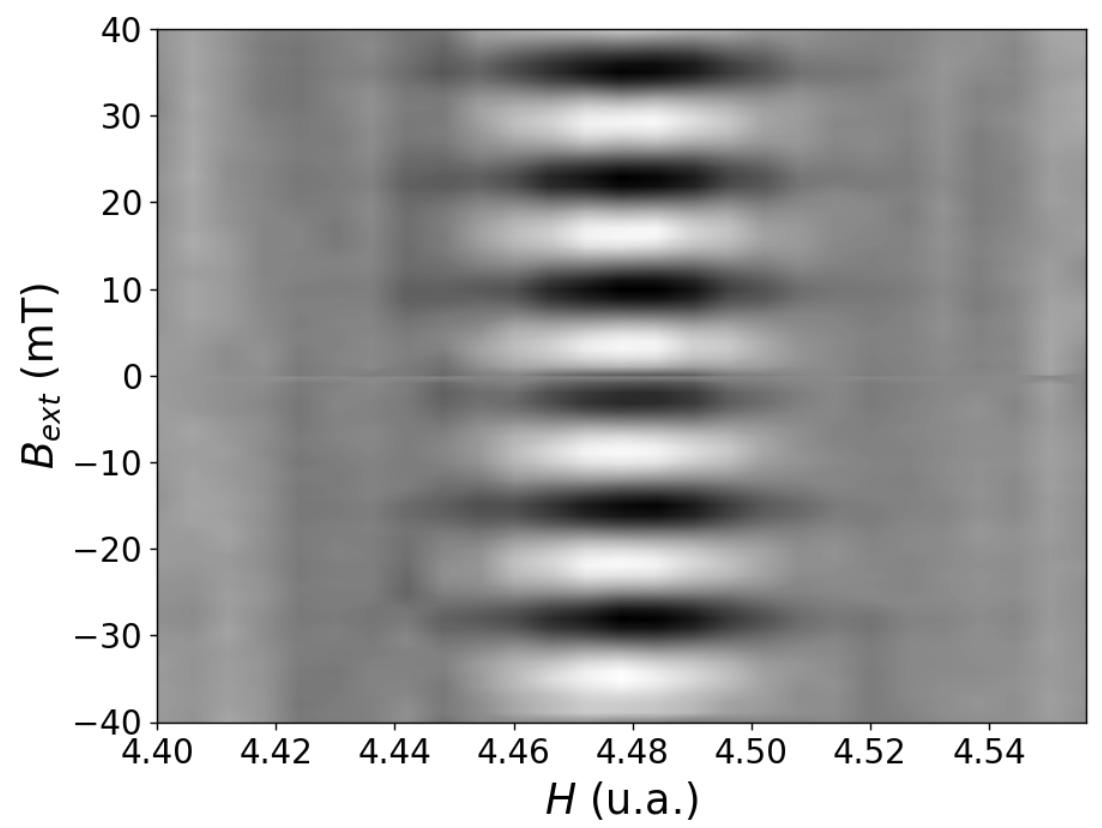

Figura 4.9: Mapa de RSA na direção horizontal com o campo magnético externo $B_{\text {ext }}$ variando de -40 a $40 \mathrm{mT}$, para a situação em que não há deriva de spin.

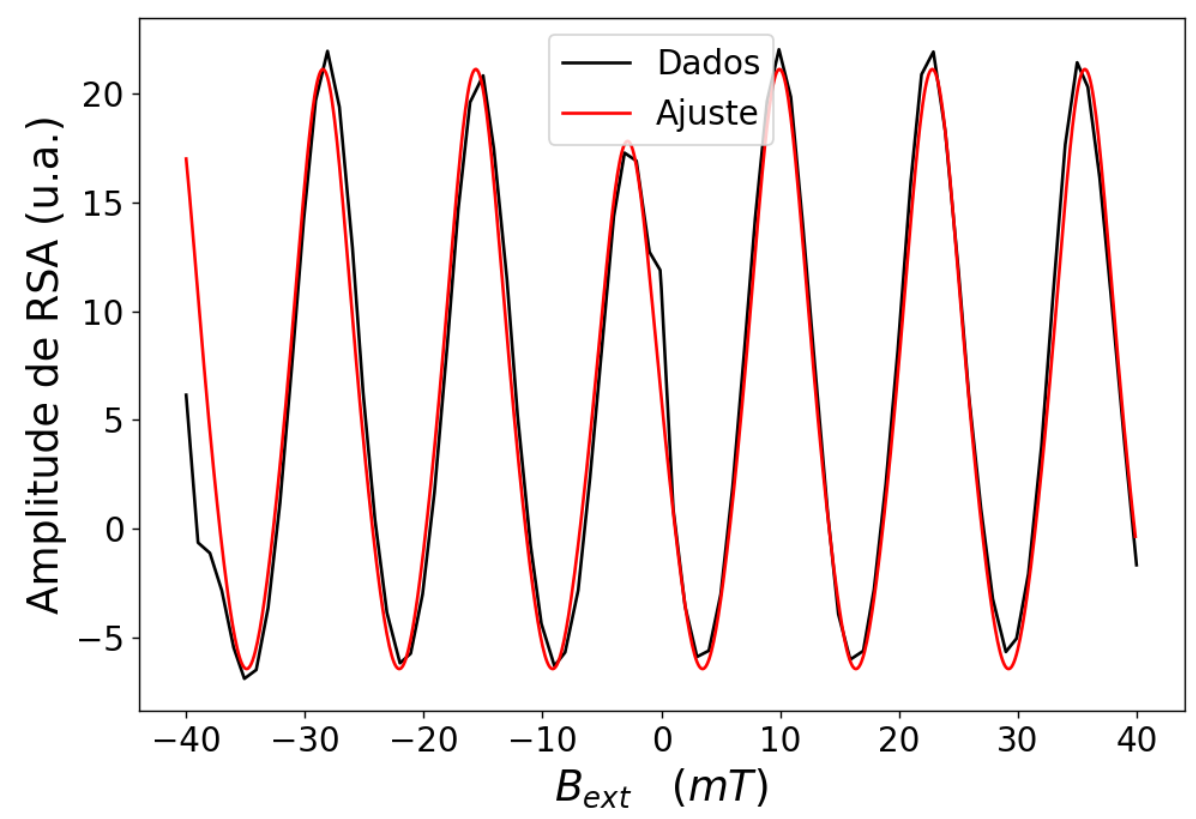

Figura 4.10: Curva de RSA obtida para a posição de overlap, extraída do mapa da figura 4.9 . para a situação em que não há deriva de spin. Os dados experimentais estão plotados em linha preta, enquanto que o ajuste da equação 4.5 está plotado em vermelho. 
O gráfico da figura 4.10 mostra em detalhe o comportamento de uma das curvas de RSA (para uma posição $H$ ) que compõem o mapa 4.9. Um ajuste da equação 4.5 nesses gráficos permite a obtenção da optimização dos parâmetros dessa função. Sobretudo, através dos parâmetros $A_{0}, A_{1}$ e $A_{2}$, a amplitude total de RSA, para cada posição $H$ do espelho, pode ser calculada como

$$
A=\sqrt{A_{0}^{2}+A_{1}^{2}+A_{2}^{2}}
$$

Plotando os valores de $A$ em função dos comprimentos reais na amostra (obtidos através da conversão das unidades do espelho descrita na seção 4.1), recupera-se o comportamento da distribuição de polarização de spin no canal $y \|$ [110], exposto no gráfico da figura 4.11, onde os pontos se ajustam bem a uma função gaussiana (equação 4.2), concordando com o que se esperava anteriormente (figura 4.8). Desse ajuste, pode-se obter a posição de overlap extraindo o parâmetro $x_{c}$ do centro da gaussiana e, através do parâmetro $w$, uma medida para a largura do sinal pode ser obtida como $2 w=66,9 \pm 0,8 \mu \mathrm{m}$.

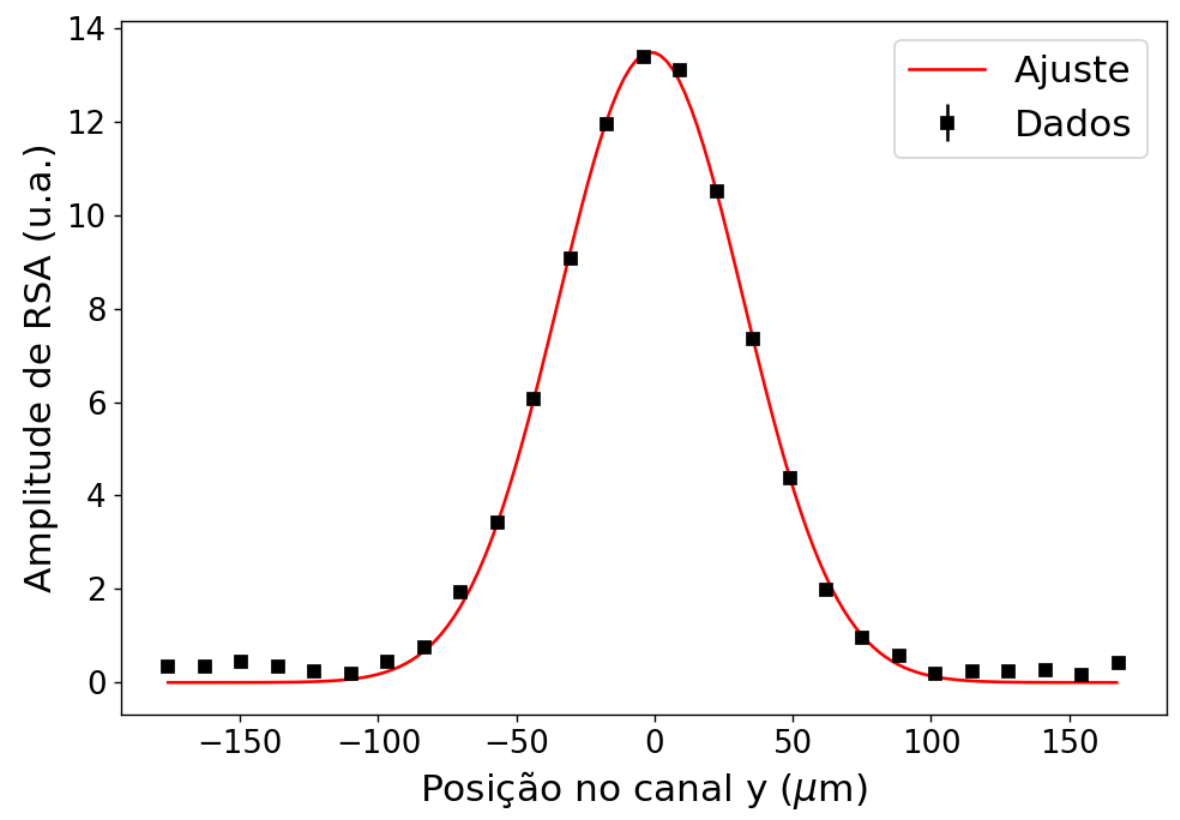

Figura 4.11: Amplitude de RSA em função das posições no canal $y$ da amostra, mostrando o comportamento da distribuição de polarização de spin em torno da posição de overlap, para a situação em que não há deriva.

Da mesma forma, os seguintes gráficos das figuras 4.12 e 4.13 mostram o comportamento do campo spin-órbita perpendicular e do fator-g, extraídos do ajuste dos parâmetros das curvas de RSA, em função da posição em torno do overlap. Observa-se que fora da largura do sinal, o comportamento dessas grandezas torna-se ruidoso e sem significado físico. 


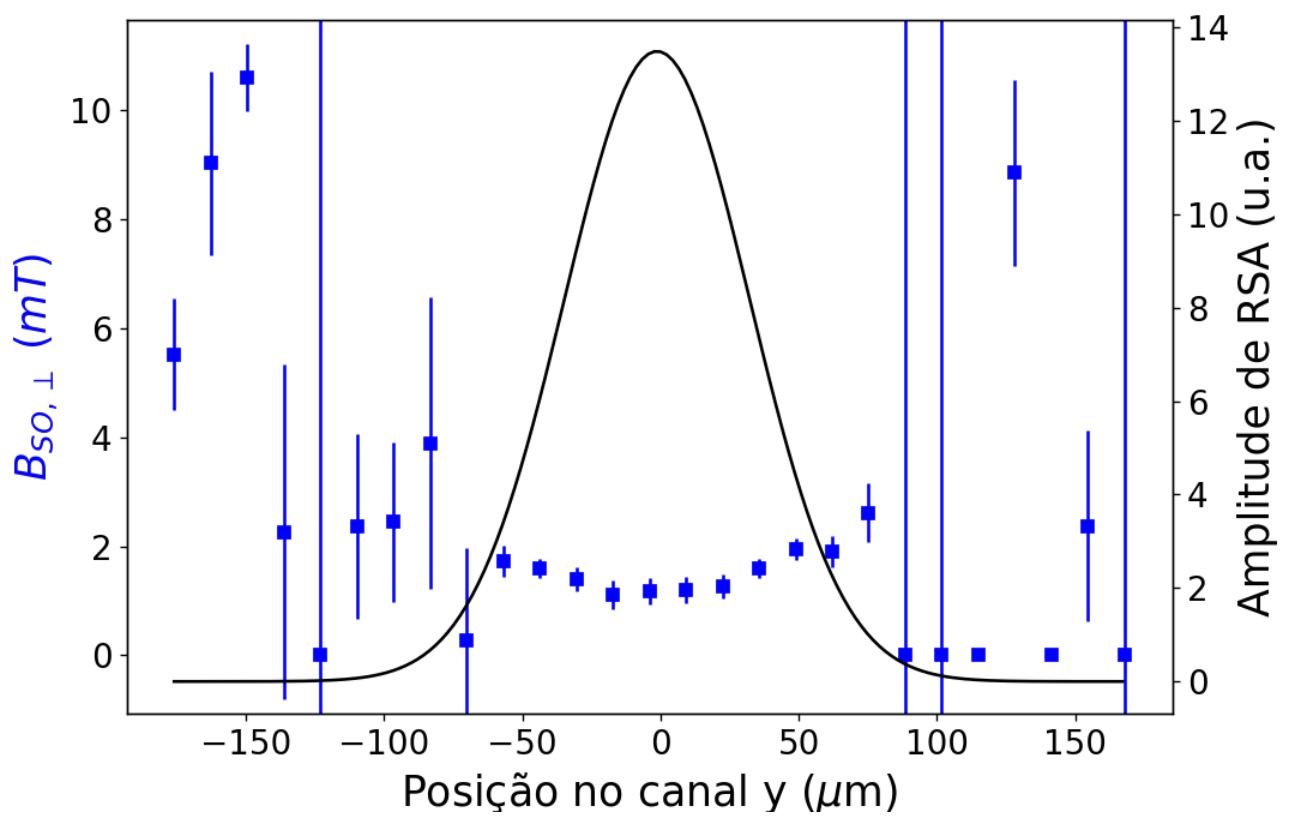

Figura 4.12: Campo spin-órbita perpendicular, obtido do ajuste das curvas de RSA, em função das posições no canal $y$ da amostra em torno do overlap, para a situação em que não há deriva. O comportamento parabólico dos dados sugere um transporte difusivo do pacote de polarização de spin.

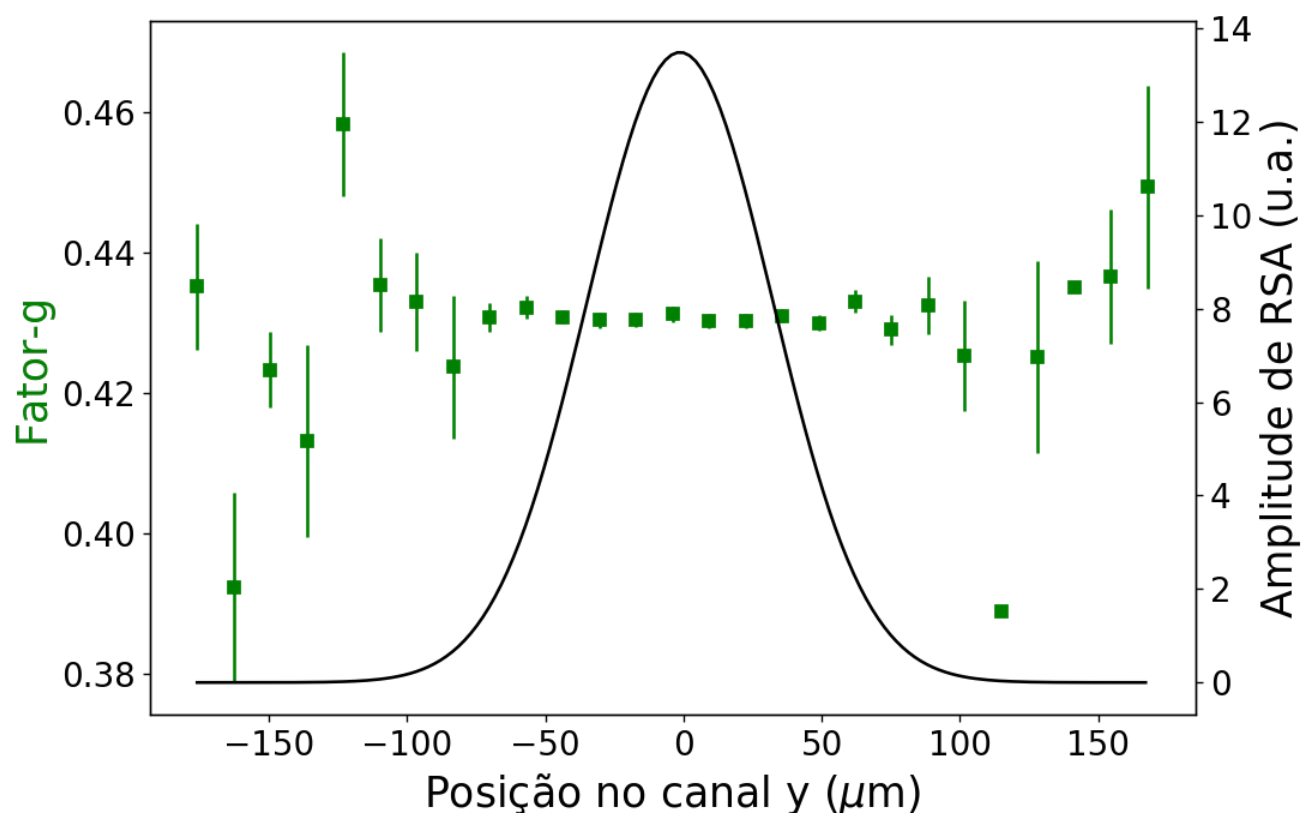

Figura 4.13: Amplitude do fator-g do elétron, obtido do ajuste das curvas de RSA, em função das posições no canal $y$ da amostra em torno do overlap, para a situação em que não há deriva.

Na figura 4.12, o comportamento parabólico dos dados de $B_{\mathrm{SO}, \perp}$ sugere um transporte difusivo do pacote de polarização de spin. Ou seja, a gaussiana do sinal deve alargar em função do tempo. Já no gráfico da figura 4.13, o fator-g observado apresenta um comportamento constante, mostrando uma distribuição espacial homogênea. 
Na posição de overlap, obtida através do ajuste da gaussiana do sinal (figura 4.11), a curva de RSA obtida é aquela plotada no gráfico da figura 4.10. É interessante se fazer um resumo dos parâmetros obtidos pelo ajuste dessa curva em específico, porque na situação onde haverá deriva serão comparadas essas quantidades no overlap. Os parâmetros de interesse estão, portanto, apresentados na tabela 4.2. Do valor encontrado para $\omega$, pôde-se encontrar a amplitude do fator-g do elétron como

$$
g=\frac{\hbar \omega}{\mu_{\mathrm{B}} \Delta t} \quad \Rightarrow \quad g=0,432 \pm 0,001
$$

onde foram utilizados os valores para as constantes físicas $\hbar=6,58 \times 10^{-16} \mathrm{eV} \mathrm{s}$ e $\mu_{\mathrm{B}}=$ $5,78 \times 10^{-5} \mathrm{eV} \mathrm{T}^{-1}$. Por fim, os parâmetros de amplitude encontrados foram $A_{0}=13,3 \pm 0,4$, $A_{1}=1,0 \pm 0,4$ e $A_{2}=0,4 \pm 0,4$, em unidades arbitrárias. Vê-se aí que o termo $A_{0}$ é dominante e que o valor de $A_{2}$ já é comparável ao seu erro, justificando portanto não ser necessário considerar termos superiores na soma da equação 4.4 .

\begin{tabular}{|c|c|c|}
\hline$\omega$ & $B_{\mathrm{SO}, \|}$ & $B_{\mathrm{SO}, \perp}$ \\
\hline $489,5 \pm 1,2 \mathrm{~T}^{-1}$ & $2,84 \pm 0,06 \mathrm{mT}$ & $1,18 \pm 0,25 \mathrm{mT}$ \\
\hline
\end{tabular}

Tabela 4.2: Parâmetros optimizados obtidos através do ajuste da função de RSA (equação 4.5) nos dados do gráfico da figura 4.10, para a posição de overlap, na situação em que não há deriva de spin.

\subsubsection{Varredura vertical}

O mesmo procedimento acima foi utilizado também para uma varredura de RSA na direção vertical, fixando dessa vez a posição $H$ do espelho no overlap. Novamente foi obtido um mapa de RSA, agora apresentado na figura 4.14, e a partir dele extraídas as amplitudes das curvas de RSA, compondo o gráfico da distribuição de polarização de spin em torno do overlap no canal $x$, exposto na figura 4.15 .

Vê-se portanto que, mais uma vez, a distribuição de polarização de spin pôde ser bem ajustada a uma função gaussiana, com uma largura $2 w=68,6 \pm 0,3 \mu \mathrm{m}$ bastante próxima da encontrada na varredura horizontal (seção 4.3.1). No gráfico da figura 4.16 estão mostradas as oscilações de RSA em função de $B_{\text {ext }}$ para a posição de overlap, encontrada a partir do ajuste gaussiano acima. Novamente os parâmetros de interesse optimizados pelo ajuste de RSA no overlap estão apresentados na tabela 4.3 , de onde para a amplitude do fator-g do elétron, 
calculado a partir de $\omega$, foi encontrado um valor bastante próximo do obtido na seção anterior

$$
g=\frac{\hbar \omega}{\mu_{\mathrm{B}} \Delta t} \quad \Rightarrow \quad g=0,4337 \pm 0,0004 .
$$

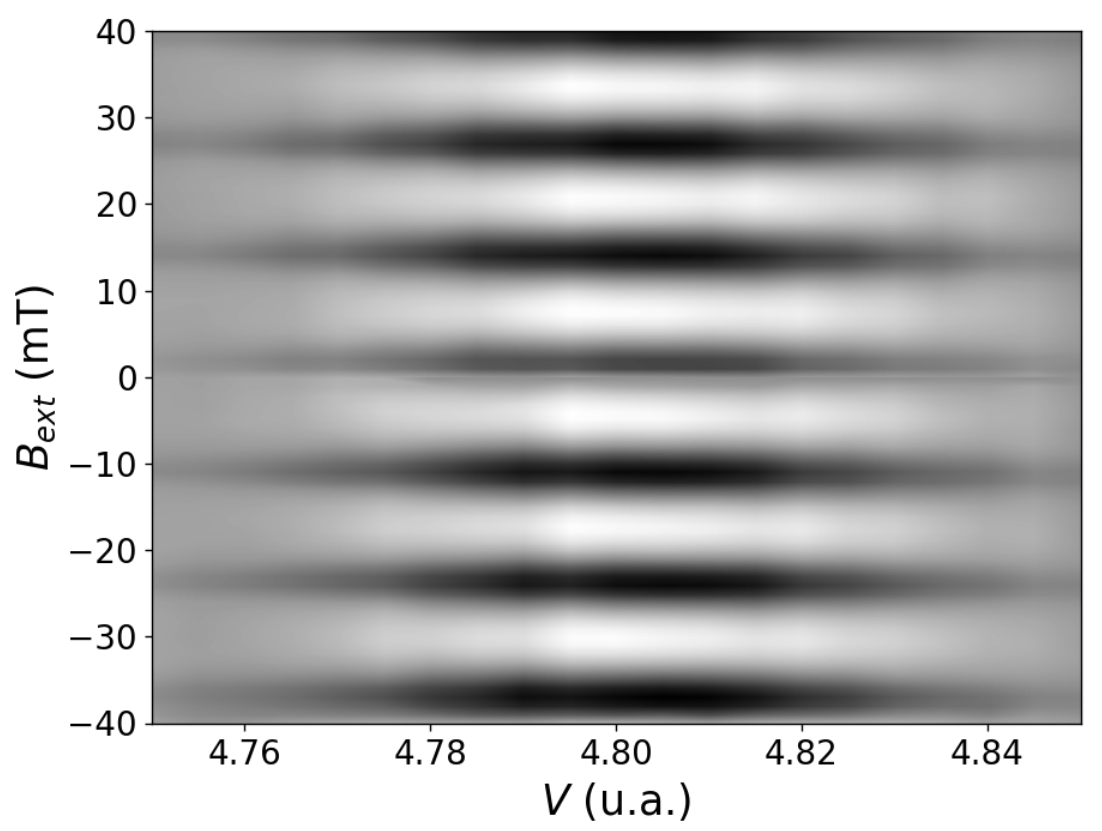

Figura 4.14: Mapa de RSA na direção vertical com o campo magnético externo $B_{\text {ext }}$ variando de -40 a $40 \mathrm{mT}$, para a situação em que não há deriva de spin.

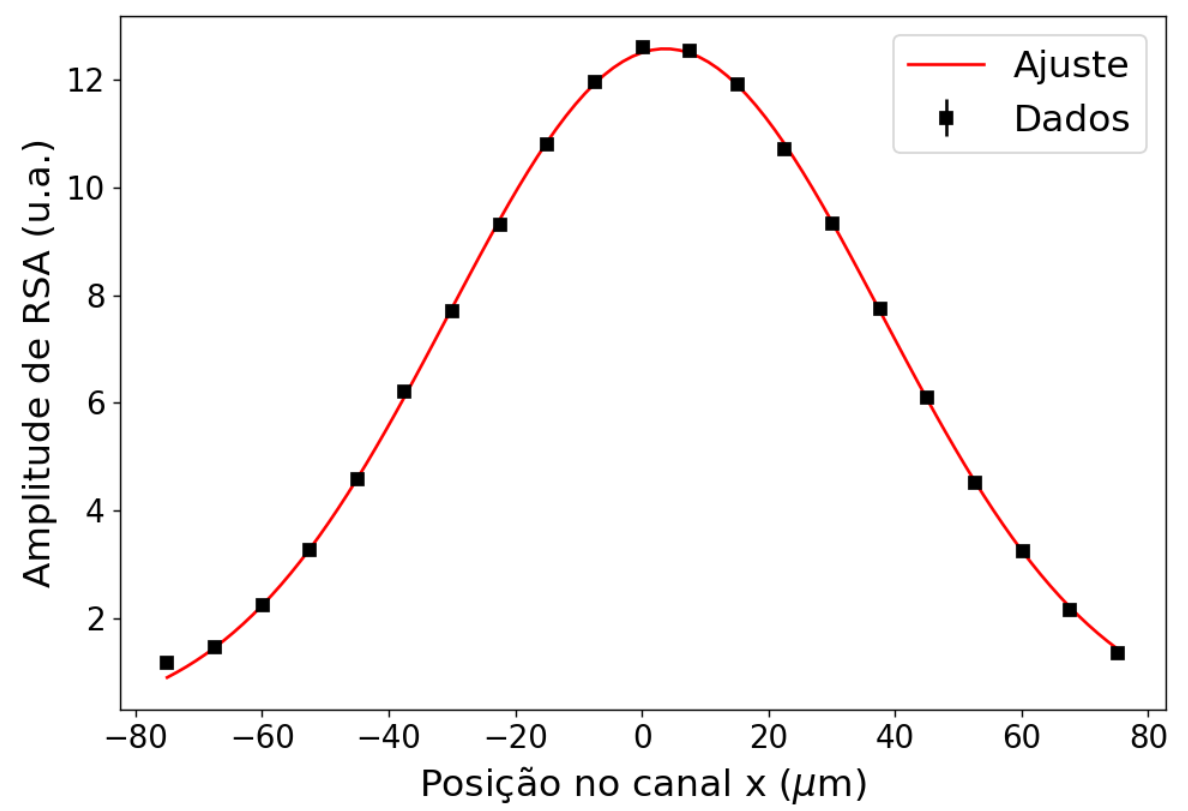

Figura 4.15: Amplitude de RSA em função das posições no canal $x$ da amostra, mostrando o comportamento da distribuição de polarização de spin em torno da posição de overlap, para a situação em que não há deriva. 


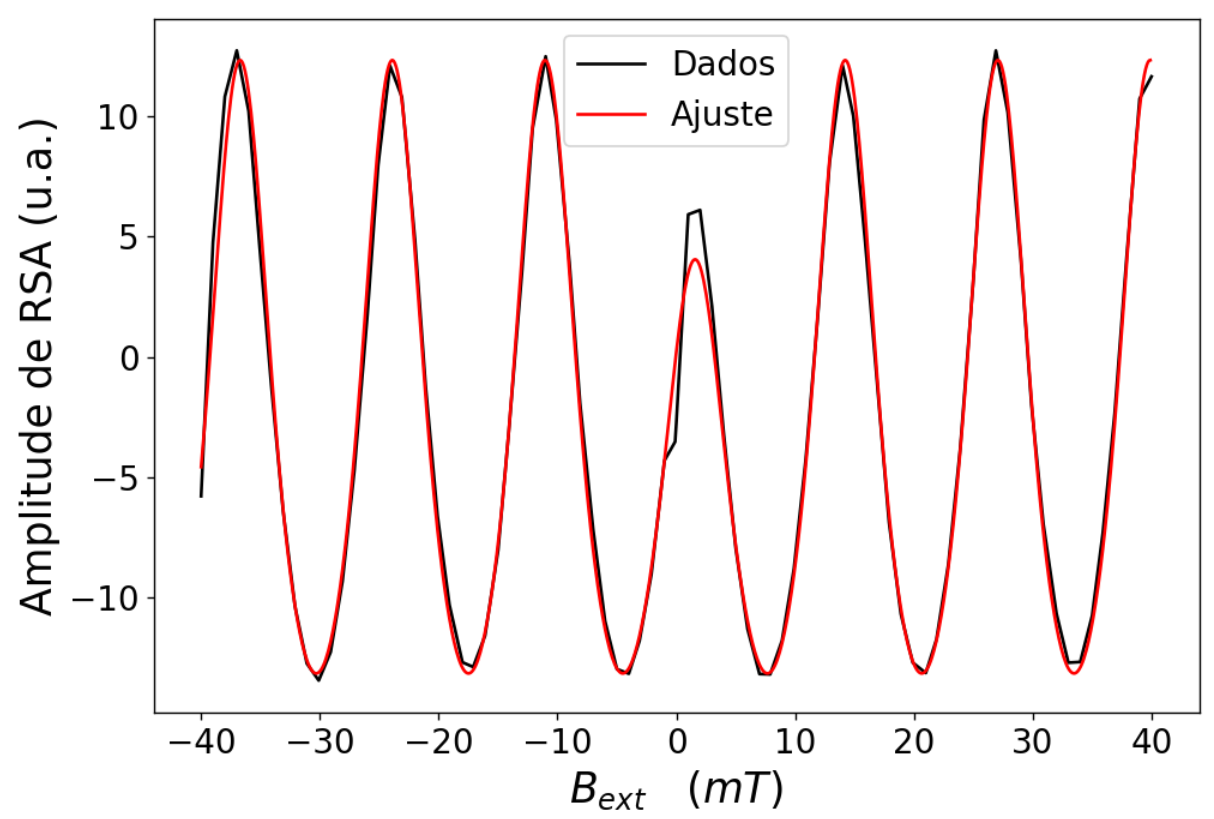

Figura 4.16: Curva de RSA obtida para a posição de overlap, extraída do mapa da figura 4.14 . para a situação em que não há deriva de spin. Os dados experimentais estão plotados em linha preta, enquanto que o ajuste da equação 4.5 está plotado em vermelho.

\begin{tabular}{|c|c|c|}
\hline$\omega$ & $B_{\mathrm{SO}, \|}$ & $B_{\mathrm{SO}, \perp}$ \\
\hline $491,5 \pm 0,5 \mathrm{~T}^{-1}$ & $-1,58 \pm 0,03 \mathrm{mT}$ & $1,95 \pm 0,07 \mathrm{mT}$ \\
\hline
\end{tabular}

Tabela 4.3: Parâmetros optimizados obtidos através do ajuste da função de RSA (equação 4.5) nos dados do gráfico da figura 4.16, para a posição de overlap, na situação em que não há deriva de spin. 


\section{Capítulo 5}

\section{Deriva de polarização de spin}

No capítulo anterior foi explorada a possibilidade de gerar e medir polarização de spin opticamente através de um sistema de bombeio e prova, onde as distribuições espaciais dessa polarização, obtidas através das amplitudes de RSA (ver figuras 4.11 e 4.15), seguiram o comportamento esperado, ajustando-se bem a uma função gaussiana. No presente capítulo, propõese utilizar da mesma técnica bem sucedida, explorada na seção 4.3 , para realizar medidas de polarização de spin na situação em que é introduzida deriva dos portadores.

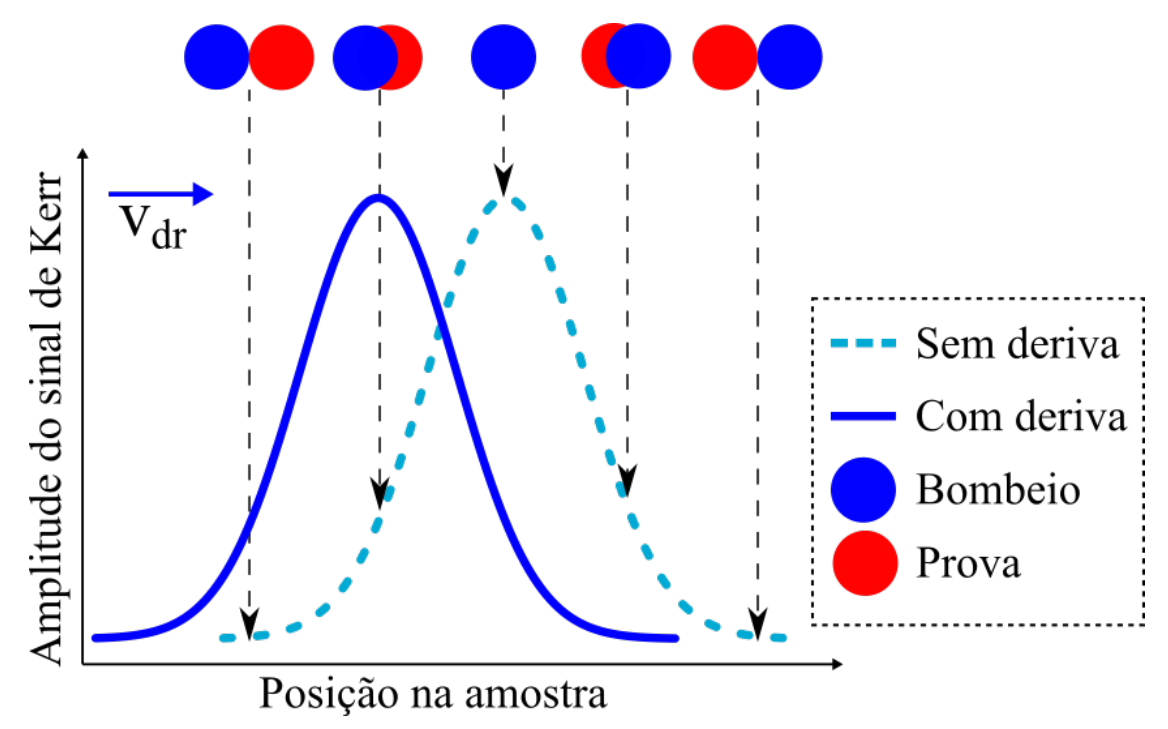

Figura 5.1: Comportamento esperado para o sinal da rotação de Kerr do feixe de prova, em função da posição de injeção de polarização de spin pelo bombeio na amostra, para a situação em que há deriva (linha contínua), em comparação com quando não há (linha tracejada). Observa-se que para um pacote de polarização de spin se movendo para a direita, a gaussiana se forma à esquerda do sinal sem deriva. 
Ao se aplicar uma diferença de potencial entre o par de contatos de um dos canais da amostra, será criado um campo elétrico que induzirá uma corrente de portadores e, como consequência, uma deriva no pacote de polarização de spin, a qual poderá ser observada como um deslocamento da posição central da gaussiana obtida das amplitudes de RSA. Ou seja, como a medida de polarização de spin é realizada aproximadamente $13 \mathrm{~ns}$ após a injeção, se um campo elétrico for aplicado de forma que seja induzida uma deriva para a direita no canal horizontal, por exemplo, a gaussiana começará a se formar para posições na amostra à esquerda da gaussiana para a situação em que não havia deriva, como ilustra a figura 5.1

Nessa seção serão estudados dois casos de deriva de spin, um em que a voltagem é aplicada no canal horizontal da amostra (direção cristalográfica y $\|$ [110]) e outro em que a voltagem é aplicada no canal vertical (direção cristalográfica $x \|$ [110]). Em ambos os casos, o campo magnético externo $B_{\text {ext }}$ será aplicado paralelamente à direção cristalográfica y, e os parâmetros experimentais utilizados serão os mesmos apresentados anteriormente na tabela 4.1 .

Deve-se recordar também que, quando há transporte dos portadores, surgem efeitos devidos às interações spin-órbita, apresentadas na seção 2.2, e que acabam por alterar a dinâmica da magnetização dos spins. Para um poço quântico de GaAs crescido na direção [001] (z), as componentes do campo spin-órbita para cada sub-banda $\nu=1,2$ são dadas por

$$
\vec{B}_{\mathrm{SO}, \nu}(\vec{k})=\frac{2}{g \mu_{\mathrm{B}}}\left(\begin{array}{l}
\left(+\alpha_{\nu}+\beta_{1, \nu}+2 \beta_{3, \nu} \frac{k_{x}^{2}-k_{y}^{2}}{k_{\mathrm{F}}}\right) k_{y} \\
\left(-\alpha_{\nu}+\beta_{1, \nu}-2 \beta_{3, \nu} \frac{k_{x}^{2}-k_{y}^{2}}{k_{\mathrm{F}}}\right) k_{x}
\end{array}\right)
$$

Devido à pequena separação energética entre as sub-bandas representadas pelas funções de onda simétrica e antissimétrica do poço quântico (ver seção 3.1), o regime estudado é o de espalhamento forte inter-subbanda, e a dinâmica da magnetização de spins é descrita por uma média entre os campos spin-órbita [24], que serão relacionados com as velocidades de deriva $v_{\text {dr }}$ através de

$$
\begin{aligned}
& \left\langle B_{\mathrm{SO}}^{x}\right\rangle=\left[\frac{m}{\hbar g \mu_{\mathrm{B}}} \sum_{\nu=1}^{2}\left(+\alpha_{\nu}+\beta_{\nu}^{*}\right)\right] v_{\mathrm{dr}}^{y} \\
& \left\langle B_{\mathrm{SO}}^{y}\right\rangle=\left[\frac{m}{\hbar g \mu_{\mathrm{B}}} \sum_{\nu=1}^{2}\left(-\alpha_{\nu}+\beta_{\nu}^{*}\right)\right] v_{\mathrm{dr}}^{x},
\end{aligned}
$$

onde $\beta_{\nu}^{*}=\beta_{1, \nu}-2 \beta_{3, \nu}$ e $m=0.067 m_{0}$ é a massa efetiva do elétron para o GaAs. Como 
$B_{\mathrm{SO}}^{x(y)} \propto v_{\mathrm{dr}}^{y(x)}$,é conveniente definir coeficientes $b^{x(y)}$ como

$$
\begin{aligned}
& b^{y}=\frac{B_{\mathrm{SO}}^{x}}{v_{\mathrm{dr}}^{y}}=\left[\frac{m}{\hbar g \mu_{\mathrm{B}}} \sum_{\nu=1}^{2}\left(+\alpha_{\nu}+\beta_{\nu}^{*}\right)\right] \\
& b^{x}=\frac{B_{\mathrm{SO}}^{y}}{v_{\mathrm{dr}}^{x}}=\left[\frac{m}{\hbar g \mu_{\mathrm{B}}} \sum_{\nu=1}^{2}\left(-\alpha_{\nu}+\beta_{\nu}^{*}\right)\right],
\end{aligned}
$$

os quais serão importantes para recuperar os valores das constantes spin-órbita $\alpha$ e $\beta$.

\subsection{Deriva de spin na direção y}

Assim como realizado na seção 4.3.1, ao se fixar a posição vertical da incidência do feixe de bombeio no overlap, e coletando as curvas de RSA para alguns valores de $H$ do espelho motorizado, é possível se obter a distribuição de algumas quantidades de interesse ao longo do canal $y$ do dispositivo. Dessa vez, entretanto, as medidas serão repetidas para alguns valores de voltagem $V_{\text {ip }}$ aplicadas no plano da amostra, entre os contatos do canal horizontal. Desse modo, serão induzidas derivas do pacote de polarização de spin na direção cristalográfica $y$, que deverão ser caracterizadas por velocidades $v_{\mathrm{dr}}^{y}$.

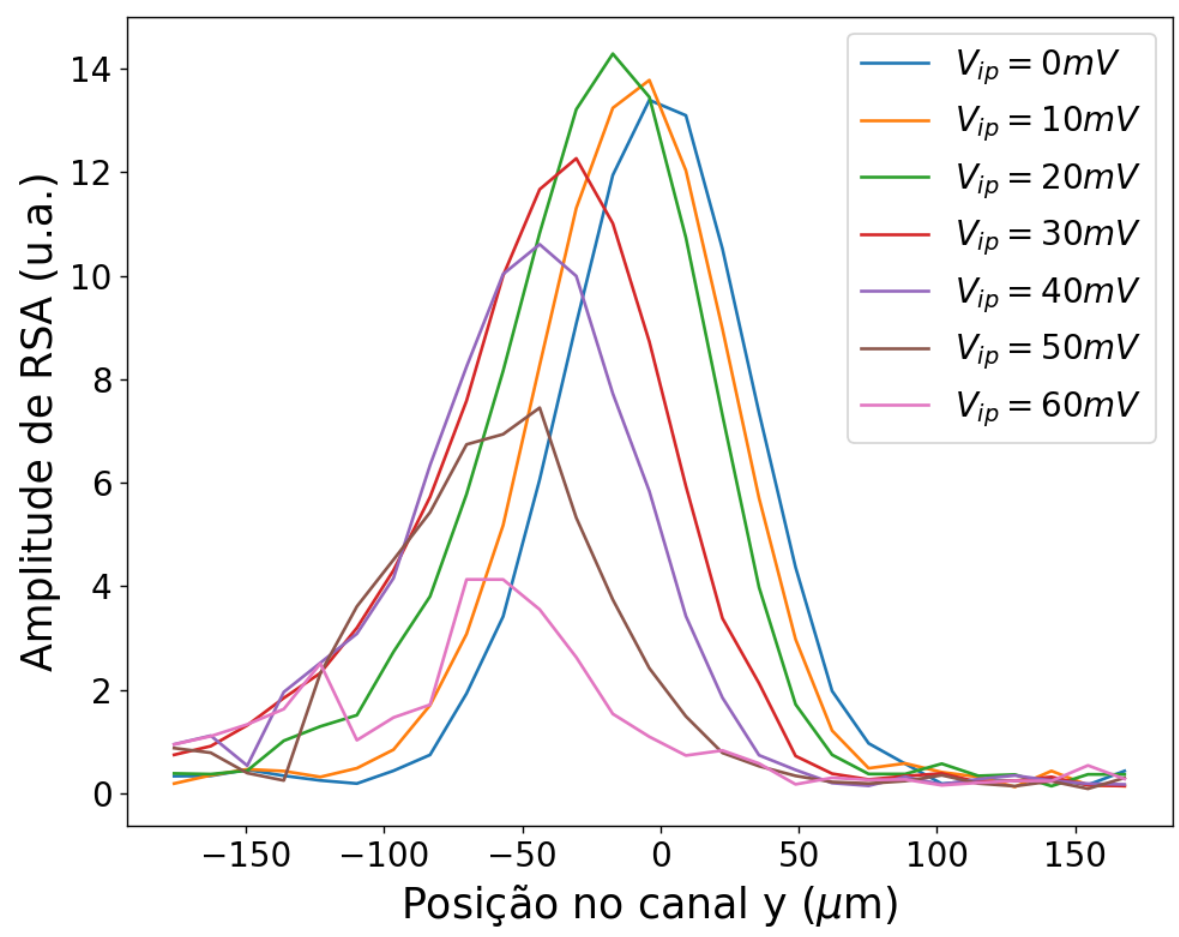

Figura 5.2: Amplitudes de RSA em função das posições no canal $y$ da amostra para derivas de polarização de spin induzidas por alguns valores positivos de voltagens $V_{\mathrm{ip}}$. 
Na figura 5.2 estão apresentadas as amplitudes de RSA em função da posição no canal $y$ da amostra, onde cada curva descreve o comportamento do sinal para diferentes voltagens $V_{\text {ip }}$ positivas (medidas com voltagens negativas também foram coletadas, mas estão omitidas nesse gráfico para uma melhor visualização). Percebe-se que quanto maior a tensão no plano, os sinais gaussianos são formados cada vez mais à esquerda, caracterizando uma deriva à direita, como discutido na figura 5.1. Além disso, observa-se que a amplitude do sinal também diminui como função de $V_{\text {ip }}$, o que o torna cada vez mais ruidoso. Um ajuste gaussiano dessas distribuições de polarização de spin permite que sejam obtidas as posições de overlap $d_{\text {overlap }}^{V_{\mathrm{ip}}}$ para cada uma das voltagens. Dessa forma as velocidades de deriva $v_{\text {dr }}$ podem ser obtidas através de

$$
v_{\mathrm{dr}}=\frac{d_{\mathrm{overlap}}^{V_{\mathrm{ip}}=0}-d_{\mathrm{overlap}}^{V_{\mathrm{ip}}}}{\Delta t}
$$

onde $d_{\text {overlap }}^{V_{\mathrm{ip}}=0}$ é a posição do overlap para a situação em que não havia deriva de spin e $\Delta t=$ 12,9 ns é o tempo de atraso entre injeção e detecção de polarização de spin.

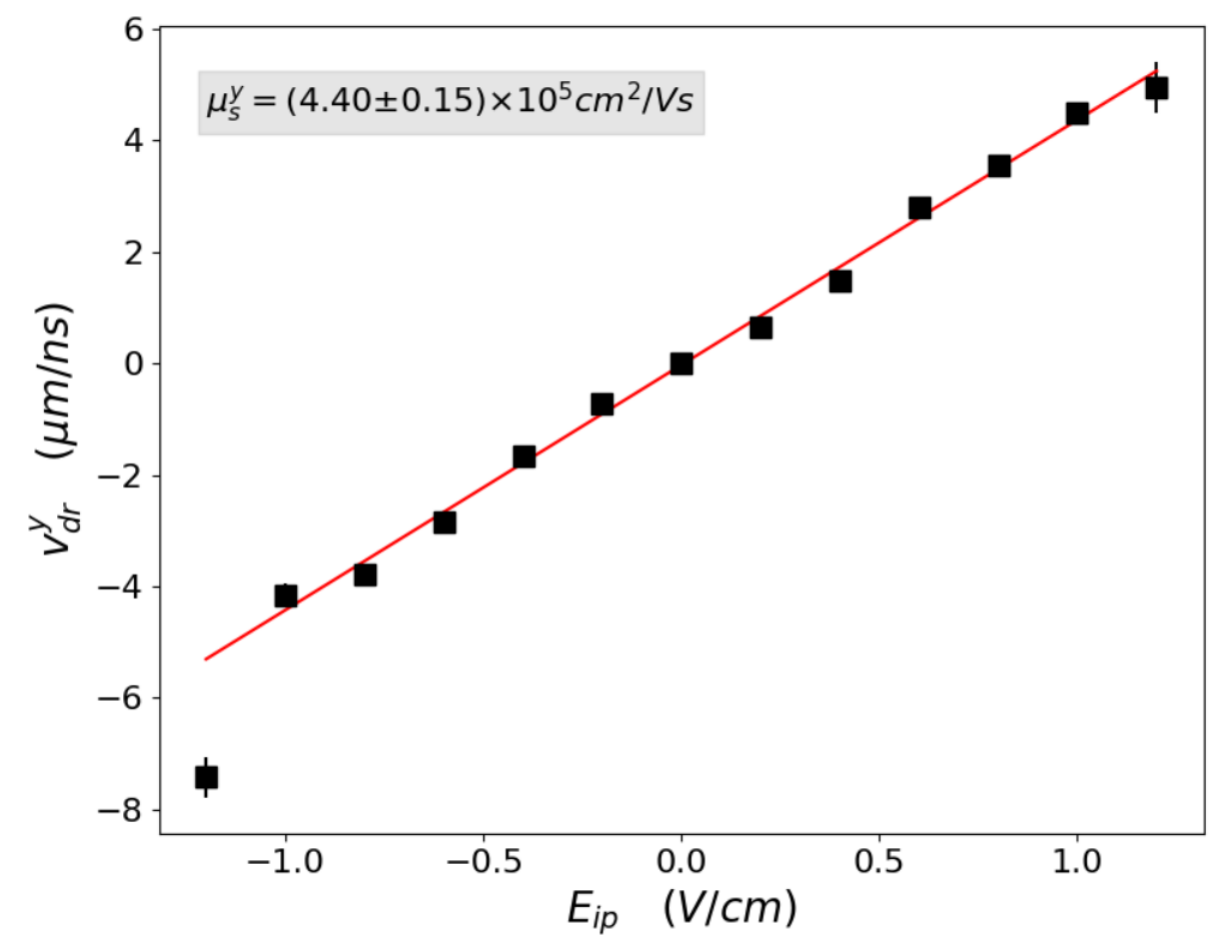

Figura 5.3: Gráfico da velocidade de deriva na direção $y$ em função do campo elétrico $E_{\text {ip }}$ gerado pela voltagem $V_{\text {ip }}$ aplicada entre os contatos do canal horizontal da amostra. Da reta ajustada, o coeficiente angular obtido é identificado como a mobilidade de spin, cujo valor encontrado foi de $\mu_{\mathrm{s}}^{y}=4,40 \pm 0,15 \times 10^{5} \mathrm{~cm}^{2} / \mathrm{Vs}$. 
No gráfico da figura 5.3 estão plotados os valores de $v_{\mathrm{dr}}$, calculados através da equação 5.6. em função do campo elétrico $E_{\mathrm{ip}}=V_{\mathrm{ip}} / l(\operatorname{com} l=500 \mathrm{~nm}$, a distância entre os contatos) que surge da voltagem aplicada no plano. Os dados dispostos nesse gráfico sugerem um comportamento linear, possibilitando que seja encontrada a mobilidade de spin $\mu_{\mathrm{s}}$ (definida de forma similar à mobilidade de carga) através do seguinte modelo:

$$
v_{\mathrm{dr}}^{y(x)}\left(E_{\mathrm{ip}}\right)=\mu_{\mathrm{s}}^{y(x)} E_{\mathrm{ip}}
$$

A partir do ajuste da equação de uma reta, portanto, a mobilidade de spin será identificada como a optimização do coeficiente angular, e o valor que pôde ser obtido através desse método foi de $\mu_{\mathrm{s}}^{y}=4,40 \pm 0,15 \times 10^{5} \mathrm{~cm}^{2} / \mathrm{Vs}$.

A partir das equações 5.2 e 5.3 vê-se que, para o modelo utilizado, quando a deriva ocorre na direção cristalográfica $y$, o campo spin-órbita gerado estará na direção $x$, e será portando perpendicular ao campo magnético externo $B_{\text {ext }}$. Dessa forma, devem ser extraídas as optimizações do parâmetro $B_{\mathrm{SO}, \perp}$ dos ajustes da função 4.5 nas curvas de RSA, para as posições de overlap. No gráfico da figura 5.4 estão plotados esses campos $B_{\mathrm{SO}}^{x}$ como função das velocidades de deriva.

O modelo utilizado sugere que haja uma relação linear entre o campo spin-órbita e a velocidade de deriva (equação 5.2), se os coeficientes spin-órbita $\alpha$ e $\beta^{*}$ não dependerem da velocidade. Ao olhar para os dados do gráfico de $B_{\mathrm{SO}}^{x} \times v_{\mathrm{dr}}^{y}$, esse comportamento parece ser satisfeito, e a partir de um ajuste linear da equação 5.4 pode ser encontrado um valor constante para o coeficiente $b^{y}=2,00 \pm 0,06 \mathrm{mT} /(\mu \mathrm{m} / \mathrm{ns})$.

Por outro lado, pode-se verificar os valores de $b^{y}$ para cada velocidade $v_{\mathrm{dr}}^{y}$ através da inserção direta dos pontos do gráfico da figura 5.4 na equação 5.4. Plotando esses coeficientes calculados em função das velocidades de deriva, foi construído o gráfico da figura 5.5, onde se obteve uma variação de $b^{y}$ com $v_{\mathrm{dr}}$, com comportamentos parecidos para ambas as velocidades positiva e negativa.

Por fim, na figura 5.6 encontram-se plotados os valores para o fator-g do elétron, obtidos através do mesmo ajuste das curvas de RSA nas posições de overlap, em função das velocidades de deriva. Nesse gráfico é possível observar também uma variação do fator-g como função de $v_{\mathrm{dr}}$ 


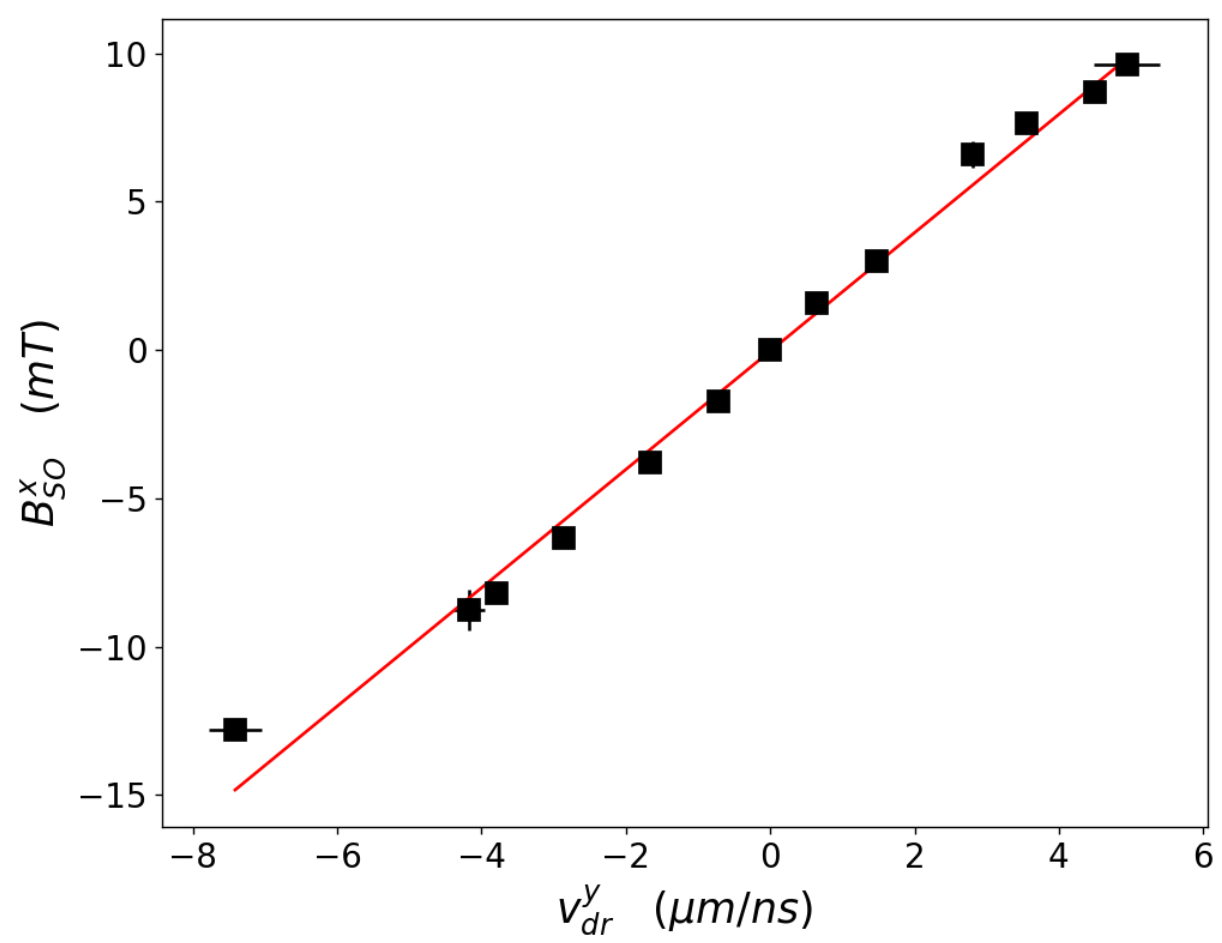

Figura 5.4: Gráfico do campo spin órbita no overlap em função da velocidade de deriva no canal $y$ da amostra. Os dados aparentam sugerir um comportamento linear, descrito pela equação 5.4 . de onde o ajuste do coeficiente angular resulta em $b^{y}=2,00 \pm 0,06 \mathrm{mT} /(\mu \mathrm{m} / \mathrm{ns})$.

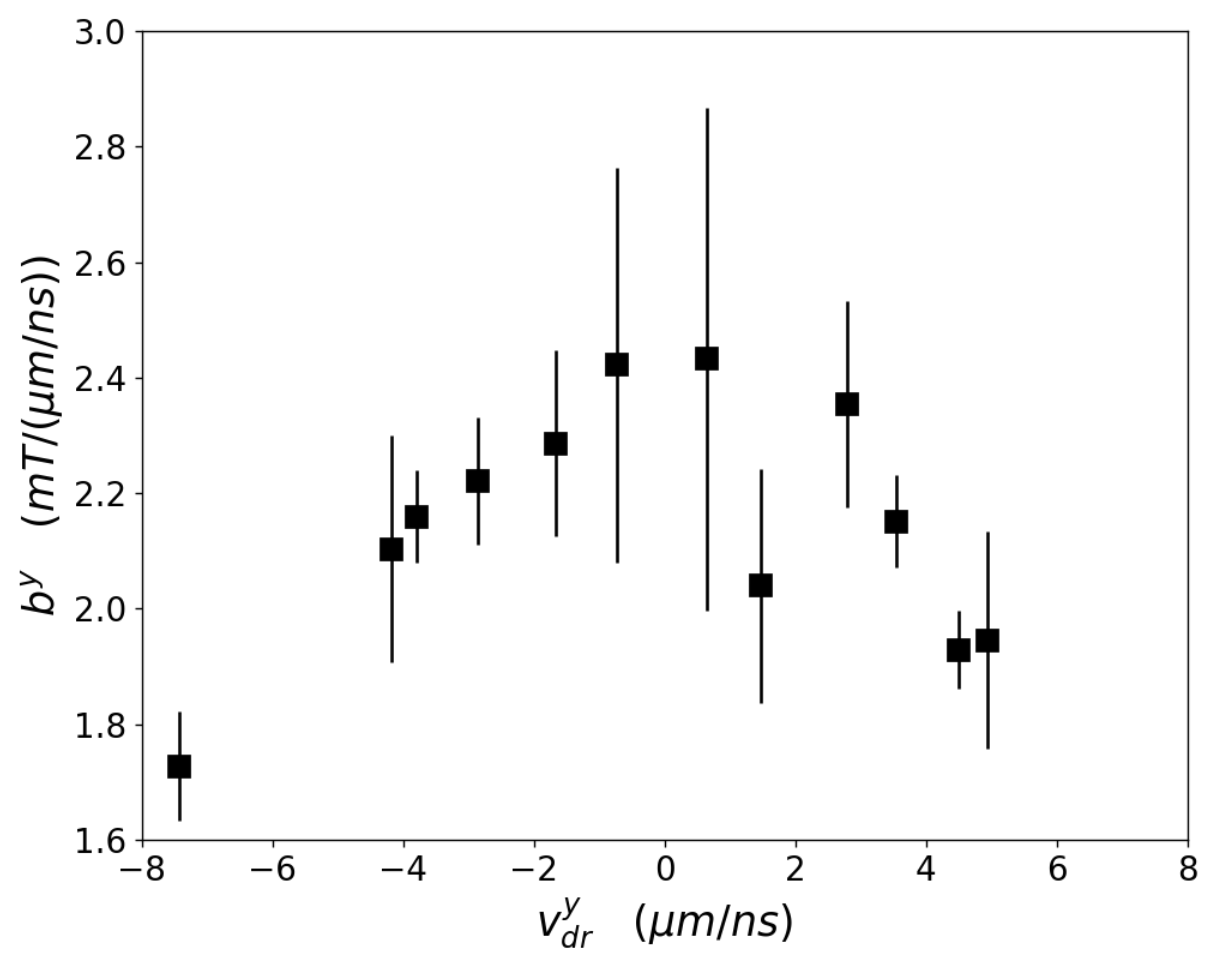

Figura 5.5: Gráfico dos coeficientes $b^{y}$, calculados ponto-a-ponto a partir da inserção dos dados da figura 5.4 diretamente na equação 5.4, em função das velocidades de deriva no canal $y$ da amostra. 


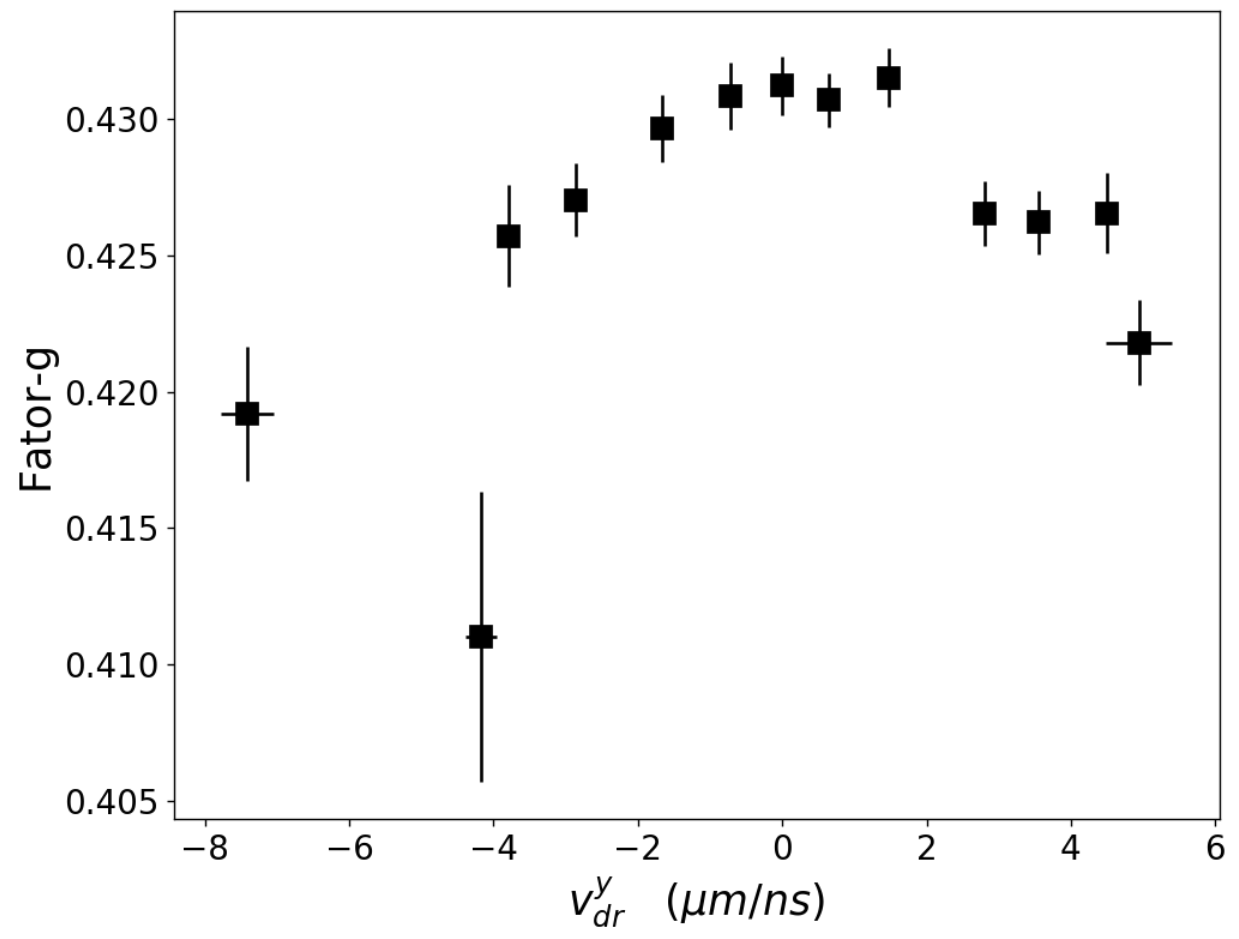

Figura 5.6: Gráfico da amplitude do fator-g do elétron em função da velocidade de deriva na direção $x$.

\subsection{Deriva de spin na direção $x$}

Nessa seção, estão apresentadas as medidas realizadas de modo análogo ao que foi feito acima, mas agora para voltagens $V_{\text {ip }}$ aplicadas entre os contatos do canal $x$ da amostra, induzindo deriva de spin nessa direção. Por isso, a posição horizontal da incidência do feixe de bombeio foi fixada no overlap e as curvas de RSA foram coletadas em função das unidades $V$ do espelho motorizado. Na figura 5.7 estão mostradas as amplitudes de RSA como função das posições no canal vertical, novamente para alguns valores de voltagens no plano $V_{\text {ip }}$, onde as curvas apresentam comportamentos similares aos encontrados na figura 5.2 .

Do ajuste das gaussianas, as velocidades de deriva $v_{\mathrm{dr}}^{x}$ foram calculadas através da equação 5.6, usando as posições de overlap encontradas. O gráfico de $v_{\mathrm{dr}}^{x}$ em função da magnitude dos campos elétricos no plano $E_{\mathrm{ip}}$ está plotado na figura 5.8. Um ajuste linear desses dados, baseado na equação 5.7, permitiu a extração do valor $\mu_{\mathrm{s}}^{x}=5,94 \pm 0,21 \times 10^{5} \mathrm{~cm}^{2} / \mathrm{Vs}$ para a mobilidade de spin. 


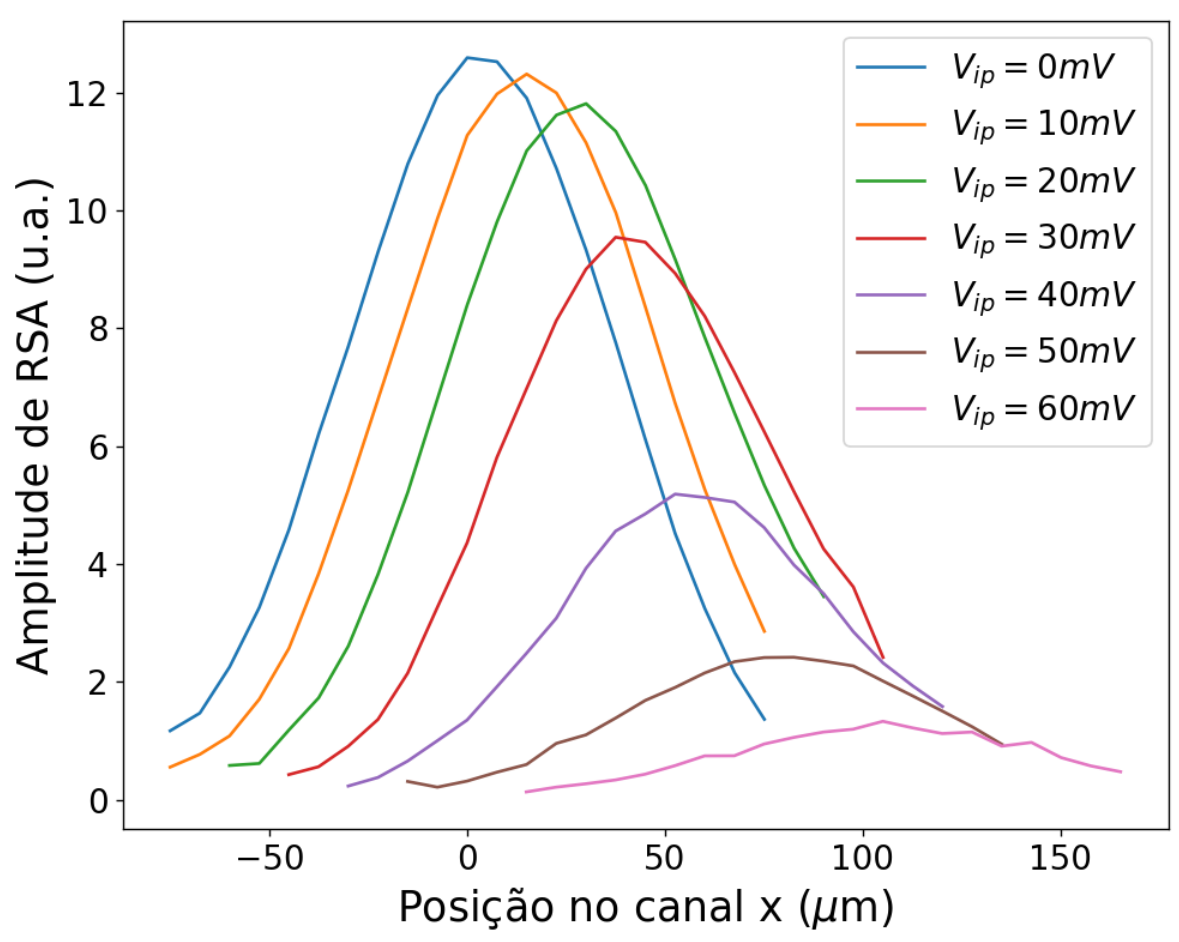

Figura 5.7: Amplitudes de RSA em função das posições no canal $x$ da amostra para derivas de polarização de spin induzidas por alguns valores positivos de voltagens $V_{\mathrm{ip}}$.

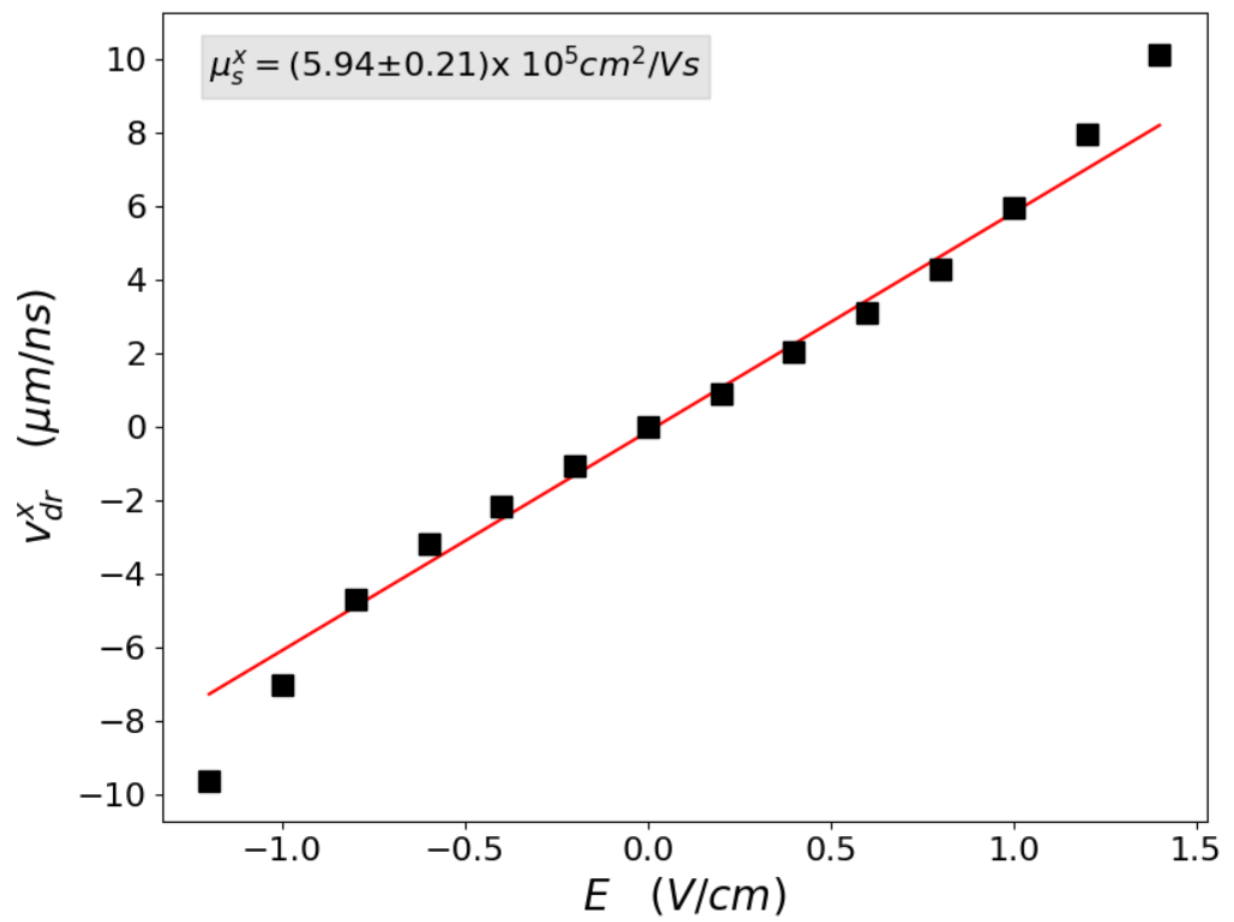

Figura 5.8: Gráfico da velocidade de deriva na direção $x$ em função do campo elétrico $E_{\text {ip }}$ gerado pela voltagem $V_{\text {ip }}$ aplicada entre os contatos do canal vertical da amostra. Da reta ajustada, o coeficiente angular obtido é identificado como a mobilidade de spin, cujo valor encontrado foi de $\mu_{\mathrm{s}}^{x}=5,94 \pm 0,21 \times 10^{5} \mathrm{~cm}^{2} /$ Vs. 


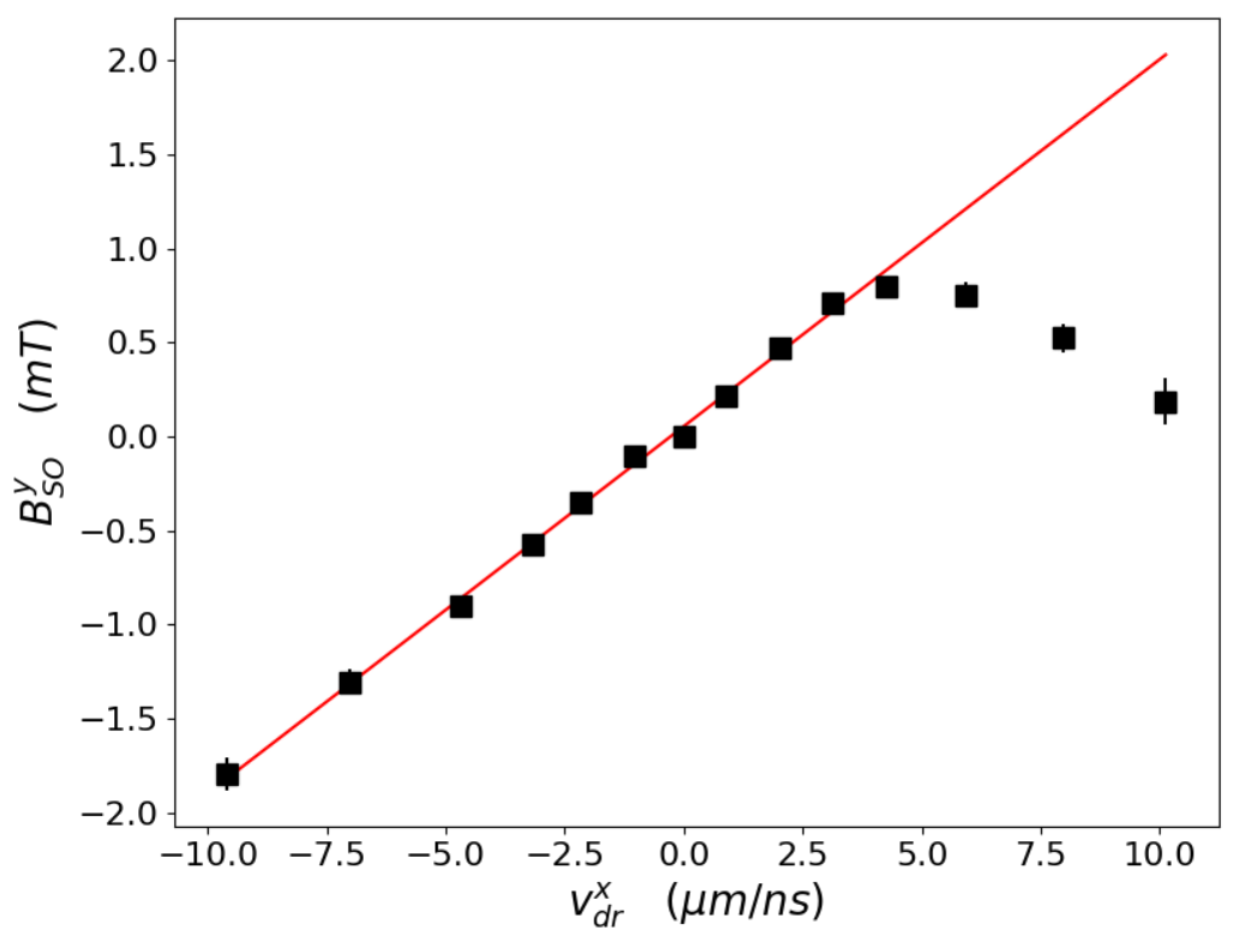

Figura 5.9: Gráfico do campo spin órbita no overlap em função da velocidade de deriva na direção $x$. Os dados aparentam sugerir um comportamento linear, descrito pela equação 5.4, até velocidades de aproximadamente $4 \mu \mathrm{m} / \mathrm{ns}$. Excluindo-se os últimos 3 pontos, o coeficiente angular de uma reta ajustada resulta em um valor para o coeficiente $b^{x}=$ $0,16 \pm 0,02 \mathrm{mT} /(\mu \mathrm{m} / \mathrm{ns})$.

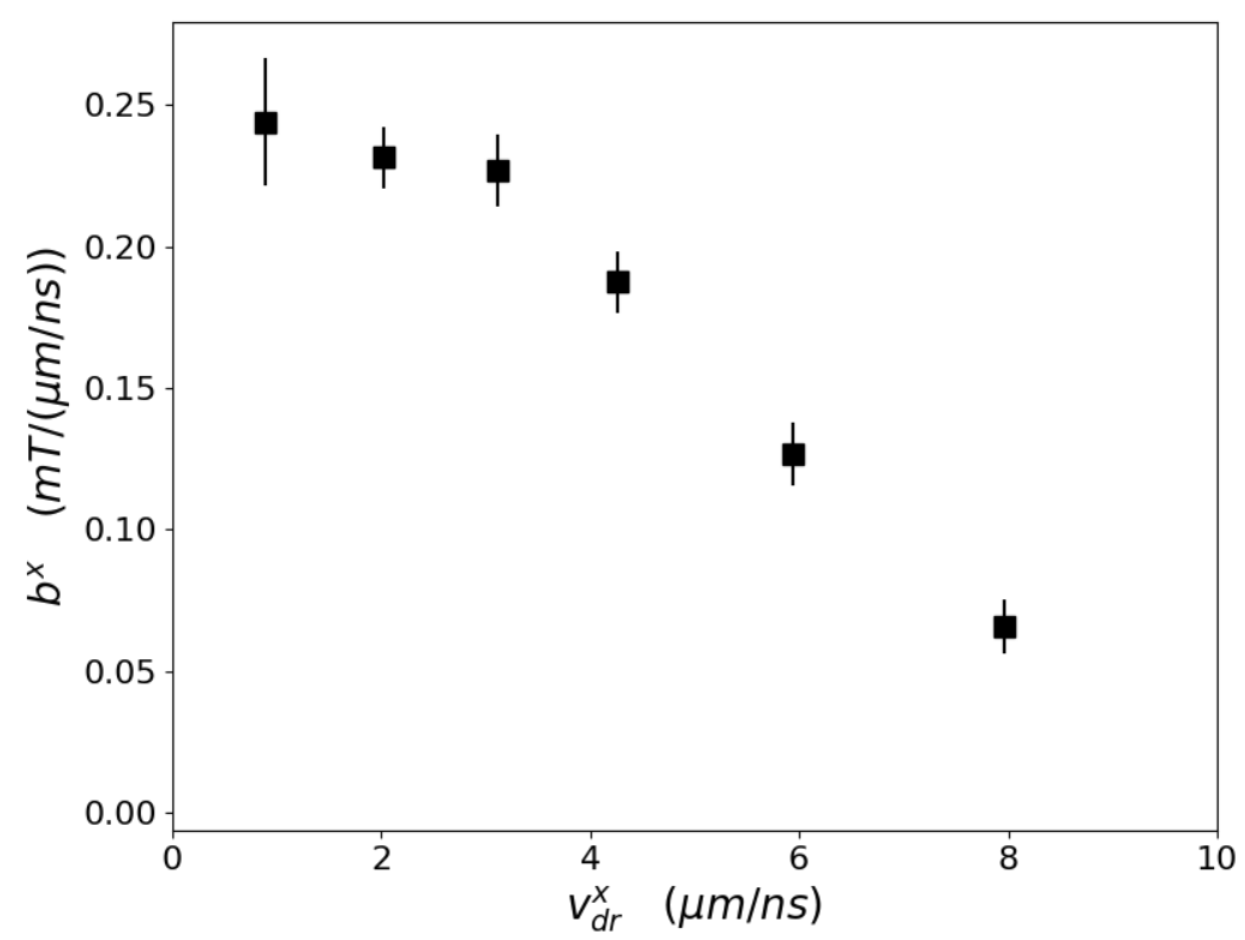

Figura 5.10: Gráfico dos coeficientes $b^{x}$ calculados ponto-a-ponto a partir dos dados da figura 5.9. em função da velocidade de deriva na direção $x$. 
Pelo modelo utilizado para a dinâmica de magnetização dos spins (equações 5.2 e 5.3 , como nesse caso a deriva foi induzida na direção cristalográfica $x$, o campo spin-órbita gerado estará na direção $y$, paralelo portanto ao campo externo $B_{\text {ext }}$. O gráfico dos campos $B_{\mathrm{SO}, \|}$, extraídos dos ajustes da equação 4.5 nas curvas de RSA para as posições de overlap, em função das velocidades de deriva $v_{\mathrm{dr}}^{x}$ está apresentado na figura 5.9, onde vê-se que os dados apresentam um comportamento linear, com exceção dos três últimos pontos para velocidades positivas, onde foi observada uma atenuação na magnitude do campo spin-órbita. Considerando o ajuste dos pontos que se comportam linearmente, obteve-se um valor para o coeficiente $b^{x}=0,16 \pm 0,02 \mathrm{mT} /(\mu \mathrm{m} / \mathrm{ns})$.

Não obstante, ao se dividir os valores de $B_{\mathrm{SO}}^{y}$ por suas velocidades associadas $v_{\mathrm{dr}}^{x}$, pontoa-ponto, recupera-se novamente uma dependência do coeficiente $b^{x}$ com a velocidade de deriva, como mostra o gráfico da figura 5.10. Por fim, também foi reportada uma variação na amplitude do fator-g do elétron em função das velocidades de deriva, como mostra o gráfico da figura 5.11 , em um comportamento similar ao encontrado para a outra direção cristalográfica (figura 5.6.).

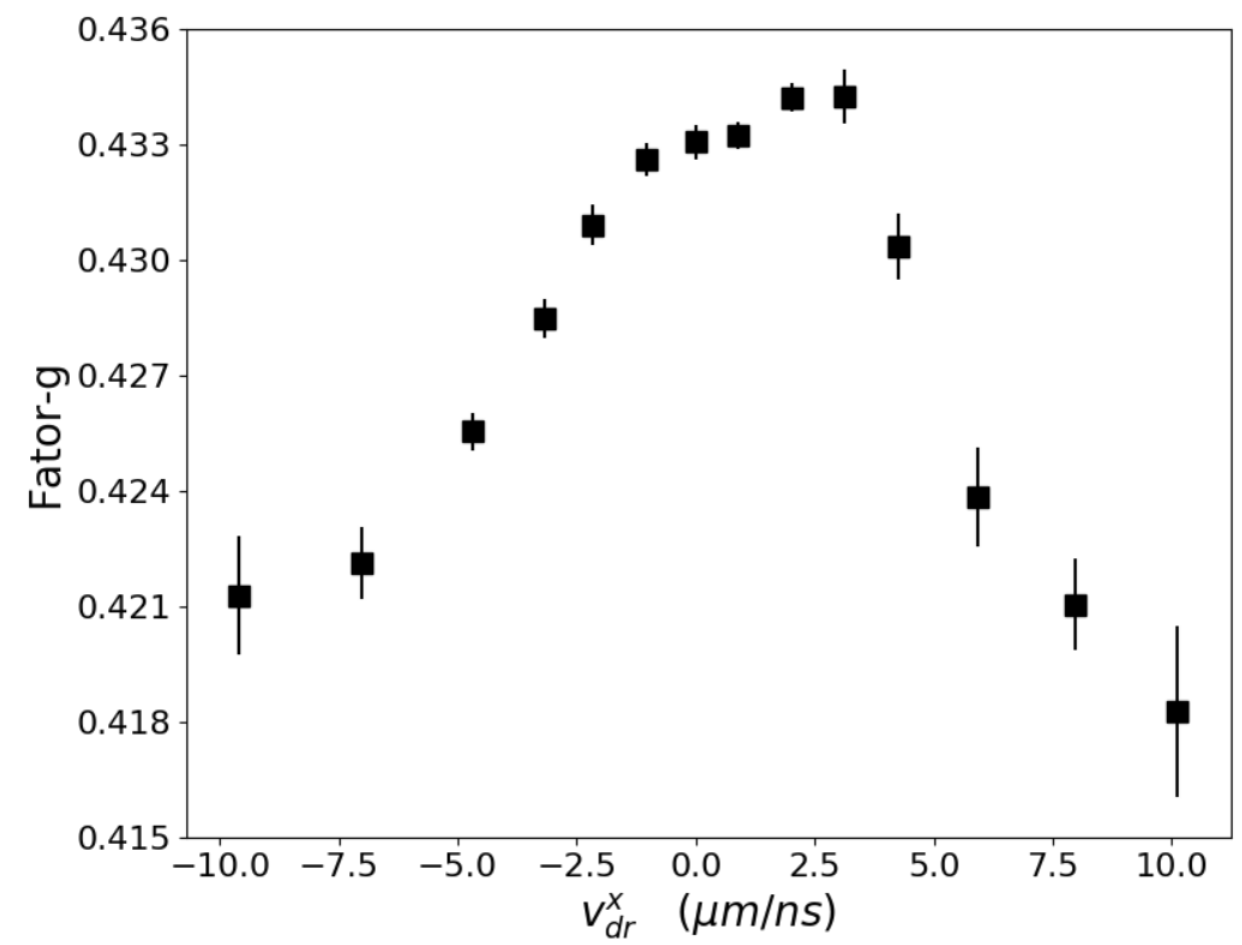

Figura 5.11: Gráfico da amplitude do fator-g do elétron em função da velocidade de deriva na direção $y$. 


\subsection{Resultados combinados}

\section{Mobilidades}

É interessante que os resultados obtidos nas seções 5.1 e 5.2 acima sejam comparados, para que se possa realizar uma análise mais completa. No gráfico da figura 5.12, encontram-se plotadas as velocidades de deriva dos pacotes de spin $v_{\mathrm{dr}}$ em função do campo elétrico $E_{\mathrm{ip}}$ que surge da aplicação de voltagens no plano em ambos os canais y (dados em vermelho) e x (dados em azul) da amostra. Os valores para as mobilidades de spin obtidos anteriormente através do ajuste linear da equação 5.7 nos dados de $v_{\text {dr }} \times E_{\text {ip }}$ encontram-se dispostos na tabela 5.1 .

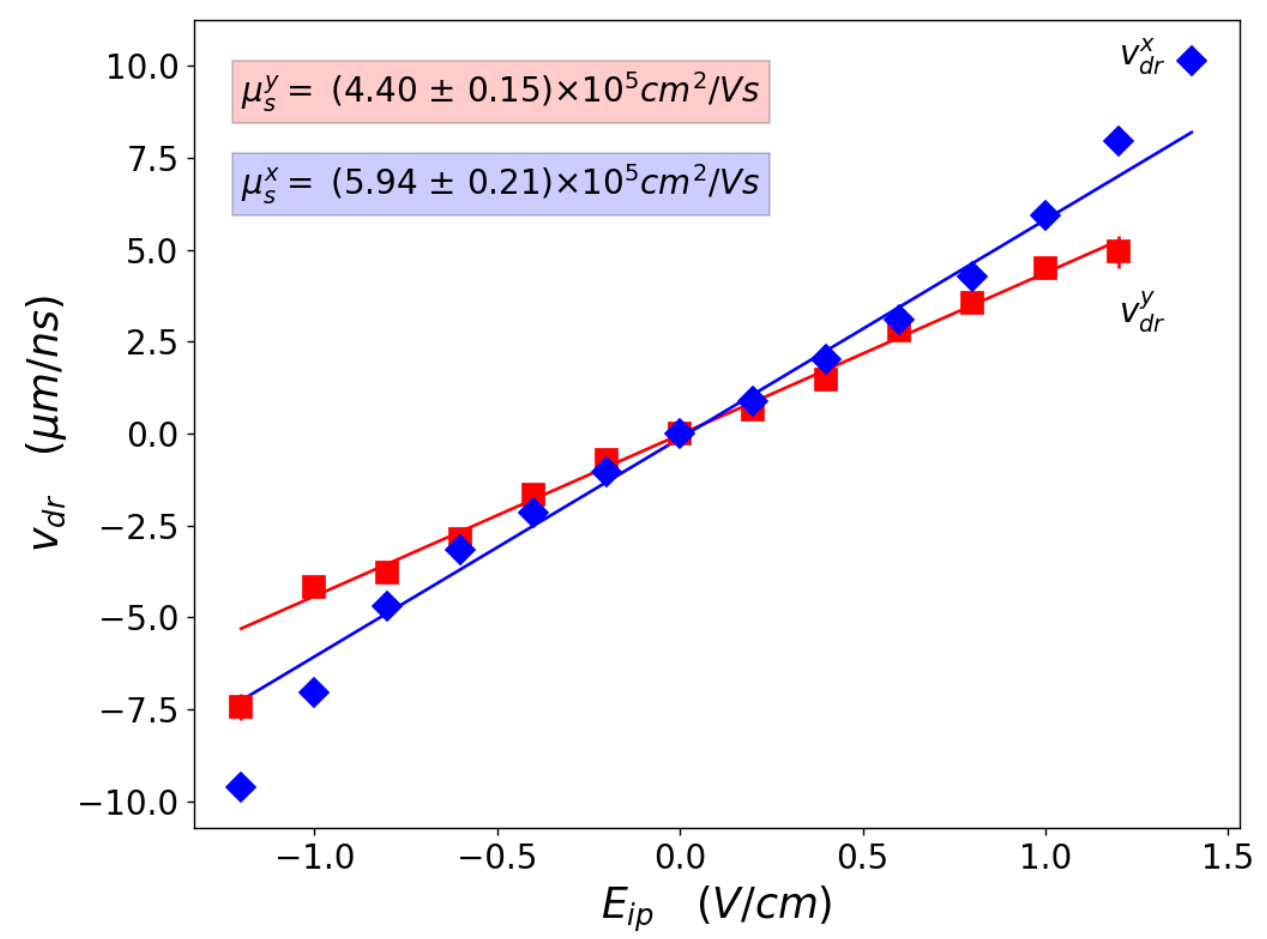

Figura 5.12: Velocidades de deriva do pacote de polarização de spin em função do campo elétrico aplicado nos canais $y$ (em vermelho) e $x$ (em azul) do dispositivo.

\begin{tabular}{|c|c|}
\hline$\mu_{\mathrm{s}}^{y}$ & $\mu_{\mathrm{s}}^{x}$ \\
\hline $4,40 \pm 0,15 \times 10^{5} \mathrm{~cm}^{2} / \mathrm{Vs}$ & $5,94 \pm 0,21 \times 10^{5} \mathrm{~cm}^{2} / \mathrm{Vs}$ \\
\hline
\end{tabular}

Tabela 5.1: Mobilidades de spin obtidas para os canais $y$ e $x$ da amostra, através do ajuste da equação 5.7 nos dados da figura 5.12 .

Vê-se, a partir dos dados acima, que o valor obtido para a mobilidade de spin no canal $x$ da amostra foi maior do que o encontrado para o canal $y$. Esse mesmo comportamento ani- 
sotrópico das mobilidades também foi observado em [24] e [25], embora no presente trabalho as magnitudes reportadas tenham sido maiores. Cabe também destacar que os valores encontrados para $\mu_{\mathrm{s}}$ estão uma ordem de grandeza abaixo da mobilidade de carga, cujo valor para baixas temperaturas, apresentado na seção 3.1 , é de $\mu_{\mathrm{c}}=2,2 \times 10^{6} \mathrm{~cm}^{2} / \mathrm{Vs}$.

\section{Campos spin-órbita}

Em contrapartida, para os campos spin-órbita, o comportamento obtido foi o inverso do que ocorreu com as mobilidades. Como pode ser visto no gráfico da figura 5.13, o campo SO gerado pela deriva na direção $y$ (em vermelho) apresenta magnitudes maiores do que os gerados pela deriva em $x$ (em azul). Ou seja, observa-se um comportamento em que a mobilidade de spin é maior para a direção em que o $B_{\text {SO }}$ gerado pela deriva é menor, o qual também foi reportado nos trabalhos citados acima.

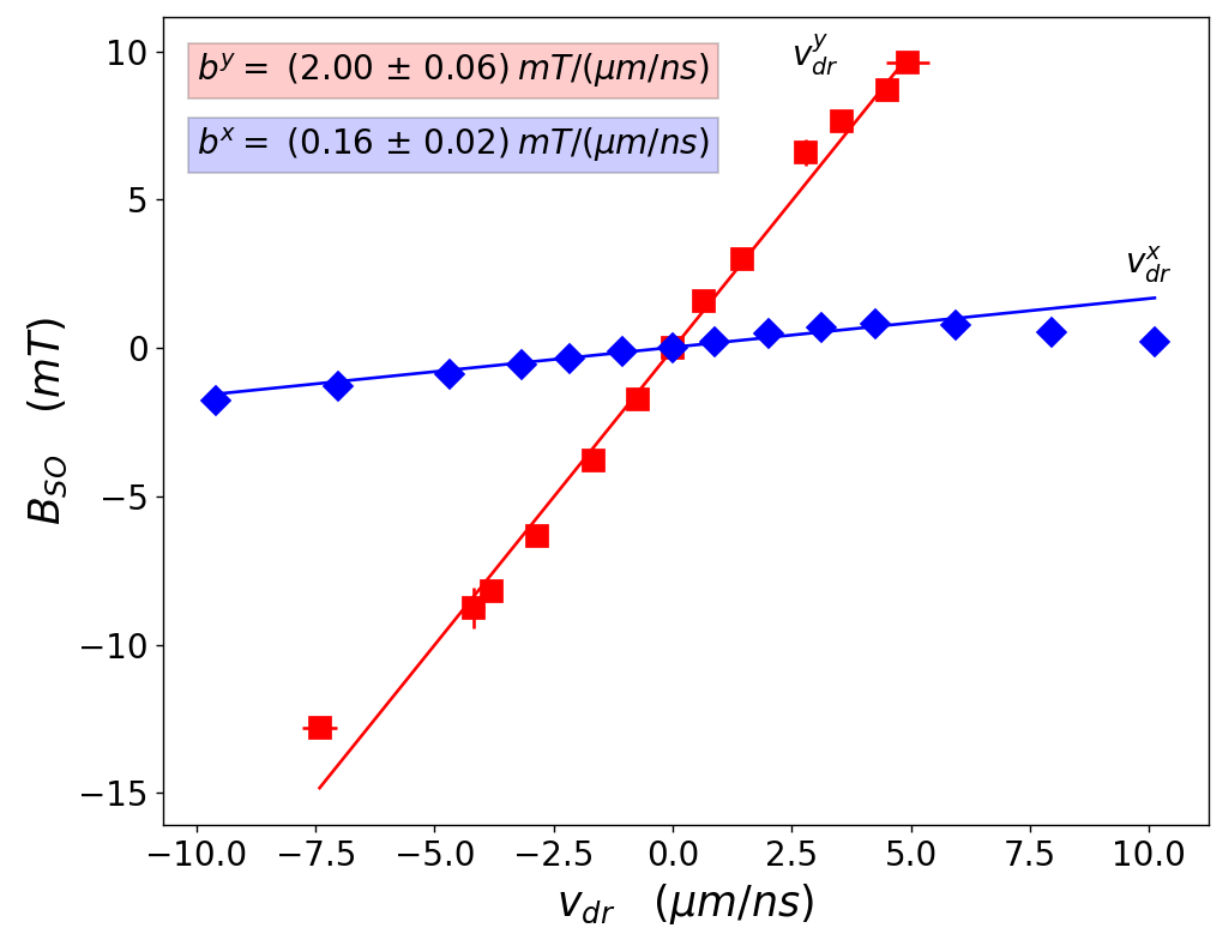

Figura 5.13: Campos spin órbita, obtidos para a posição de overlap, em função das velocidades de deriva nos canais $y$ (em vermelho) e $x$ (em azul) do dispositivo.

O modelo físico utilizado como base para a dinâmica de magnetização de spins foi apresentado nas equações 5.2 e 5.3 , as quais sugerem uma relação linear entre o campo spinórbita e as velocidades de deriva. Os conjuntos de dados plotados na figura 5.13 parecem se aproximar razoavelmente desse comportamento, de onde o ajuste de uma reta para cada um 
deles permitiu que fossem encontrados os seguintes valores para os coeficientes $b$ :

$$
\begin{aligned}
& b^{y}=\frac{B_{\mathrm{SO}}^{x}}{v_{\mathrm{dr}}^{y}}=\left[\frac{m}{\hbar g \mu_{\mathrm{B}}} \sum_{\nu=1}^{2}\left(+\alpha_{\nu}+\beta_{\nu}^{*}\right)\right]=2,00 \pm 0,06 \mathrm{mT} /(\mu \mathrm{m} / \mathrm{ns}) \\
& b^{x}=\frac{B_{\mathrm{SO}}^{y}}{v_{\mathrm{dr}}^{x}}=\left[\frac{m}{\hbar g \mu_{\mathrm{B}}} \sum_{\nu=1}^{2}\left(-\alpha_{\nu}+\beta_{\nu}^{*}\right)\right]=0,16 \pm 0,02 \mathrm{mT} /(\mu \mathrm{m} / \mathrm{ns}) .
\end{aligned}
$$

Da definição dessas quantidades provém um calculo simples para os coeficientes spin-órbita (SOC) $\alpha$ de Rashba e $\beta$ de Dresselhaus:

$$
\begin{aligned}
& \sum_{\nu=1}^{2} \beta_{\nu}^{*}=\frac{\hbar g \mu_{\mathrm{B}}}{2 m}\left(b^{y}+b^{x}\right)=0,47 \pm 0,01 \mathrm{meV} \AA \\
& \sum_{\nu=1}^{2} \alpha_{\nu}=\frac{\hbar g \mu_{\mathrm{B}}}{2 m}\left(b^{y}-b^{x}\right)=0,40 \pm 0,01 \mathrm{meV} \AA .
\end{aligned}
$$

Esses valores estão na mesma ordem de grandeza dos obtidos em [24], e com o mesmo comportamento de $\sum \beta_{\nu}^{*}>\sum \alpha_{\nu}$, embora aqui tenham sido obtidas magnitudes um pouco menores para ambos os coeficientes. Se os SOC forem mesmo constantes, como obtidos acima, isso significaria que as intensidades das interações spin-órbita não seriam influenciadas pelas velocidades de deriva.

Por outro lado, como visto nas seções anteriores, se os coeficientes $b$ são calculados ponto-a-ponto a partir da divisão direta dos valores de $B_{\text {SO }}$ pelos respectivos valores de $v_{\mathrm{dr}}$, recupera-se uma dependência desses coeficientes com as velocidades, que pode ser verificada a partir do gráfico da figura 5.14, cujo comportamento ilustrado é bastante similar ao apresentado em um artigo de Yoji Kunihashi, et al., do NTT Basic Research Lab. no Japão [30]. Nesse artigo, o grupo aponta que a deriva dos spins no material causa um aquecimento da amostra e um consequente aumento na magnitude do coeficiente cúbico de Dresselhaus $\beta_{3}$, como função das velocidades de deriva.

Nesse sentido, para investigar a dependência dos SOC com $v_{\text {dr }}$, deve-se inserir os valores de $b^{y}$ e $b^{x}$ para velocidades iguais nas equações 5.9. No entanto, como pode ser verificado pela figura 5.14, os pontos obtidos não possuem velocidades muito parecidas. Foi escolhido portanto ajustar os gráficos de $b \times v_{\text {dr }}$ por retas que, ao serem inseridas na equações 5.9, resultaram no seguinte gráfico da figura 5.15 


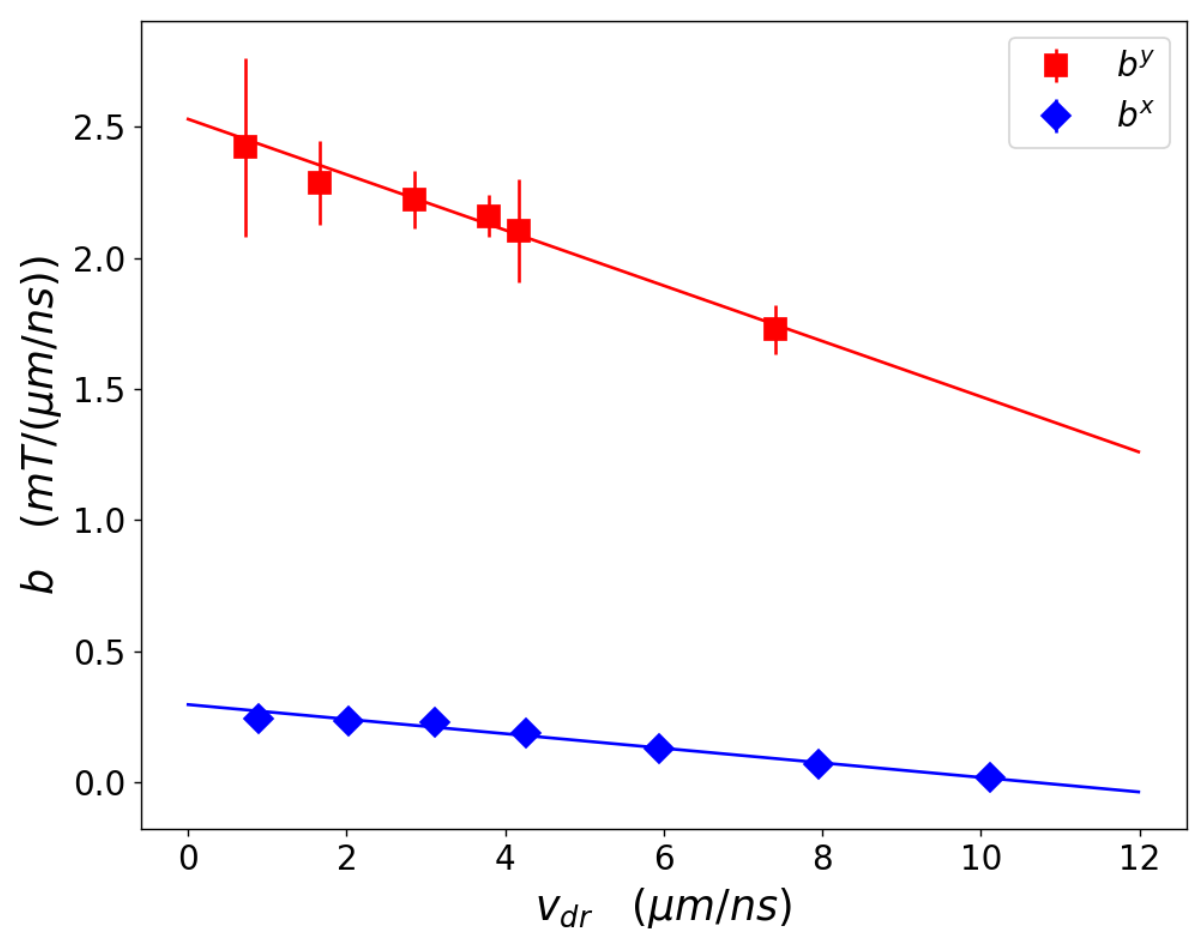

Figura 5.14: Coeficientes $b$ calculados ponto-a-ponto a partir dos dados da figura 5.13, em função das velocidades de deriva.

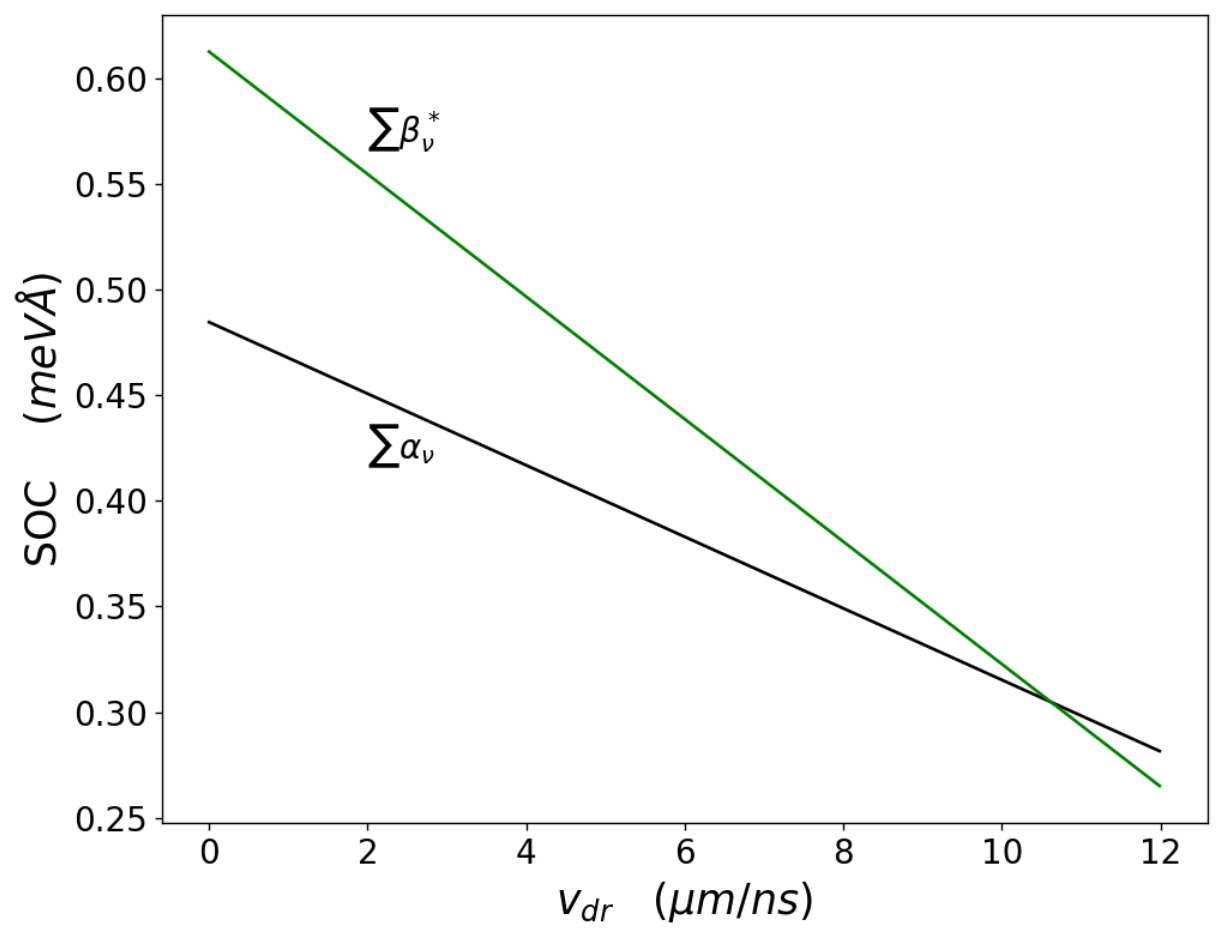

Figura 5.15: Dependência dos coeficientes spin órbita de Rashba $\left(\sum \alpha_{\nu}\right)$ e de Dresselhaus $\left(\sum \beta_{\nu}^{*}\right)$ com a velocidade, como obtido através da inserção das retas ajustadas na figura 5.14 nas equações 5.9 . 
De fato, ao visualizar as retas plotadas na figura 5.15, verifica-se uma dependência dos coeficientes spin-órbita de Dresselhaus $\sum \beta_{\nu}^{*}$ com as velocidades de deriva $v_{\mathrm{dr}}$. Dessa forma, como foi definido que $\beta_{\nu}^{*}=\beta_{1, \nu}-2 \beta_{3, \nu}$, pode ser inferido que a diminuição observada em $\sum \beta_{\nu}^{*}$ como função de $v_{\text {dr }}$ seja devida ao aumento do coeficiente cúbico de Dresselhaus com a temperatura, como reportado em [30] - já que, em teoria, o coeficiente linear $\beta_{1}$ depende apenas da largura do poço (como visto na equação 2.9). Não era esperado, entretanto, que houvesse uma dependência do coeficiente spin-órbita de Rashba $\sum \alpha_{\nu}$ com as velocidades de deriva, como observado nesse mesmo gráfico, por ser um coeficiente que depende da simetria do poço.

\subsection{Medidas como função da voltagem no eletrodo de porta}

Outras medidas foram também realizadas, dessa vez para estudar a influência de voltagens $V_{g}$ aplicadas no eletrodo de porta do dispositivo. Recordando as discussões apresentadas no capítulo 2, os eletrodos de porta têm uma grande importância na idealização de um transistor de spin como um dispositivo ativo (seção 2.4), pela possibilidade que uma voltagem $V_{\mathrm{g}}$ fornece de se alterar a simetria de um poço quântico, e consequentemente controlar a constante $\alpha$ da interação de Rashba (seção 2.2.2).

Mantendo as mesmas condições experimentais das medidas acima, expostas na tabela 4.1. dessa vez a deriva foi aplicada no sistema com uma mesma voltagem no plano de $V_{\text {ip }}=$ $40 \mathrm{mV}$. Para diferentes voltagens $V_{\mathrm{g}}$, verificou-se uma modificação na mobilidade de spin em ambas as direções cristalográficas, como pode ser visto no gráfico da figura 5.16 . Novamente há uma diferença entre as mobilidades em ambos os canais, sendo maior para a direção $x$ do que para a $y$, da mesma forma que constatado no gráfico da figura 5.12 .

Na sequência, a figura 5.17 apresenta os gráficos dos campos spin-órbita como função das voltagens $V_{\mathrm{g}}$ no eletrodo de porta, onde novamente os $B_{\mathrm{SO}}$ medidos foram maiores para derivas em $y$ do que em $x$, assim como na seção anterior. Aqui, é importante notar que o com-

portamento dos campos SO como função das $V_{\mathrm{g}}$ é bastante similar ao reportado em [24], mas as mobilidades apresentados na figura 5.16 resultaram em um comportamento diferente, ainda que a ordem de grandeza seja a mesma. Consequentemente, os coeficientes $b^{y}$ e $b^{x}$ calculados aqui pela divisão direta entre os $B_{\mathrm{SO}}$ e as velocidades de deriva para cada voltagem no eletrodo de porta, expostos no gráfico da figura 5.18, também não se comportaram como o esperado. 


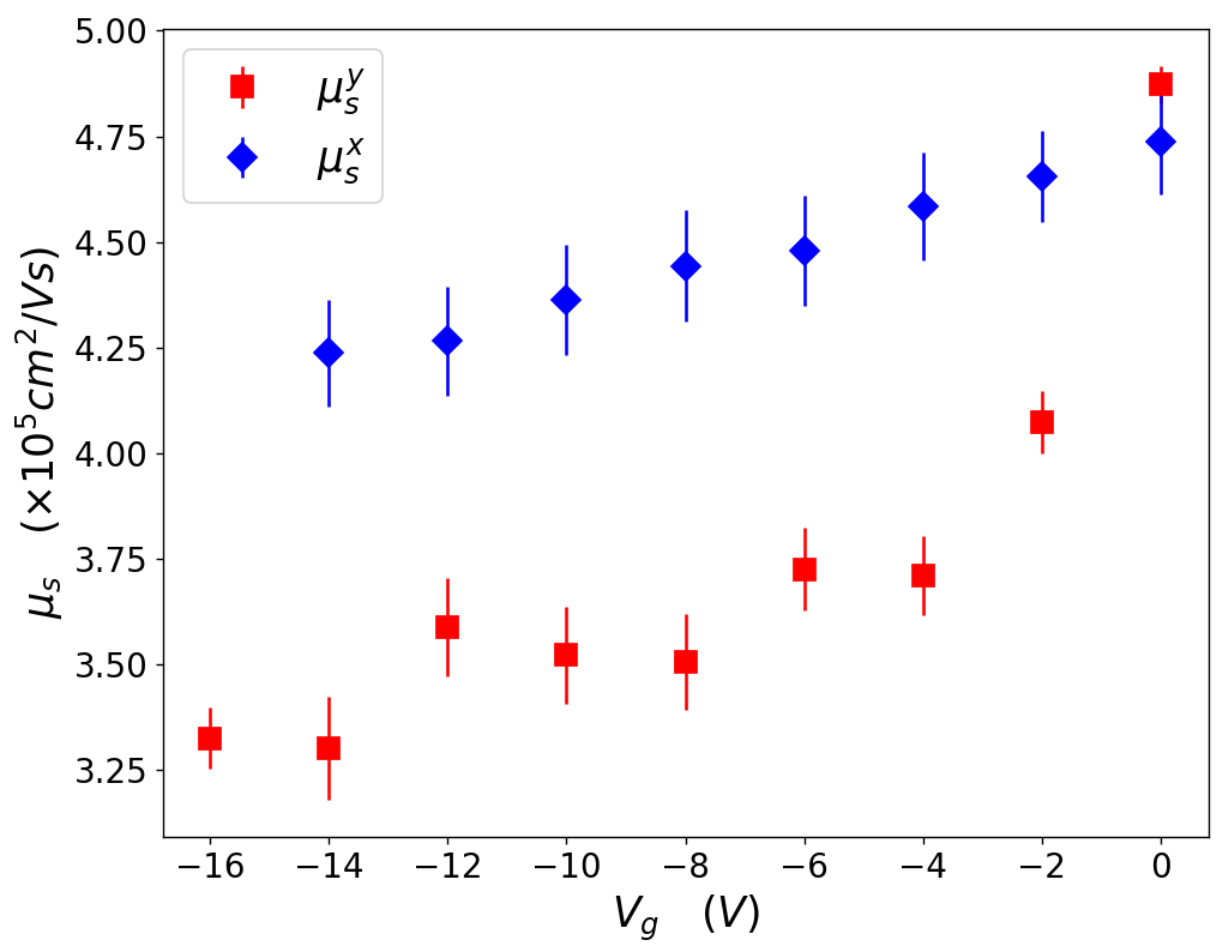

Figura 5.16: Variação das mobilidades de spin, medidas em ambos os canais $y$ (em vermelho) e $x$ (em azul), como função da voltagem $V_{\mathrm{g}}$ aplicada no eletrodo de porta do dispositivo, com a temperatura na amostra estabilizada em $T=10 \mathrm{~K}$.

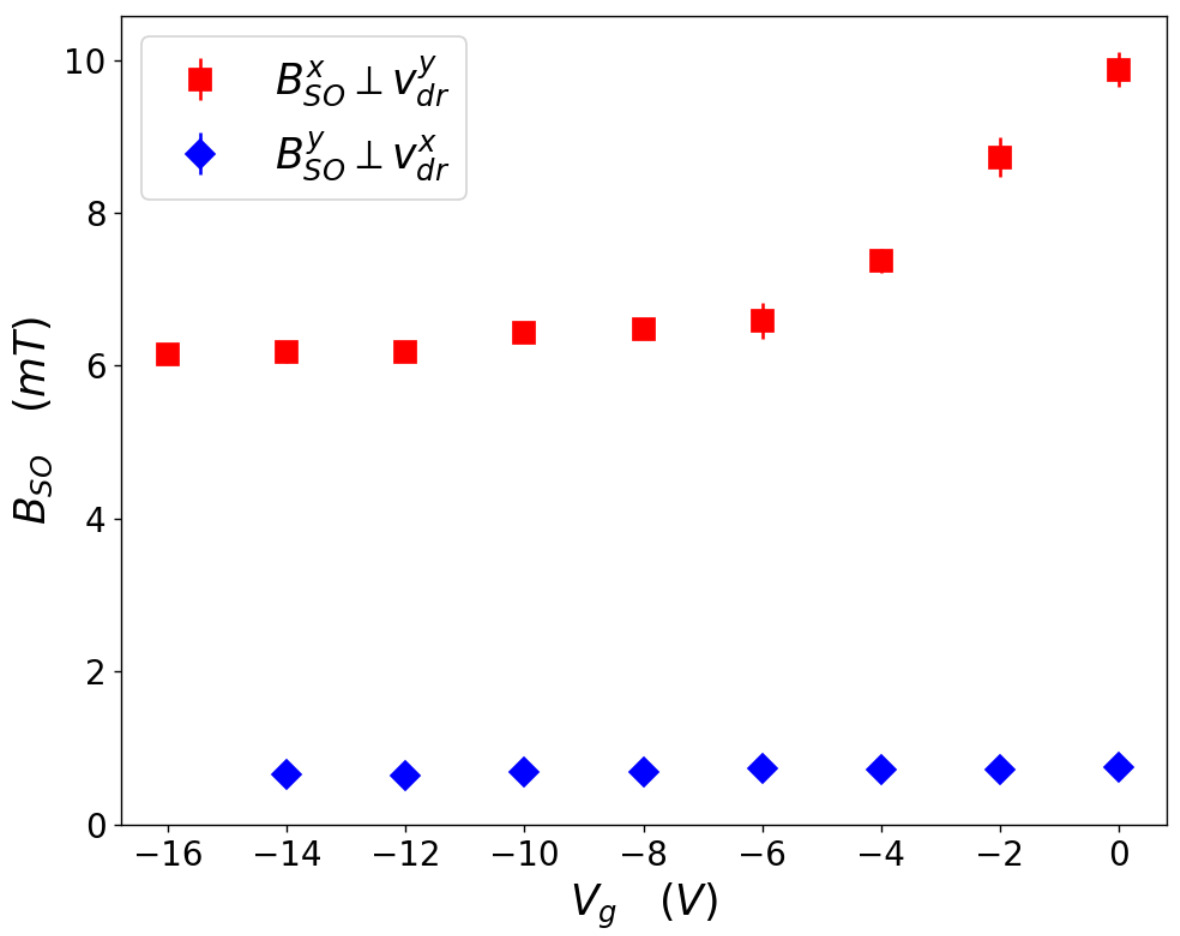

Figura 5.17: Comportamento dos campos spin-órbita, gerados por deriva nos canais $y$ (em vermelho) e $x$ (em azul), como função da voltagem $V_{\mathrm{g}}$ aplicada no eletrodo de porta do dispositivo, com a temperatura na amostra estabilizada em $T=10 \mathrm{~K}$. 


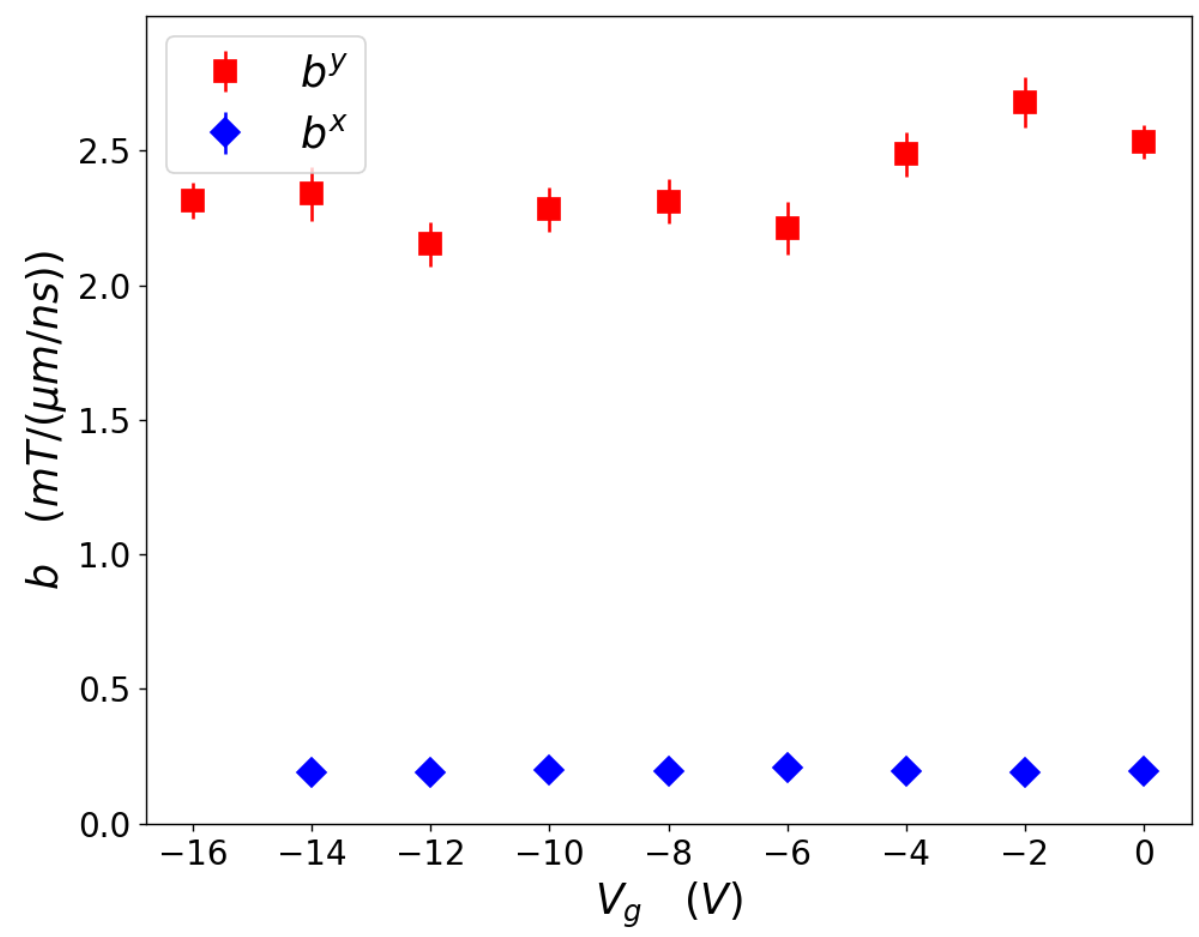

Figura 5.18: Coeficientes $b^{y}$ (em vermelho) e $b^{x}$ (em azul), calculados a partir da divisão direta entre os $B_{\mathrm{SO}}$ e as velocidades de deriva para cada voltagem $V_{\mathrm{g}}$ no eletrodo de porta, com a temperatura na amostra estabilizada em $T=10 \mathrm{~K}$.

Esse comportamento obtido para os coeficientes $b$ no gráfico da figura 5.18 não é interessante, porque não mostra uma dependência clara entre eles e as $V_{\mathrm{g}}$ aplicadas. De fato, isso implica que os coeficientes spin-órbita, sobretudo o $\alpha$ de Rashba, pouco estariam sendo influenciados pelas $V_{\mathrm{g}}$, o que contraria o comportamento encontrado em [24] e previsto pela teoria.

\section{Repetindo as medidas com $V_{\mathrm{g}}$ para $\mathbf{T}=\mathbf{2 0 K}$}

As medidas acima foram também repetidas para outras temperaturas, apresentando sempre resultados muito parecidos. Para ilustrar portanto esses dados, serão mostrados os comportamentos obtidos para uma temperatura na câmara da amostra estabilizada em $T=20 \mathrm{~K}$. Na figura 5.19 estão apresentados os gráficos das mobilidades de spin como função das voltagens aplicadas no eletrodo de porta, para ambas as direções cristalográficas, onde podem ser vistos valores um pouco maiores do que os obtidos quando $T=10 \mathrm{~K}$, ainda que os comportamentos tenham sido semelhantes. 


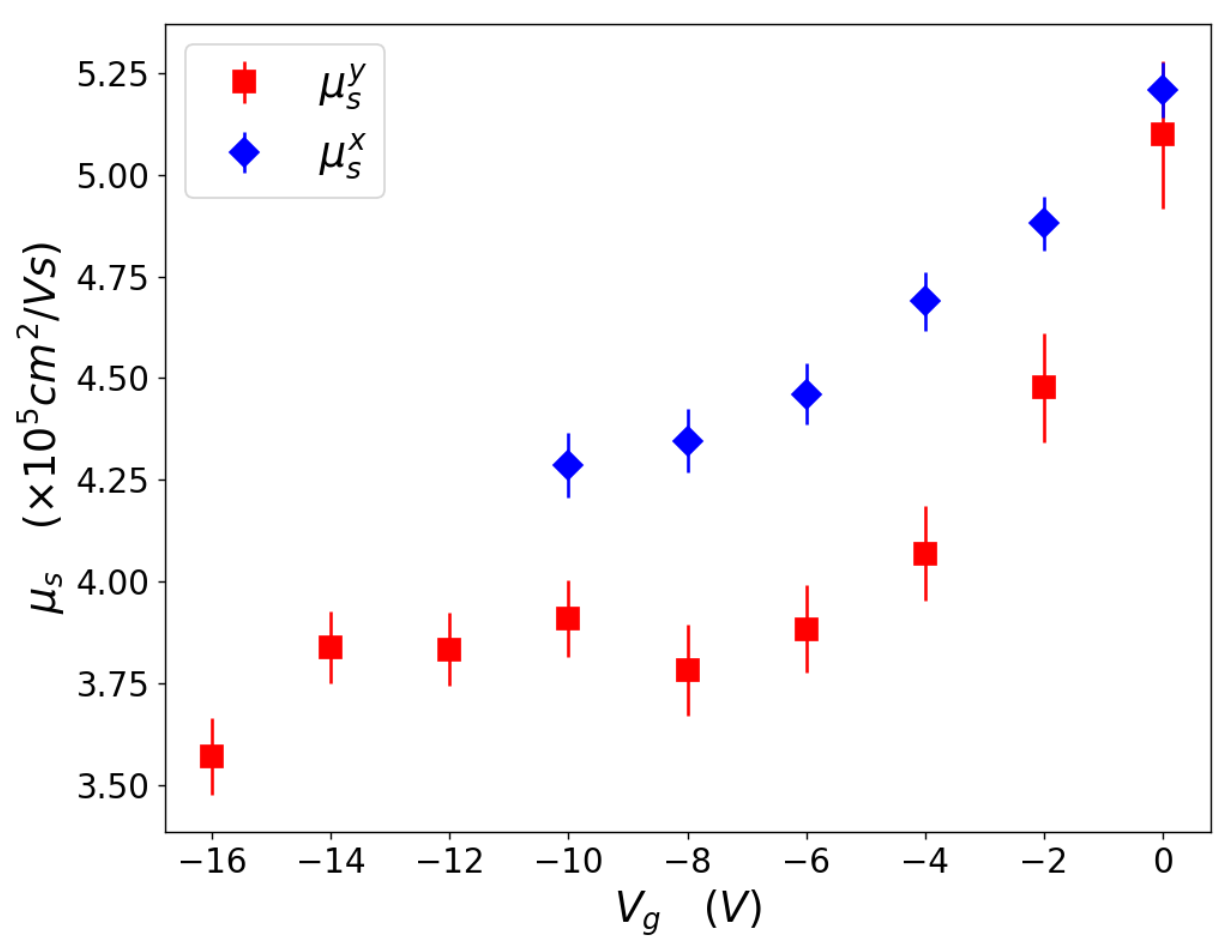

Figura 5.19: Variação das mobilidades de spin, medidas em ambos os canais $y$ (em vermelho) e $x$ (em azul), como função da voltagem $V_{\mathrm{g}}$ aplicada no eletrodo de porta do dispositivo, com a temperatura na amostra estabilizada em $T=20 \mathrm{~K}$.

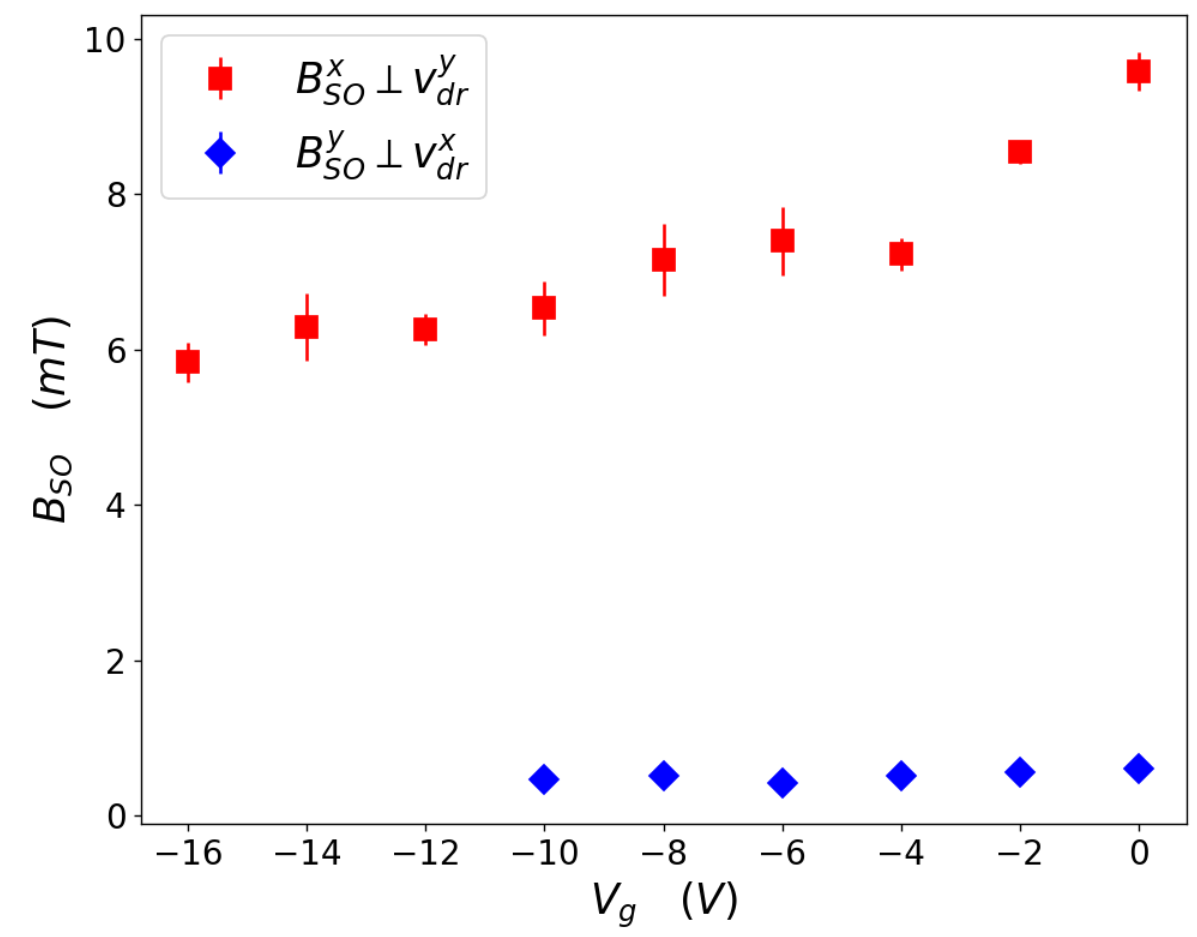

Figura 5.20: Comportamento dos campos spin-órbita, gerados por deriva nos canais y (em vermelho) e $x$ (em azul), como função da voltagem $V-\mathrm{g}$ aplicada no eletrodo de porta do dispositivo, com a temperatura na amostra estabilizada em $T=20 \mathrm{~K}$. 


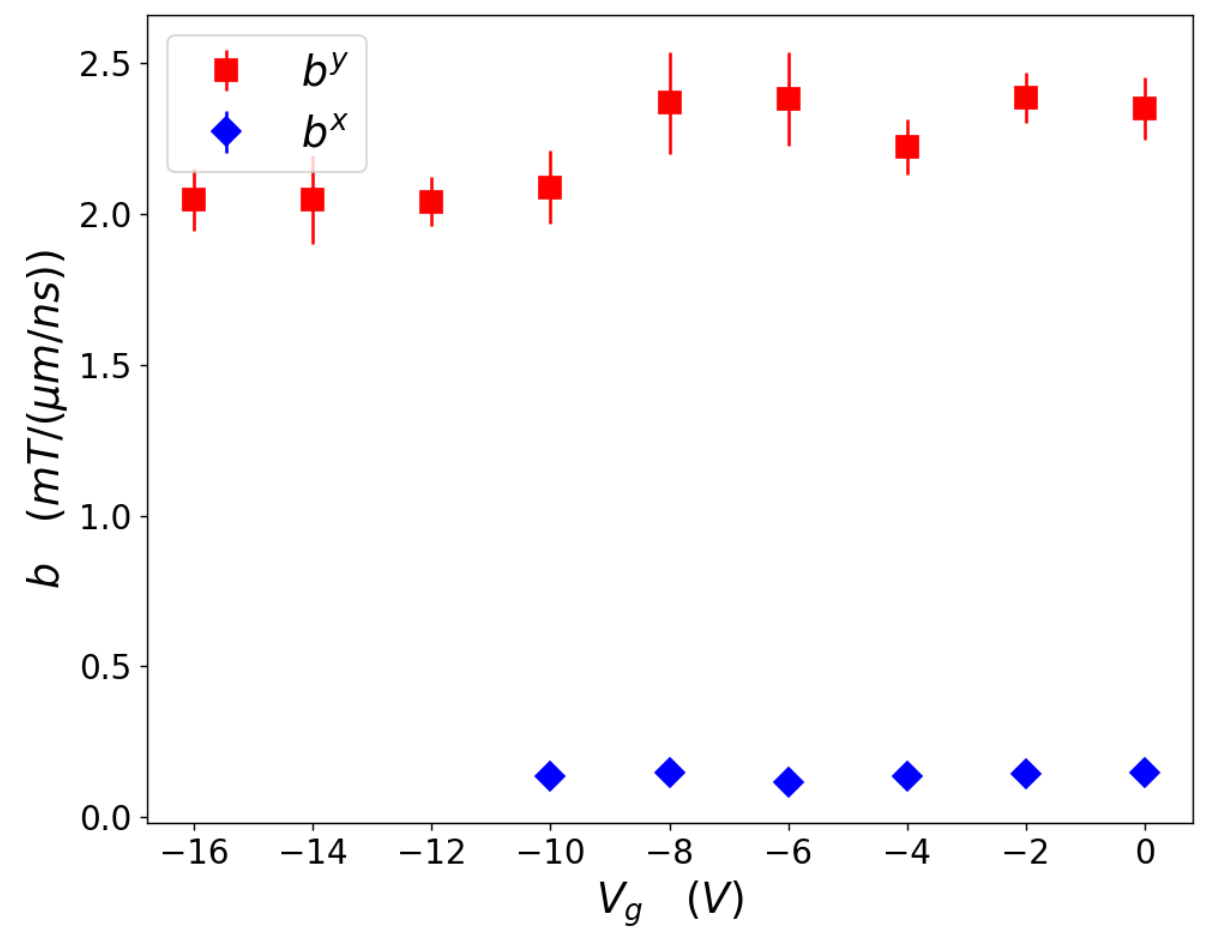

Figura 5.21: Coeficientes $b^{y}$ (em vermelho) e $b^{x}$ (em azul), calculados a partir da divisão direta entre os $B_{\mathrm{SO}}$ e as velocidades de deriva para cada voltagem $V_{\mathrm{g}}$ no eletrodo de porta, com a temperatura na amostra estabilizada em $T=20 \mathrm{~K}$.

Para os campos spin-órbita, os comportamentos obtidos para as duas temperaturas foram ainda mais parecidos. Para ambos os $B_{\mathrm{SO}}^{x}$ gerados pela deriva na direção $y$ e representados por pontos vermelhos nos gráficos das figuras 5.17 e 5.20, observa-se um máximo de $10 \mathrm{mT}$ para $V_{\mathrm{g}}=0$ descendo suavemente até se manter aproximadamente constante em $6 \mathrm{mT}$ para voltagens $V_{\mathrm{g}}$ negativas. Ao mesmo tempo, os campos SO na outra direção se mantiveram constantes para todas as $V_{\mathrm{g}}$, com valores um pouco menores do que $1 \mathrm{mT}$.

Como consequência, os coeficientes $b$ calculados ponto-a-ponto para as medidas realizadas em $T=20 \mathrm{~K}$ também não diferem consideravelmente dos obtidos anteriormente, com os $b^{y}$ flutuando entre 2 e $2,5 \mathrm{mT} /(\mu \mathrm{m} / \mathrm{ns})$ e $b^{x} \approx 0,2 \mathrm{mT} /(\mu \mathrm{m} / \mathrm{ns})$ para todas as $V_{\mathrm{g}}$.

\subsection{Medidas como função da temperatura}

Na seção 5.3 foi observada uma dependência dos SOC com as velocidades de deriva. Em específico, para o aumento do coeficiente cúbico de Dresselhaus em função de $v_{\text {dr }}$ obtido, discutiu-se a possibilidade de um aquecimento da amostra, devido à deriva dos portadores, ser a 
causa para esse efeito, como reportado em [30]. Por outro lado, na seção 5.4, foram apresentadas medidas em função de voltagens no eletrodo de porta do dispositivo para duas temperaturas diferentes nas quais a câmara da amostra foi estabilizada - em $T=10 \mathrm{~K}$ (como nas medidas anteriores) e $T=20 \mathrm{~K}$-, resultando em comportamentos muito parecidos. Sobretudo, as tendências similares para os coeficientes $b$ sugerem não ter havido uma mudança nos SOC com a temperatura, contrariando a hipótese levantada acima.

Nessa última seção, serão apresentados mais alguns dados obtidos como função da temperatura, novamente para derivas geradas por uma voltagem no plano $V_{\mathrm{ip}}=40 \mathrm{mV}$, mas dessa vez apenas na direção cristalográfica $y$, e com a voltagem no eletrodo de porta fixada em $V_{\mathrm{g}}=0 \mathrm{~V}$. Como pode ser visto nos gráficos das figuras $5.22,5.23 \mathrm{e} 5.24$, parece não haver um comportamento claro de relação das mobilidades, campos spin-órbita e coeficientes $b$ com as temperaturas estabilizadas na câmara da amostra.

Sobretudo, parece haver no gráfico de $B_{\mathrm{SO}} \times T$ alguma tendência de diminuição do campo SO com a temperatura, que é o comportamento inverso do que foi encontrado na seção 5.1 como função das velocidades de deriva.

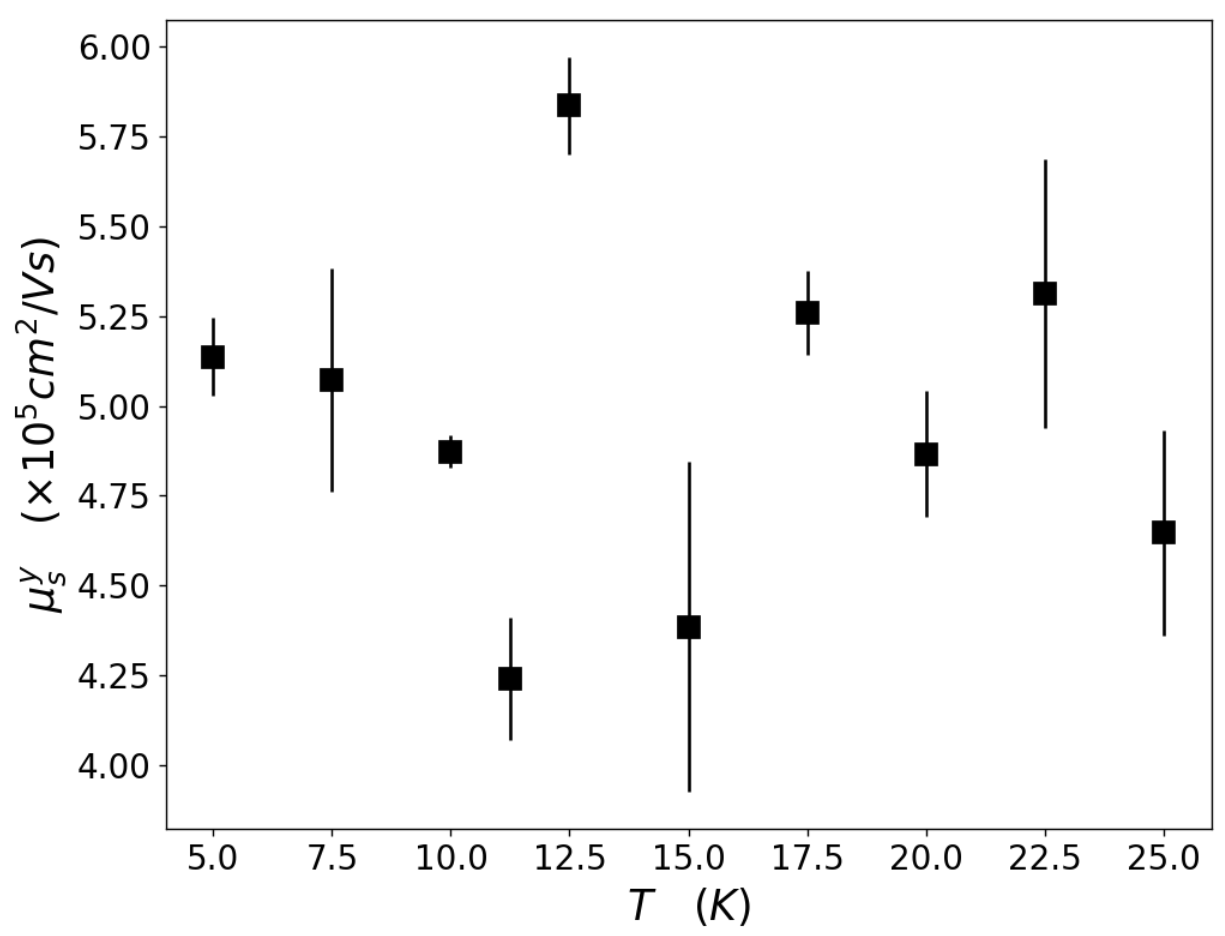

Figura 5.22: Medidas de mobilidade de spin como função da temperatura na câmara da amostra, para derivas no canal $y$ induzidas por uma voltagem no plano de $V_{\text {ip }}=40 \mathrm{mV}$, com uma voltagem no eletrodo de porta fixada em $V_{\mathrm{g}}=0 \mathrm{~V}$. 


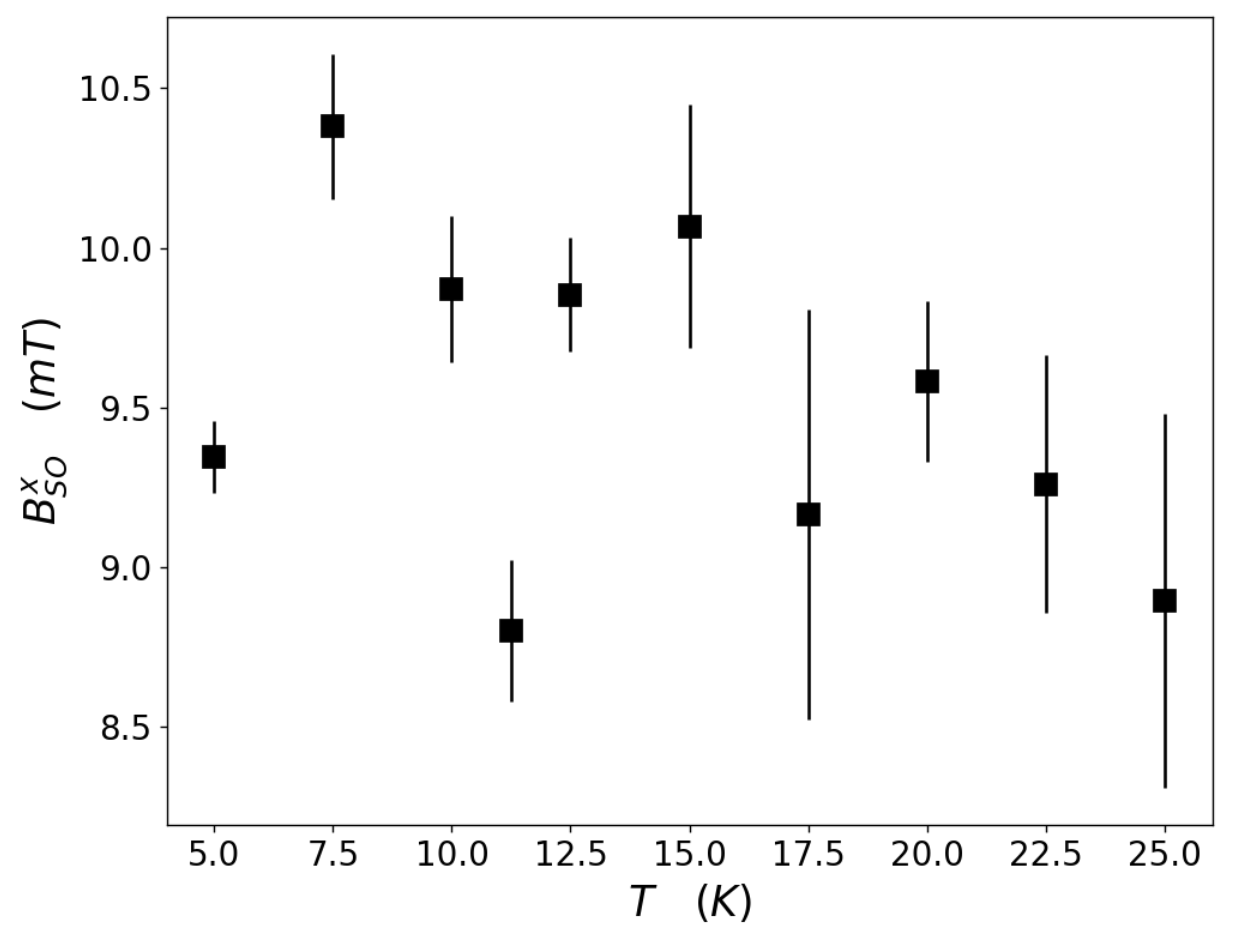

Figura 5.23: Campos spin-órbita $B_{\mathrm{SO}}^{x}$ como função da temperatura na câmara da amostra, gerados por derivas no canal $y$ induzidas por uma voltagem no plano de $V_{\text {ip }}=40 \mathrm{mV}$, com uma voltagem no eletrodo de porta fixada em $V_{\mathrm{g}}=0 \mathrm{~V}$.

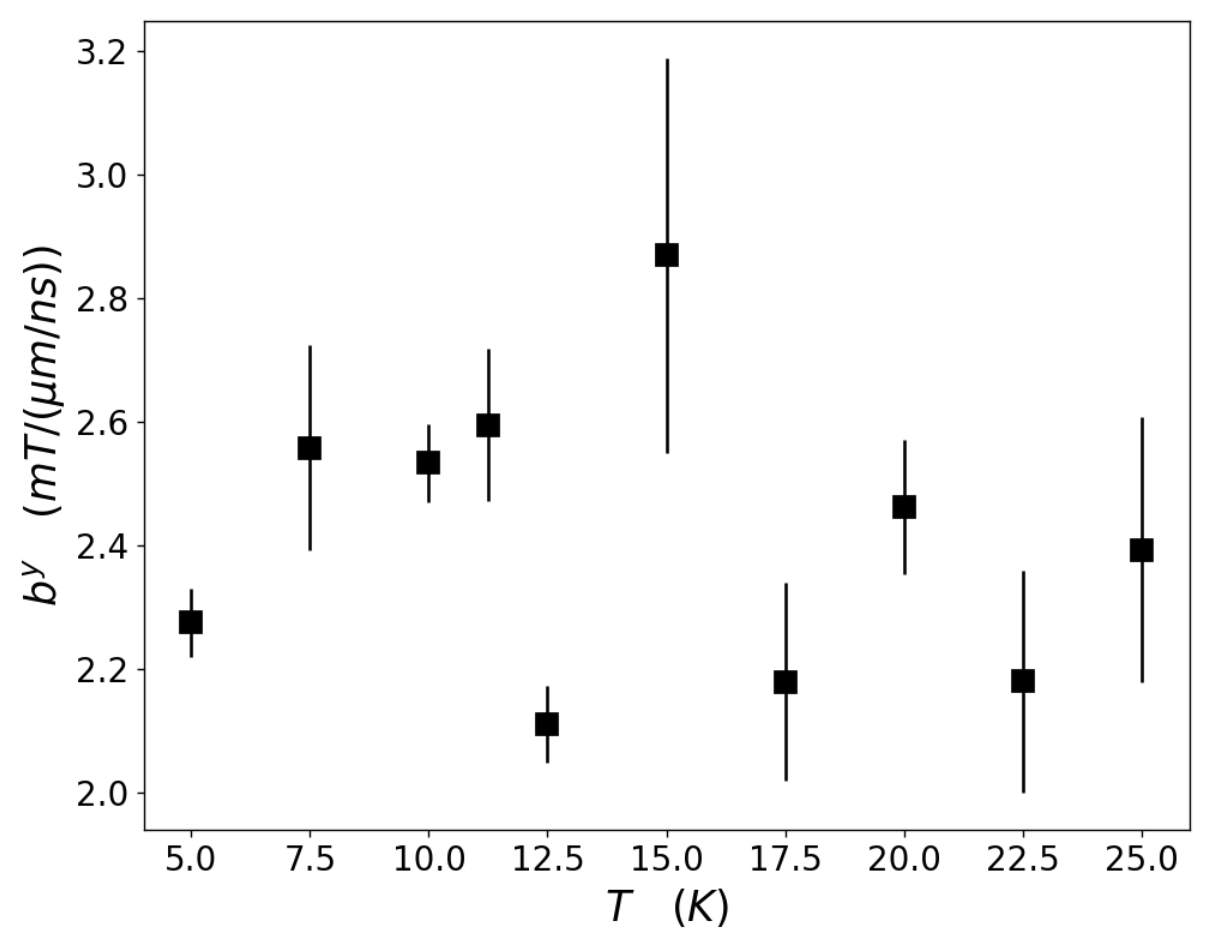

Figura 5.24: Coeficientes $b^{y}$ como função da temperatura na câmara da amostra, calculados a partir da divisão dos campos SO expostos no gráfico da figura 5.23 por suas respectivas velocidades de deriva. 
Para o gráfico da figura 5.24, não há uma tendência clara entre os $b^{y}$ e as temperaturas, contrariando o comportamento encontrado nas medidas como função das $v_{\mathrm{dr}}$. De fato, como $b^{y}$ é uma função da soma dos SOC, $b^{y} \propto \alpha+\beta^{*}=\alpha+\beta_{1}-\beta_{3}$, era de se esperar pelo menos uma variação devida à dependência do coeficiente cúbico de Dresselhaus com a temperatura.

Investigações futuras deverão ser realizadas para esclarecer se existem problemas no método experimental para as medidas com as temperaturas, as quais eram recuperadas por um termômetro disposto na câmara da amostra, podendo, portanto, não ter capturado a temperatura interna da amostra. 


\section{Capítulo 6}

\section{Considerações Finais}

Nessa dissertação foi proposto um estudo de como as diferentes velocidades de deriva de pacotes de polarização de spin - particularmente em um poço quântico de GaAs com duas sub-bandas - poderiam influenciar na dinâmica de magnetização de spin no material. Para tanto, foram utilizadas técnicas ópticas de injeção e detecção de polarização de spin, introduzidas no capítulo 3, que se mostraram bem sucedidas para a recuperação dos dados experimentais. De fato, através da técnica de RSA, ajustes da amplitude do sinal resultaram em gaussianas bem definidas (ver seção 4.3), como era esperado e desejado, as quais foram posteriormente decisivas para que as velocidades de deriva pudessem ser obtidas nas medidas do capítulo 5. Além disso, a conveniência do uso do RSA reside também no fato de que, a partir de um mesmo ajuste, podem ser igualmente recuperados os campos spin-órbita - que são muito relevantes para o estudo - e o fator-g do elétron.

Ao serem introduzidas medidas com deriva, as mobilidades de spin puderam ser obtidas com valores $\mu_{\mathrm{s}}^{y}=4,40 \pm 0,15 \times 10^{5} \mathrm{~cm}^{2} /$ Vs e $\mu_{\mathrm{s}}^{x}=5,94 \pm 0,21 \times 10^{5} \mathrm{~cm}^{2} /$ Vs (para as direções cristalográficas $y \|$ [110] e $x \|$ [11̄0], respectivamente), não muito distantes da mobilidade de carga $\mu_{\mathrm{c}}=2,2 \times 10^{6} \mathrm{~cm}^{2} / \mathrm{Vs}$, e que mostram uma anisotropia no material. Posteriormente, verificou-se que voltagens no eletrodo de porta $V_{\mathrm{g}}$, aplicadas na direção de crescimento do poço quântico $(z)$, podem alterar essa mobilidade de spin.

Outro comportamento anisotrópico observado foi o dos campos spin-órbita, cujas magnitudes foram maiores para campos gerados por derivas na direção de menor mobilidade - ou seja, direção cristalográfica y -, onde foram obtidos valores próximos a $10 \mathrm{mT}$ para velocidades em torno de $5 \mu \mathrm{m} / \mathrm{ns}$. Em contrapartida, para a direção $x$, o campo encontrado para essa mesma velocidade foi de aproximadamente $1 \mathrm{mT}$, isto é, $\sim 10 \%$ do valor em $y$.

Segundo o modelo utilizado para a dinâmica de magnetização dos spins no material, 
descrito pelas equações 5.2 e 5.3 , esperava-se que os campos SO variassem linearmente com as velocidades de deriva, com as constantes de proporcionalidade $b^{y}$ e $b^{x}$ dependendo dos coeficientes spin-órbita $\beta_{1}, \beta_{3}$ (linear e cúbico de Dresselhaus) e $\alpha$ (de Rashba). Em uma primeira aproximação, os dados de $B_{\mathrm{SO}} \times v_{\text {dr }}$ pareciam se ajustar razoavelmente a retas com coeficientes angulares dados por $b^{y}=2,00 \pm 0,06 \mathrm{mT} /(\mu \mathrm{m} / \mathrm{ns})$ e $b^{y}=0,16 \pm 0,02 \mathrm{mT} /(\mu \mathrm{m} / \mathrm{ns})$, o que implicaria na não dependência dos SOC com as velocidades de deriva, com valores $\sum \alpha_{\nu}=0,40 \pm 0,01 \mathrm{meV} \AA$ e $\sum \beta_{\nu}^{*}=0,47 \pm 0,01 \mathrm{meV} \AA-$ onde $\beta^{*}=\beta_{1}-2 \beta_{3}$ e as somas são feitas sobre as duas sub-bandas $\nu=\{1,2\}-$, os quais são compatíveis com os encontrados em outros trabalhos [24,25].

No entanto, investigações mais cuidadosas revelaram uma tendência de diminuição dos coeficientes $b$ - calculados diretamente através da divisão dos $B_{\text {So }}$ por seus respectivos valores de $v_{\mathrm{dr}}$ - como função das velocidades de deriva, similar ao descrito em um artigo do NTT Basic Research Lab. no Japão [30]. Nesse artigo, é apontado que a deriva dos portadores gera um aquecimento da amostra, o que causa um consequente aumento no coeficiente cúbico de Dresselhaus. Aqui, esse aumento pôde ser observado através da diminuição de $\sum \beta_{\nu}^{*} \operatorname{com} v_{\mathrm{dr}}$, já que $\beta^{*}=\beta_{1}-2 \beta_{3}$ e, em teoria, o coeficiente linear de Dresselhaus depende apenas da largura do poço (ver seção 2.2.1). Em contrapartida, foi observada também uma inesperada diminuição na magnitude do coeficiente $\alpha$ de Rashba com as velocidades de deriva.

Investigações posteriores, como função da temperatura medida na câmara da amostra, cujos dados estão expostos na seção 5.5. mostraram resultados inconclusivos e incompatíveis com a hipótese de modificação dos coeficientes spin-órbita pela ação da temperatura. Isso não significa, entretanto, que essa hipótese deve ser descartada, ainda por estar muito bem fundamentada em [30]. Como argumentado, o fato de as medidas de temperatura serem realizadas na câmara da amostra não garantem que as temperaturas medidas sejam as reais no dispositivo, o que deve motivar estudos futuros com algum método mais preciso.

Fato é que os dados experimentais apresentados nessa dissertação apontam para uma dependência dos SOC com as velocidades de deriva não prevista pelo modelo teórico considerado, sobretudo com comportamentos como o da modificação do coeficiente de Rashba que não havia sido observado anteriormente. Esses são resultados interessantes que motivam investigações futuras acerca dos mecanismos que estariam envolvidos nesses efeitos, e que buscam contribuir para os avanços da spintrônica e para o desenvolvimento de um transistor de spin funcional. 


\section{Referências Bibliográficas}

[1] M. Riordan, L. Hoddeson, C. Herring. "The invention of the transistor". Rev. Mod. Phys. 71, S336, (1999).

[2] G. E. Moore. "Cramming more components onto integrated circuits". Electronics 38(8), 114-117, (1965).

[3] G. E. Moore. "Progress in digital integrated electronics". International Electron Devices Meeting, IEEE, 11-13, (1975).

[4] D. Loss, D. P. DiVincenzo. "Quantum computation with quantum dots". Phys. Rev. A 57(1), 120-126, (1998).

[5] D. D. Awschalom, D. Loss, N. Samarth. Semiconductor spintronics and quantum computation (Springer, Berlin, 2002).

[6] S. A. Wolf, D. D. Awschalom, R. A. Buhrman, J. M. Daughton, S. von Molnár, M. L. Roukes, A. Y. Chtchelkanova, D. M. Treger. "Spintronics: A Spin-Based Electronics Vision for the Future". Science 294(5546), 1488-1495, (2001).

[7] D. D. Awschalom, M. E. Flatté. "Challenges for semiconductor spintronics". Nat. Phys. 3, 153-159, (2007).

[8] S. Datta, B. Das. "Electronic analog of the electro-optic modulator". Appl. Phys. Lett. 56(7), 665-667, (1990).

[9] J. Schliemann, J. C. Egues, D. Loss. “Nonballistic spin-field-effect transistor". Phys. Rev. Lett. 90(14), 146801, (2003).

[10] Y. A. Bychkov, E. I. Rashba. "Oscillatory effects and the magnetic susceptibility of carriers in inversion layers". J. Phys. C 17, 6039-6045, (1984).

[11] G. Dresselhaus. "Spin-orbit coupling effects in zinc blende structures". Phys. Rev. 100(2), 580-586, (1955). 
[12] J. D. Koralek, C. P. Weber, J. Orenstein, B. A. Bernevig, Shou-Cheng Zhang, S. Mack, D. D. Awschalom. "Emergence of the persistent spin helix in semiconductor quantum wells". Nature 458, 610-613, (2009).

[13] M. P. Walser, C. Reichl, W. Wegscheider, G. Salis. "Direct mapping of the formation of a persistent spin helix". Nat. Phys. 8, 757-762, (2012).

[14] Matthias Walser. Spin-orbit interaction and the persistent spin helix in two-dimensional electron gases. PhD thesis, ETH Zurich, (2013).

[15] Matthias Detlef Studer. Spin manipulation in two-dimensional electron and hole gases. PhD thesis, ETH Zurich, (2010).

[16] H. Schmidt-Böcking, L. Schmidt, H. J. Lüdde, W. Trageser, A. Templeton, T. Sauer. "The Stern-Gerlach experiment revisited". Eur. Phys. J. H 41, 327-364, (2016).

[17] D. J. Griffiths. Introduction to quantum mechanics, 2nd ed. (Pearson Prentice Hall, Upper Saddle River, NJ, 2005).

[18] M. I. Dyakonov. Spin physics in semiconductors (Springer, Berlin, 2009).

[19] C. Kittel. Introduction to solid state physics, 8th ed. (John Wiley \& Sons Inc., Hoboken, NJ, 2005).

[20] S. M. Sze, Kwok K. Ng. Physics of semiconductor devices, 3rd ed. (John Wiley \& Sons Inc., Hoboken, NJ, 2007).

[21] M. P. Walser, U. Siegenthaler, V. Lechner, D. Schuh, S. D. Ganichev, W. Wegscheider, G. Salis. "Dependence of the Dresselhaus spin-orbit interaction on the quantum well width". Phys. Rev. B 86, 195309, (2012).

[22] P. Y. Yu, M. Cardona. Fundamentals of Semiconductors, 4th ed. (Springer, Berlin, 2009).

[23] A.Y.Cho, J.R.Arthur. "Molecular beam epitaxy". Prog. Solid State Chem. 10, 157-191, (1975).

[24] M. Luengo-Kovac, F. C. D. Moraes, G. J. Ferreira, A. S. L. Ribeiro, G. M. Gusev, A. K. Bakarov, V. Sih, F. G. G. Hernandez. "Gate control of the spin mobility through the modification of the spin-orbit interaction in two-dimensional systems". Phys. Rev. B 95, 245315, (2017). 
[25] Amina Solano Lopes Ribeiro. Interações de Rashba e Dresselhaus induzidas por deriva de spin. Dissertação de Mestrado, Universidade de São Paulo, (2018).

[26] Flávio Campopiano Dias de Moraes. Indução ótica de magnetização em semicondutores magnéticos. Tese de Doutorado, Universidade de São Paulo, (2017).

[27] M. I. Dyakonov, V. I. Perel. "Spin orientation of electrons associated with the interband absorption of light in semiconductors". Sov. Phys. JETP 33, 1053, (1971).

[28] Saeed Ullah. Controle ótico e detecção de coerência de spin em sistemas de multicamadas. Tese de doutorado, Universidade de São Paulo, (2017).

[29] J. M. Kikkawa, D. D. Awschalom. "Resonant Spin Amplification in n-Type GaAs". Phys. Rev. Lett. 80(19), 4313, (1997).

[30] Y. Kunihashi, H. Sanada, Y. Tanaka, H. Gotoh, K. Onomitsu, K. Nakagawara, M. Kohda, J. Nitta, T. Sogawa. "Drift-Induced Enhancement of Cubic Dresselhaus Spin-Orbit Interaction in a Two-Dimensional Electron Gas”. Phys. Rev. Lett. 119, 187703, (2017).

[31] Y. Kato, R. C. Myers, A. C. Gossard, D. D. Awschalom. "Coherent spin manipulation without magnetic fields in strained semiconductors". Nature 427, 50-53, (2004).

[32] Niko Churata Mamani. Magnetotransporte em poços quânticos de AlGaAs/GaAs com diferentes formas de potencial. Tese de doutorado, Universidade de São Paulo, (2009). 